\title{
Labor Supply, Informal Economy and Russian Transition
}

\author{
By: Maxim Bouev
}

William Davidson Working Paper Number 408

October 2001 
Preliminary Version

\title{
Labour Supply, Informal Economy and Russian Transition*
}

\author{
Maxim Bouev ${ }^{\gamma}$ \\ First version: May 2001 \\ Current version: October 2001
}

\begin{abstract}
The literature on economics of transition has suggested a number of scenarios to explain unemployment and labour reallocation in Eastern Europe. However, it has recently been argued that these so-called Optimal Speed of Transition (OST) studies do not account for many stylised facts concerning transitional labour markets (such as a drop in participation rates, job-to-job shifts of workers, development of an informal labour market, etc.).

The transformation in Russia has witnessed an increase in moonlighting opportunities for workers and a rapid growth of the informal sector. To allow for this fact, which has a strong structural and qualitative effect on Russian transition, I attempt to incorporate secondary job holding in the OST framework.

I first consider a time-allocation model in the spirit of Gronau (1977), which takes account of institutional peculiarities of the Russian state sector allowing workers to moonlight in the informal market. I introduce the motivational factor describing a heterogeneous worker's propensity to informal activity.

The time-allocation model leads into an OST-type dynamic model with on-the-job search, labour shifts underground and state sector hirings. Numerical simulations of the model help look at Russian transition from a new angle and explain several stylised facts.
\end{abstract}

JEL classification: J22, J63, J64, P20

Keywords: time allocation, moonlighting, informal economy, job reallocation, structural change, speed of transition, earnings inequalities, Russia

\footnotetext{
* This paper is based on the author's MPhil thesis written at the University of Oxford. I am thankful to Margaret Stevens for numerous and very helpful discussions, valuable suggestions, and for her patience while reading drafts of this work. I would also like to thank Nadia Joubert and Tito Boeri for useful references, Ekaterina Vostroknoutova and Micael Castanheira for the help with simulation software. I undoubtedly benefited from discussions with Carol Leonard and Richard Jackman. I gratefully acknowledge the financial help of N M Rothschild \& Sons Ltd., London, and the OSI Foundation. All remaining errors are solely my responsibility. Comments are welcome.

${ }^{\gamma}$ St.Antony's College, Oxford, OX2 6JF, UK. E-mail: maxim.bouev@sant.ox.ac.uk or maxbouev@hotmail.com
} 


\section{Non-technical Summary}

Theoretical work on economics of transition from plan to market system has suggested a number of scenarios to explain unemployment and labour reallocation in Eastern Europe. The main strand of this literature has become known as so-called Optimal Speed of Transition (OST) studies, since they try to figure out what speed of labour reallocation would be optimal for the economies. Usually, such work focuses on different variants of the Harris and Todaro (1970) two-sector migration model adapted to a transitional setting.

Although the OST literature has predicted a number of qualitative outcomes such as a decline in the share of state employment and a rise in private employment, it has recently been argued (Boeri, 2000, inter alia) that, nevertheless, it does not account for many stylised facts concerning transitional labour markets such as a drop in participation rates, job-to-job shifts of workers, development of an informal labour market, etc.

The transformation in Russia has witnessed an increase in moonlighting opportunities for workers and a rapid growth of the informal sector. Some authors (Clarke, 1998; Standing, 1998) report on the phenomenon of "dead souls", when workers, formally registered with official enterprises to be eligible for different social benefits, are actually working in the shadow economy.

Obviously, the presence of the informal sector and the mechanisms of workers adaptation to market reality mentioned above, have a strong structural and qualitative effect that should not be ignored when studying labour reallocation in transition. To allow for this fact I attempt to incorporate secondary job holding in the OST framework.

To this end, in this study I consider a partial equilibrium OST model with workers allocating hours of work between three sectors of employment - the sector of old enterprises, the sector of new official firms and the informal sector.

First I develop a time-allocation model in the spirit of Gronau (1977), which takes account of institutional peculiarities of the Russian state sector allowing workers to moonlight in the informal market. I introduce the motivational factor describing a heterogeneous worker's propensity to informal activity.

The time-allocation model then leads into an OST-type dynamic model with on-thejob search, labour shifts underground and state sector hirings. The presence of job-to-job transitions suggests that the assumption of the Agion and Blanchard (1994) OST model, when unemployment benefits are regarded as floors for private wages, should be dropped. It is more likely that in the Russian case it is the state sector wages that have actually formed such a floor.

Numerical simulations of this model help to look at Russian transition from a new angle, explain several stylised facts and offer policy implications concerning provision of old sector benefits, unemployment benefits, etc. In particular, I argue that in the Russian case a policy raising the level of unemployment benefits would not slow down the transition. The paper also suggests that incorporation of job-to-job flows into a standard OST model may cancel the earlier theoretical prediction that too slow a speed of transition leads to its derailment. However, more rigour theoretical research is needed to prove this. 


\section{Setting the Stage}

\subsection{Introduction}

The so-called transition period in Eastern Europe and the former Soviet Union (FSU) countries has been upon the stage for about 10 years. After the political processes of the late 80-s, the break-up of the CMEA and then the Soviet Union, the economic links between former socialist countries ceased to exist, and the Soviet bloc went bust leading the countries to the reorganisation of their economies. All the Central and Eastern European (CEE) countries embarked on a process of structural reforms, and the former system of central planning gave way to the new type of organisation that was called a transition economy and that is yet to become a developed market.

The transition in CEE countries has led to a U-shaped response of output (Blanchard, 1997). That is, a sharp recession, that all the countries started to experience right after the beginning of reforms, was followed by a recovery. However, many countries - members of the FSU - are still close to the bottom of the U-curve.

It is widely held that the principal driving force of the economies, capable of pulling them out of the downside of the $\mathrm{U}$, is the private sector that emerged at the beginning of transition. Its emergence was especially notable in Russia where the private form of ownership was not at all possible before the start of reforms in the early $90-\mathrm{s} .{ }^{1}$ The idea of a buoyant private sector proved so attractive that it was absorbed by many economists studying the transition. A lot of theoretical work was put forward, in which transformation was modelled as a process of a more or less gradual fade-out of the state sector and the flowering of the private firms. This view had an important implication for studies of labour markets of transition economies.

In a number of papers (Burda, 1993; Aghion and Blanchard, 1994; Rodrik, 1995; Blanchard, 1997; etc.) processes taking place in transitional labour markets were represented as shifts of labour from the shrinking state sector to emerging private firms. However, those shifts were not usually seen as a direct movement of labour from one sector to the other: periods of employment were separated by unemployment spells. In a nutshell, the simple but very appealing mechanism can be described as follows. Workers, fired from state enterprises during their restructuring, become unemployed and start to search for a job in the growing private sector. After some time the growth rate of private firms becomes greater than the rate of the decline of the state sector, and more workers are able to find jobs, which leads to a decrease in unemployment.

These studies have become known as the OST (for Optimal Speed of Transition) literature, since they try to figure out what speed of labour reallocation would be optimal for the economies. Usually, such work focuses on different variants of the Harris and Todaro (1970) two-sector migration model adapted to a transitional setting.

However, just recently attention has been drawn (Boeri, 1999, 2000) to the fact that this literature does not provide a satisfactory explanation of output trends in many transition economies nor does it explain a number of stylised facts concerning labour markets. The flowering of the informal economies (Johnson et al, 1997), moonlighting and a decrease in participation rates have been widely observed in Eastern Europe (Boeri et al., 1998), and, particularly, in Russia (Standing, 1998), but were ignored by the majority of OST studies. Little attention was given to labour supply (Boeri (1999) is among rare exceptions).

The main goals of this work are (1) to show how moonlighting practices and the presence of the informal sector in Russia can influence labour reallocation in transition; (2)

\footnotetext{
${ }^{1}$ In other countries, such as Poland or Hungary, some private enterprises were allowed even before the countries began the reformation.
} 
to modify the traditional OST models to take into account such an impact of the informal economy and moonlighting; and (3) to throw some light on a number of stylised facts that earlier models fail to explain.

The work is organised as follows. The rest of this section is devoted to research motivation, stylised facts and the OST literature review. Section 2 presents two models of transition: the first one is a simple Gronau-type ${ }^{2}$ time-allocation problem with moonlighting that provides insights for the second, OST-type dynamic model. The latter features the informal economy and a number of other innovations. Section 3 considers numerical simulation and interpretation of the dynamic model and explains the main findings. Section 4 concludes.

\subsection{Background}

Let us consider the main stylised facts about the transition in Russia and give an overview of the main OST literature.

\subsubsection{Stylised Facts}

In many respects Russian transition has resembled transformation in Eastern Europe. However, some features were distinct. The main stylised facts are as follows.

1. The last decade has witnessed the evolution of output in Russia following an L-type trajectory rather than a U-type one (Fig.1.1). Unemployment has still been growing (Fig.1.2), while the share of the private sector in employment was already comparable to the share of the state sector after 5-6 years of transition (Fig.1.5).

2. The informal sector was expanding in many transitional economies in the beginning of 90-s (Fig.1.7). However, this was especially notable in FSU countries (Fig.1.8, see also Table 1), where irregular activities still keep on mounting. Barsukova (2000) reports on various forms of informal employment. Traditionally it has been combined with regular employment (Boeri et al., 1998).

3. The last fact is consistent with significant multiple job holding reported in various labour force surveys (Boeri et al., 1998; Foley, 1997b). The empirical studies show that income from secondary jobs constitutes up to $50 \%$ of the overall labour income of those who have an informal job (Roshchin and Razumova, 1999). Wage rates at secondary jobs are much higher than wage rates at primary places of employment (Kolev, 1998; Roshchin and Razumova, 1999).

4. At the same time, many workers, notably among the male population, left the labour force altogether after the start of transition (Boeri, 1999, 2000; Standing, 1998). This led to the drop in participation rates both in CEE countries and in Russia (Fig.1.4). Lehmann and Wadsworth (1997) report an average of $20 \%$ of the labour force inactive in five Russian regions in 1996.

5. The flows into inactivity take place mainly through unemployment. Boeri (1999), Boeri and Bruno (1997), Foley (1997a) estimate the probability of leaving the labour force to be in a range of $15-20 \%$ for the unemployed in many CEE countries and Russia. At the same time, Russia is also notable for a low transition probability from employment to out-of-labour-force. Boeri's (1999) and Foley's (1997a) empirical results show that in some CEE countries it was nearly 1.5-2 times as high as in Russia.

6. The allocation of labour between the official sectors has been not only through the unemployment pool as postulated by OST studies. In years of progressive employment decline there were many more job leavers as opposed to job losers (Boeri, 2000). That is, quite a few workers left their jobs voluntarily, they were not fired in the process of restructuring of state enterprises. Layard and Richter (1995) note that workers "start looking for other jobs and in due course labour is redeployed to other sectors through the

\footnotetext{
${ }^{2}$ Gronau (1977)
} 
mechanism of voluntary quitting rather than through unemployment." Private firms recruit their workers mainly from state enterprises rather from the unemployment pool which would have otherwise offered cheaper labour (ibid.).

7. Most of the unemployed in Russia are eventually rehired in old state enterprises rather than in the new private sector (Layard and Richter, 1995).

These facts suggest that flows to inactivity, informal employment, and moonlighting have been important in labour force reallocation in transition. The way economies develop cannot be completely described by ignoring such phenomena. The truth, however, is that these facts were passed over by the traditional OST literature. Other features of labour markets (e.g. job-to-job flows) have also been ignored in most of the work. None takes account of reemployment in the state sector. The earlier research obviously makes its point but produces the oversimplified picture of transition from plan to market. However, more recent work tends to take into account some of the evidence above. A good attempt to explain the drop in participation rates and flows to inactivity was recently made by Boeri (1999). This research makes another attempt, explicitly allowing for moonlighting and informal employment. We draw upon insights provided by many earlier studies, an overview of which we present below.

\subsubsection{Review of the OST Literature}

The process of reallocation of labour during transition has been the focus of many studies. Different models with labour moving from the state (public, old) to the private (new) sector have been used. Usually authors concentrate on the labour demand side of the economy, looking at how different policy rules influence labour shedding in the state sector, emergence of unemployment and development of the private sector. In some sense all such studies are reminiscent of the Harris and Todaro (1970) migration model.

Harris and Todaro (1970) build a two-sector model of internal trade with unemployment. The crux of that model is a migration of the labour force from one (agricultural) sector to another (urban sector) which is prompted by the wage differential between the sectors, and the fact that, even given unemployment in the urban sector, the expected wage in it is higher than the marginal product in the agricultural sector. Such wage differentials and differences in sector productivity are also a common feature of studies of transition economies. Many of them continue the tradition of the Harris and Todaro model by assuming the private (urban in the original model) sector to randomly select a desired number of workers from the pool of workers not employed in the other sector.

The overwhelming majority of the studies of transition concentrates on homogeneous labour and usually only single job holding is allowed (i.e. an individual can be employed only in one sector at once).

The earlier work by Burda (1993) is among the first studies to stress the importance of unemployment as a component of the transformation process. He points to three main reasons for its mediating role in transition. First, it provides the "disciplining device" as in Shapiro and Stiglitz (1984), raising effort and productivity. Second, it restricts the growth of real wages. Finally, job creation can be seen as a function of the number of unemployed and open vacancies - the reason offered by the "flow approach" to labour markets (see, e.g., Blanchard and Diamond, 1992).

These ideas are developed in a benchmark model by Aghion and Blanchard (1994) and Blanchard (1997). They use the dynamic programming technique to solve a two-sector model with state and private sectors. Transition is viewed as a process of reallocation of labour from state ineffective enterprises to more productive private firms. The two important assumptions of the model concern private wage setting and job creation. The former is based upon the level of unemployment benefits and satisfies efficiency wage conditions - the value of being employed in the sector exceeds the value of being unemployed by a fixed quantity. Similar assumptions are also used in other OST studies. The derived market (private) wage 
rate is a decreasing function of unemployment. Job creation is viewed as an investment by the private sector. It is decreasing in the market wage (i.e. increasing in the unemployment rate) and depends on some exogenous parameter reflecting the general state of the economy (e.g. level of corruption) as well as costs of adjustment, expertise of employers, etc. The rate of state sector layoffs is exogenously given and can be chosen freely by the government. Restructuring of the state sector in the model implies an increase both in output and in unemployment. The higher unemployment rate makes restructuring less probable. Hirings are possible only in the private sector. It generates vacancies only for unemployed workers. Having obtained a private sector job an individual keeps on enjoying it forever - no layoffs are considered.

The start of transition is presented as some initial shock leading to an increase in unemployment. Then, given the interaction between private sector employment creation, restructuring and unemployment the transition path depends on the level of unemployment. The authors show that there exists some critical level of unemployment. If the initial shock leads to unemployment below this level, then restructuring takes place instantaneously. After the critical level of unemployment is achieved, transition settles down and the unemployment level remains constant (flows of layoffs from the state sector are equal to flows of hirings in the private sector). If the initial unemployment level is higher than the critical value then restructuring does not take place until private employment creation has decreased unemployment down to the critical value. Then transition continues with unemployment remaining constant. Along the balanced transition path only the proportions of workers in both sectors and in the unemployment pool change. The proportion of workers employed in private firms steadily increases while the proportion of workers in state enterprises steadily decreases. The proportion of unemployed remains constant until the end of transition. When restructuring comes to an end, however, the state sector stops feeding the unemployment pool, and it dwindles away to nothing as a result of private job creation. (Fig.1.10 to 1.14 show our simulations of the model).

The benchmark model has several implications. First, it points to the importance of the initial shock, i.e. the extent of unemployment achieved at the beginning of transition. Second, it suggests a U(or J)-type evolution for output in transition economies (Fig.1.13). Finally, expanding the model by introducing a government budget shows the possibility of transition derailment. If unemployment benefits are financed through taxes, in the case of too high a speed of transition when unemployment rises quickly, the negative effect of the fiscal burden on private firms can exceed the positive effect of unemployment (this consists in bringing wages down and increasing private job creation). Transition may fail.

This benchmark model gave rise to the large literature on the topic. Different policy tools were suggested to manage the pace of labour reallocation and growth of unemployment.

For example, Chadha and Coricelli (1994) study the influence of fiscal constraints on the process of restructuring. They build a model similar to the Aghion and Blanchard one, but the driving force of the economy is viewed as accumulation of human capital in the private sector. Its level negatively affects state sector employment. The authors consider both exogenous and endogenous accumulation of human capital. Under the assumption of exogeneity Chadha and Coricelli show that along the equilibrium path employment in the state sector shrinks continuously while employment in the private sector expands continuously. Allowing for endogenous accumulation of skills leads to different implications when there are no forces in the system that would necessarily place the economy on a path converging to eventual specialisation in a private sector good. Now, slowing of restructuring and even the reverse of transition are possible, producing the expansion of state sector employment. Introducing into the model a government budget balance with payroll taxation of the state sector only, and taking the tax rate in the state sector as a control variable, the 
authors show that varying the tax rate lets the government change the pace of restructuring and reallocation of labour by creating different fiscal pressure on the state sector.

Commander and Tolstopiatenko (1996) present another model of transition which builds on the insights provided by the two papers just discussed. An interesting innovation of their model is a consideration of two probabilities of closure and restructuring for the state sector. Commander and Tolstopiatenko differentiate between firms' collapse and actual restructuring while looking at shrinking of the state sector. The flow of labour from the state sector to unemployment is presented as consisting of two flows: the one as a consequence of state firms failure and the other one as a result of turning to more effective production and shedding excess employment. The model also considers the direct movement of labour from the state sector to the private one. However, this is due to restructuring of the whole firms only, but not due to a decision of a separate worker or a group of workers.

The authors show that there exists some critical value of the probability of closure of state enterprises above which restructuring is most likely to take place. The probability of closure together with the probability of restructuring exogenously defines a constant probability of contraction of the state sector. It differs from the Aghion and Blanchard study where the probability of state sector contraction is increasing with its overall shrinkage. The existence of some threshold level of the probability of closure suggests using this probability as a policy tool. A dynamic analysis of the system shows that varying the probability leads to changes in the speed of adjustment of the state sector and extent of unemployment.

The studies above are very similar in basic ideas. In particular, they all present partial equilibrium models which assume fixed labour supply, the absence of on-the-job search, constant sector productivities and financing of unemployment benefits through taxation of either state or private sectors or both. More departures from the benchmark model were offered in the following literature. It also points out the possibilities of transition failure (Ruggerone, 1996), high unemployment at the beginning (Shimer, 1997) or at the end of transition (Garibaldi and Brixiova, 1998). Possibilities of a transition slowdown are shown as well (Atkeson and Kehoe, 1996; Shimer, 1997).

Ruggerone (1996) changes the set-up of the Aghion and Blanchard model to include financing of unemployment benefits through printing money rather than through taxing labour. The main assumption made in the paper is that private firms can hold their working capital in the form of monetary assets if they do not have access to external financing. At the same time the government may finance its deficit by issuing more money provided that the tax system is inefficient. Ruggerone argues that in the case of constant demand for money the government "can always "choose" the level of inflation such that the seigniorage finances the deficit". Exploiting the seigniorage would place the burden on private firms, whose profitability and, hence, job creation, is negatively affected by inflation tax. This can slow down the transition process or even destroy the emerging private sector if the rate of labour shedding in the state sector gets too high. However, the financial sector can alone provoke private firms to collapse. This can follow from the explosion of inflation as a consequence of inflationary finance. The author shows that if the deficit is unsustainable the system diverges without bound to hyperinflation. The unstable behaviour of the monetary sector then "feeds through into the real sector, and makes the transition fail, pushing unemployment to its maximum level, and destroying the new private sector" (p.492).

Shimer (1997) considers an economy, in which productivity varies across jobs and changes over time according to a Poisson process. The state sector in the model maintains jobs regardless of its productivity which is consistent with guarantees of full-employment historically adopted in CEE and FSU. The private sector, however, lays off workers if their productivity falls below an endogenously determined threshold. The model implies that the threshold will increase over time with the rise in unemployment. This, in turn, leads job destruction rates in the private sector to grow. Rates of job creation also increase since rising 
unemployment makes its value drop, pushing workers to seek jobs more actively. However, job creation is sluggish, while job destruction maybe very rapid. The model suggests that high unemployment at the beginning of transition is a necessary feature of the transition path to provide firms with incentives to create vacancies. This supports the importance of the initial shock mooted by Aghion and Blanchard. It is shown that high unemployment and an associated speed of transition are efficient in the basic model. Extensions, allowing for government interventions, point out that subsidisation of existing jobs may result in a too slow equilibrium speed of transition.

The study by Garibaldi and Brixiova (1998) is very similar to Shimer's work. However, job destruction is endogenised in the state sector. Private sector layoffs are absent. The objective of the paper is to focus on the influence of labour market institutions such as unemployment benefits and minimum wages on job destruction in the state sector and reallocation of jobs into the private sector. The main conclusion is that the relationship between unemployment benefits and private sector job creation is ambiguous, which is essentially a finding of Blanchard (1997). However, some model simulations show that higher benefits speed up reallocation at the beginning of transition but slow it down closer to its end, which imply lower job creation and high equilibrium unemployment.

Atkeson and Kehoe (1996) look at general equilibrium effects of social insurance in a two period search model. Agents in the model have two options. They can either stay in the state sector and produce a moderate amount of output in both periods or can leave the sector for private firms. If they leave they produce nothing over the first period, but can acquire new skills and search for a good match with a private firm. In the second period they face a certain probability of finding a good match and producing a high level of output. Alternatively they find a worse match and produce less output. The authors show that if agents have strong precautionary demand for saving, social insurance in a closed economy will increase consumption in the first period, increasing the number of producers in the state sector to accommodate the demand and, thus, reducing the number of searchers. This will lead the transition to slow down.

The slowdown was also a result of another paper that introduces job-to-job transitions of workers and analyses search effectiveness. Brixiova (1997) develops the model of Burda (1993) by modelling the movement of labour from the state to the private sector as resulting from both shifts through the unemployment state and direct job-to-job relocation. She uses the dynamic programming approach along with a matching process framework in the spirit of Pissarides (1990) to work out a transition equilibrium path. The main message of the paper concerns the impact of on-the-job search of state workers during transition. It is shown that both the unemployment level and unemployment duration are higher when workers in the state sector are more actively involved in on-the-job search. This is because the unemployed workers searching for private sector employment "compete" with the workers employed in the state sector. ${ }^{3}$ Implications for the speed of transition suggest a slower optimal rate of state sector closure in case of more effective on-the-job search, because of state sector workers searching and producing at the same time.

Thus, we can see that the literature offers a number of reasons for high unemployment and transition slowdown. Either labour market frictions or various government policies may produce such a result. The literature, however, has neglected general equilibrium effects of reallocation. A rare exception is the work of Atkeson and Kehoe. The study by Castanheira and Roland (2000) also deserves separate attention.

An important dissimilarity with previous work is that Castanheira and Roland treat transition first of all as reallocation of capital, while labour is perfectly mobile and moves freely from one sector to another. This paper has few implications for labour market policies,

\footnotetext{
${ }^{3}$ Gavin (1993) also concentrates on the role of congestion externalities in transformation process.
} 
since all imperfections or fiscal externalities are excluded from the model. One of the findings, however, is still interesting for us. It says that even if the rate of state enterprise closure is too low, the transition can still not slow down unless the public sector faces soft budget constraints (i.e. wages exceed marginal product). To put it another way, transition will never derail if hard budget constraints are imposed and the closure of state firms is slow. We shall see in Section 3 that the model we present in this work suggests that supporting job creation in the old sector is never fatal for the final outcome of transition.

At this point we can sum up the main features of the OST literature. It offers the view of transition as reallocation of labour between two formal sectors usually through unemployment. The labour supply is assumed fixed, implying constant participation (Fig.1.14). Jobs are created in the private (new) sector only. The stress is put on the labour demand side. Workers are homogeneous. A number of policy tools were offered to control the speed of restructuring, which in principle can be so high or low that it derails transition.

These models proved successful in explaining such facts as the U-shaped evolution of output as well as high unemployment rates at the beginning of transition in some CEE countries. Growth of the private sector and the state sector recession have been also described. However, we can see that a number of stylised facts (subsection 1.2.1) was left unexplained. Reallocation of labour through unemployment only, appropriate for the Harris and Todaro model in which a physical distance between the two sectors is assumed, looks less plausible in a transition setting. No attention was drawn to labour supply, declining participation rates, growth of moonlighting and informal employment. It was Commander and Tostopiatenko (1997) who pointed to possibilities of labour shifts to the informal economy, when considering the importance of state sector subsidisation in a model with part-time workers. However, the study by Boeri (1999) is of greater importance despite ignoring moonlighting. It accounts better for flows of labour than previous OST work. We briefly consider its main features.

Boeri (1999) drops the assumption of fixed labour supply and introduces heterogeneous labour. In particular, workers in the model differ along two dimensions: they have different skills and varying reservation utilities or productivities in the subsistence (informal) sector. Boeri shows that a possibility of drawing some utility from the third sector gives workers additional strategies in the labour market. In fact, non-employed individuals can be actively seeking jobs or not. If they are seeking they get unemployment benefits and face a probability of finding a job in the new sector. If they are not seeking they get unemployment benefits and on the top of that can draw their reservation utility in the subsistence sector. But in this latter case workers have no chance of being employed in the new sector, the only hiring sector in the model. It can hire both inactive, unemployed workers and those from the old, declining, sector. The model generates at each point in time flows from employment to unemployment and inactivity, flows from inactivity to unemployment and the other way round, old-new sector flows, flows from inactivity and unemployment to the new sector. Old sector hirings are missed out, though. In total the model accounts for 5 times as many flows as the number allowed by previous OST studies of other authors (for details see Boeri 1999, 2000).

Boeri stresses the importance of labour supply in transition and revisits the role of unemployment benefits. Previous OST studies can provide arguments both for high (e.g., to facilitate restructuring, Blanchard, 1997) and low (e.g., to avoid high equilibrium unemployment, Garibaldi and Brixiova, 1998) unemployment benefits. Boeri adds that the non-employment rate can, in fact, be positively related to the level of benefits, since in his model the steady state proportion of non-employed seeking jobs declines with the level of unemployment benefits. On these grounds, high benefits are detrimental: at the beginning of 
reforms they led to a sharp drop in labour force participation rates and generated substantial sectors of inactivity.

However, Boeri's findings are consistent with the evidence from CEE but not Russia. In Russia unemployment benefits have been very low (e.g. Coricelli, 1998; Guriev and Ickes, 2000), but the extent of informal employment and inactivity has anyway been growing since the beginning of 90-s. Nor have Boeri's (1999) results anything to say about other phenomena, such as moonlighting and significant state sector hirings, widely observed in many FSU countries. Other OST studies are of no help here either. Nevertheless, Boeri's work points to the direction in which further research should be developed. It highlights the importance of looking at a heterogeneous labour force and the role played by the supply side in reallocation of labour.

In this work we use these hints to offer our view of the Russian transition in the presence of hiring state enterprises, the informal sector and moonlighting. We suggest how the last two factors affect choices of individuals and labour reallocation. However, before formulating the main hypotheses we first have to review some important features of moonlighting and informal employment that should provide additional insights for our models.

\subsubsection{Moonlighting and Informal Labour in Russia}

The informal (shadow, irregular, underground, hidden, etc.) sector in Russia comprises both subsistence activities and informal entrepreneurship. Such structural heterogeneity is inherent in many informal economies of both developing and developed countries (Portes and Sassen-Koob,1987). However, the peculiarity of the Russian informal labour market is that it has established itself as a mixture of genuine shadow and so-called fictitious markets (Barsukova, 2000).

The shadow market is understood in its usual sense - it comprises concealment of actually existing employment, non-registered entrepreneurship, etc. For example, many individuals in Russia are involved in various kinds of self-employment. It can give more or less serious additional income that as a rule is not declared. Such activities include growing plants, fruit and vegetables in owned plots of land (dachas) and selling them in the market places, informal cab services, construction services, etc. ${ }^{4}$ The motivation for this work is similar to motivation for moonlighting that we consider below. It is often just a refuge from destitution. However, informal entrepreneurs can also seek higher earnings, avoiding taxes, or red-tape and bribing, that they would often face if acting formally. Importantly, the informal sector overlaps with home production and "a large proportion of non-registered economic agents work in households" (Lackó, 2000, p.125).

The fictitious labour market is based upon falsification of records. It is needed both by employees and by employers. The former preserve a direct relationship with the official sector and remain eligible for its benefits ${ }^{5}$ at the same time earning additional money in the shadow sector with higher wages; the latter can benefit from a simplified version of accounting control and tax rebates that they become eligible for by reporting a substantial amount of employed labour force.

Fictitious employment can be seen as a degenerate form of moonlighting - workers are required to spend only tiny amount of time at their primary official jobs where they may not even earn any wage, and the remaining time they work underground.

As reported by Clarke (1998), most of the secondary employment in Russia is not in the new private sector. This point contradicts Layard and Richter (1995) who mention a

\footnotetext{
${ }^{4}$ Usually shadow entrepreneurial activities are related to providing different kind of services or redistribution (e.g., reselling of goods in order to make money on price differences - so called shuttles have covered all over Russia with the net of outlets where they sell goods gross purchased in, e.g., Turkey or China), but not to production.

${ }^{5}$ We discuss some kinds of benefits later.
} 
significant number of state sector workers earning income from second occupations in the private sector. However, Standing (1998) also points out that workers rather moonlight in the informal economy. Interestingly, many unemployed workers also work in the informal sector (Clarke, 1998; Commander and Yemtsov, 1995).

There are several reasons for moonlighting.

So, Guariglia and Kim (1999) studying precautionary savings in Russia point out that under increased uncertainty surrounding jobs in transition the widespread multiple job holding in Russia can be considered as a self protection strategy against job insecurity. This strategy is an alternative to the more usual increase in savings to smooth fluctuations in income and consumption.

The other reason is that many employers can just not hinder moonlighting (Clarke et al., 1998) or even facilitate it. This is often the case in numerous factories in periods of downtime, etc. Employers can send workers on administrative leave without pay (Standing, 1998) or just not require full effort from workers. Matveenko et al. (1998) argue that the latter has even become an institutional arrangement adopted in the state sector of the Russian economy. In enterprises bought out by employees during privatisation workers can bargain over lower wages in exchange for secure workplaces. This "opens the door to time-theft, the use of work time to conduct personal business" (Linz, 1995).

Finally, the informal sector often offers the possibility of earnings exceeding wage income. Layard and Richter (1995) note an important feature of the Russian labour market: quite a few households or workers make their living out of non-wage income.

In the presence of a profitable informal sector it can seem odd that workers still prefer to retain ties with the official sectors. However, this can be explained by the fact that Russian old sector firms have a long history of providing a significant range of nonmonetary benefits (kindergartens, subsidised housing, etc.) that were not only quite large, but were also an important factor in motivating workers (Commander et al. 1996b). ${ }^{6}$ Such benefits comprise a good proportion of the total remuneration of workers (Standing, 1998). Another reason for not quitting may be that staying in the enterprise workers can continue using its equipment to earn their additional income (Layard and Richter, 1995; Matveenko et al. 1998). It also important that being registered with the official enterprise is crucial for qualifying afterwards for a pension after retirement.

\subsubsection{Outlining the Hypotheses}

Having looked at workings of the informal labour market in Russia, one can see that modelling decisions of individuals should take account of such features mentioned in the previous subsection as 1) fictitious employment, 2) a possibility of exerting less than full effort in the old sector or working less than the official working time, and 3) the influence of non-wage benefits. We will turn back to these issues again in the next section, and now we put forward our main hypotheses and formulate objectives of the work more precisely.

In particular, we believe that:

1. the decline in participation rate in Russia has been associated with shifts of workers to the informal sector;

2. the growth of the informal economy is caused not only by the people who decide to work there full time, but also by spreading moonlighting practices;

3. the level of benefits provided by the old sector can affect job creation and wage setting in the new sector; ${ }^{7}$ it can also prove important in affecting a worker's sector choice.

\footnotetext{
${ }^{6}$ Commander and Tostopiatenko (1997) draw upon this hypothesis.

${ }^{7}$ We will model the economy as consisting of the old and the new sectors rather than of the public and private sectors. Boeri (1999) writes that it is better to use the former split "as neither privatisation nor downsizing are sufficient for a firm to move from one sector to another." Similar reasoning is used in our previous work - see Matveenko et al. (1998).
} 
Thus, we aim to show that 1) the shadow economy influences labour reallocation in transition; 2) its growth can also be explained by the character of labour supply in the official sectors; 3 ) old sector benefits affect the choice of workers and can be crucial for labour reallocation as well.

The work should also cast some light on the stylised facts mentioned at the beginning of this section. In particular, it should help in explaining

- the decline in participation rates (Fig.1.4);

- the growing share of the informal economy (Fig.1.8);

- the L-shape of output evolution in Russia (Fig.1.1);

- the lower probability of direct shifts from employment to inactivity in Russia compared to Eastern European countries.

To model labour reallocation with a role for individual labour supply in the presence of moonlighting and informal employment opportunities, we suggest the following approach. First, it is useful to look separately at a static system with an informal sector to clarify possible choices of an individual concerning labour supply. For this purpose in the next section we build a time-allocation model similar in spirit to models with home production (Gronau, 1977, 1980). Then, a dynamic OST model can be constructed to carry over the main findings of the static model regarding behaviour of agents in particular situations.

\section{The Two Models}

In this section we present two models featuring multiple job-holding in transition and intersectoral allocation of labour in the presence of the informal sector.

The first model is a version of a standard problem of time allocation in the spirit of Becker (1965) or Gronau (1977). It highlights the institutional peculiarities of the Russian labour market and considers the choices facing individuals employed in different sectors.

The second model is a partial-equilibrium dynamic OST model of labour relocation in transition with possibilities of informal work. It draws upon the insights provided by the first model.

\subsection{The Time Allocation Model}

Consider an economy consisting of three sectors: two official sectors - old and new, and one informal sector. By the old sector we understand state enterprises that are not efficient, offer their workers a flexible work regime, a low fixed wage ${ }^{8}$ and some unique benefits (we assume here for the purpose of modelling that they can be expressed in pecuniary terms). By the new sector we understand de novo (newly established) private enterprises and successfully restructured former state enterprises that offer a flexible (hourly) wage rate and do not offer separate benefits like those in the old sector. ${ }^{9}$ Finally, the informal sector is understood as subsistence activities, home production (e.g. work on a worker's own land plot), informal entrepreneurship and non-registered activities of official private firms in the new sector. We will think of this sector as giving some informal hourly income (informal wage), but not offering any kind of additional benefits. It is assumed that employment in the informal sector can be considered first of all on the grounds of getting a supplementary income.

\footnotetext{
${ }^{8}$ The way it is fixed is discussed later in the section.

${ }^{9}$ It seems reasonable to separate benefits and wages in the old sector in order to capture the effect of its attractiveness for a worker despite low wages. In the case of the new sector we assume that the same benefits are already incorporated in the wage paid to its workers. Commander et al. (1996b) report that de novo private sector wages incorporate lower social benefits provision, which, thus, depress the value of the total relative compensation in the private sector in Russia.
} 
In this model the wages both in the old and the new sectors and in the informal economy are viewed as exogenously determined.

While working in the official economy any individual can find herself in three possible states: old sector employment, new sector employment and unemployment. We assume that in each of these states she can either spend all the available time doing a primary activity or combine it with secondary informal employment. The reasons for moonlighting should be clear from the previous section. It can also be the case that the worker would prefer full-time informal employment to full-time official activities or moonlighting. We exclude possibilities of combining work in the two official sectors at once.

In each state the worker faces the problem how to allocate her available stock of time between the primary work or activity (i.e. job-search if unemployed) and underground work. The work in the informal sector is assumed to be always available for the individual.

The analysis proceeds by considering the utility maximisation problem of the worker.

\subsubsection{The Utility Maximisation Problem of a Worker}

In general, the utility maximisation problem of a representative worker should comprise two simultaneous problems of 1) an optimal allocation of worker's time between labour and leisure and 2) a choice between formal and informal activities (see, e.g. Lacroix and Fortin, 1992). Solving these problems the representative agent works out her labour supply function in the old and the new sectors of the economy given the wage in the informal sector, and other parameters that can influence her employment decision (e.g. fringe benefits, etc.).

We assume that all the workers in the economy are different with respect to some intrinsic desire or propensity to perform non-market (i.e. informal) activities. This difference in the propensity to informal work can be explained by a number of reasons. The obvious rationale behind it is that non-market activities can be judged adversely by the society and, thus, individuals differ in their courage to defy the public opinion by working underground. ${ }^{10}$ It might also be possible that different individuals have different access to informal sector jobs (especially those that do not include home production). Then they could meet different costs of getting in principle an available job underground. ${ }^{11}$ This would again make workers different with respect to their utility drawn from "shadow" activities. ${ }^{12}$

We start by writing down the utility maximisation problem in a very general case.

\subsubsection{The general case}

The formal way to show the problem that faces the worker is to consider a utility function depending on three variables - leisure and consumption of goods produced in the official and informal sectors. We will assume that goods produced in the official economy and in the informal one are not perfect substitutes. ${ }^{13}$ It is also assumed that all the money

\footnotetext{
${ }^{10}$ This courage, in turn, might result from, for example, financial needs of individuals. That is, different people can be more or less willing to take up a secondary job in the informal sector depending on the current state of their home budget. Some researchers (Roshchin and Razumova, 1999) do not support this point, however, admitting that their conclusions might have been caused by the quality of available data.

${ }^{11}$ Heterogeneity in costs can be justified by the importance of personal contacts in secondary job search stressed by Clarke (2000).

${ }^{12}$ Such an approach is different from the variation in reservation utilities proposed by Boeri (1999). In his model all workers are different with respect to their productivity in the informal sector. Our model assumes the same level of marginal informal income for everyone.

${ }^{13}$ When studying a business cycle model with home production Benhabib et al. (1991) suggest that home produced goods and market goods are not perfect substitutes. However, they refer to the evidence by Eichenbaum and Hansen (1990), who support the hypothesis of perfect substitutability. In our case, the informal sector is a wider notion than just the home production. So, at first sight, the idea of full substitutability could be more applicable here. However, if one recalls that the official sector can provide some kind of social benefits that cannot be consumed in the informal sector, a lower degree of substitutability should be assumed between official and informal goods.
} 
earned in the economy by workers is designated for consumption only and cannot be saved. Thus, consumption of goods is directly related to hours of work.

It is important to note that incentives to participate in the informal economy and consume its goods may differ according to whether the worker is employed in the old sector or in the new sector or unemployed.

The old sector worker may wish to supplement his low income from the official job (or, equivalently, the consumption of official good) by working informally (consuming informal good). The wage in the old sector could be too low compared to the informal one to satisfy the worker, but the latter can still want to be attached to the sector because of nonwage benefits.

For the new sector worker the only incentive for preferring shadow activities may be her personal propensity to such work. At the same time the wages and incomes themselves in both sectors can be comparable.

Tax incentives can also be important both for old and new sectors employees, but we will not consider them in this work. The evidence from the Western countries (see, e.g., Lemieux et al. (1994) who study labour supply in the Canadian underground economy) suggests that the tax distortion of labour supply in the regular sector is small for the average worker. For transition countries Schaffer and Turley (2000) note that in the tax system that existed under the socialist command economy direct taxes on individuals were unimportant. They write that the transition to the market meant that a personal income tax system as operates in Western economies was to be introduced. However, until quite recently the administration of collection of income taxes has been weak in Russia (Treisman, 1999). Friedman et al. (2000), studying informal economies, also note that it is not higher taxes are associated with more unofficial activities but rather the burden of corruption and bureaucracy facing entrepreneurs.

The unemployed worker may wish to work informally to gain some income in addition to unemployment compensation. This is similar to the situation in the old sector. However, unemployed workers do not have access to benefits which are available for the old sector workers.

The old sector benefits are unique and not offered elsewhere. This makes the old sector good different at least from the good offered by the new sector. The benefits in the old sector are actually different from unemployment benefits too - it might be even difficult to express them in money terms. The conception of the old sector benefits is made clearer later in this section.

Thus, three different utility maximisation problems for the worker should be considered. The first one is for the situation when the worker chooses between leisure, old sector employment and informal employment. The second problem when she chooses between leisure, new sector employment and informal employment. Finally, the third maximisation problem has to be solved when the worker turns out to be unemployed. She then decides how much time to devote to consuming unemployment benefits (and probably searching for a new job), to working underground and to leisure.

\subsection{The worker's choice in the old sector}

If the propensity to work informally is denoted by $q$, the problem of the worker choosing between the old and informal sector employment can be seen as

$$
\begin{array}{ll}
\max _{C_{o}, C_{i}, l} U_{o}^{q}\left(C_{o}, C_{i}, l\right) \\
\text { s.t. } & C_{o}=W_{o}\left(h_{o}\right)+B\left(h_{o}\right) \\
& C_{i}=w_{i} h_{i} \\
& l=1-h_{o}-h_{i} \\
& h_{o}, h_{i} \geq 0 .
\end{array}
$$


$C_{o}$ and $C_{i}$ above denote consumption of the goods in the old and informal sectors, respectively. All available time ( 24 hours) is normalised to 1 , so leisure, $l$, is equal to 1 less the time spent in the old sector, $h_{o}$, and in the informal sector, $h_{i}$. The superscript $q$ in the utility function implies that each particular worker is unique in her preferences, which parameterised by $q$.

The most important assumption regarding the work in the old sector is made when considering the sector's wage rate. It is assumed fixed and dependent on the hours of work in the old sector in the following way:

$$
W_{o}\left(h_{o}\right)=\left\{\begin{array}{l}
w_{o}, \text { if } h_{o} \geq H \\
0, \text { if } h_{o}<H
\end{array}\right.
$$

where $0<H<1$. $H$ denotes the amount of time that old sector workers tacitly agree to work to earn the old sector wage, $w_{o}$.

In the literature on multiple job holding it is usual to assume that workers take up their secondary jobs as a response to upper-bound constraints on their primary jobs (see, e.g. Shisko and Rostker, 1976). However, it is hardly applicable to the case of the Russian old sector. There could not be any kind of upper-bound constraints on a worker's time. Some authors (Matveenko et al., 1998) have argued that state enterprises do not even require complete use of working time from their employees. At the same time, there might exist some lower-bound constraints, violating which a worker can end up either being fired or not getting any wage. The amount of time $H$ reflects these lower-bound constraints: if workers work less than $H$, they earn a zero wage. However, they still can get fringe benefits. ${ }^{14}$ That is, the consumption of social benefit good $B_{o}$ satisfies:

$$
B_{o}\left(h_{o}\right)=\left\{\begin{array}{l}
b_{o}, \text { if } B \leq h_{o} \leq 1 \\
0, \text { if } 0 \leq h_{o}<B,
\end{array}\right.
$$

where $B$ is some amount of time less than $H .^{15}$

This view of benefits in the old sector corresponds to the widespread situation in Russia. Some workers can be just registered with state enterprises in order to maintain an official employment record ${ }^{16}$ (which is important for obtaining a pension after retirement), but in fact they work elsewhere not getting any earnings from an enterprise where registered. ${ }^{17}$ In this example, the benefit of maintaining the employment record is what is captured by term $b_{o}$ in the model. ${ }^{18}$

The problem (1) can be further rewritten as

$$
\begin{array}{ll}
\max _{h_{o}, h_{i}, l} U_{o}^{q}\left(C_{o}\left(h_{o}\right), C_{i}\left(h_{i}\right), l\right) \\
\text { s.t. } & C_{o}=W_{o}\left(h_{o}\right)+B\left(h_{o}\right) \\
& C_{i}=w_{i} h_{i} \\
& l=1-h_{o}-h_{i} \\
& h_{o}, h_{i} \geq 0
\end{array}
$$

Then the Lagrangean of the problem (1a) is

\footnotetext{
${ }^{14}$ One can consider this situation as an example of so-called collectivist labour relations when workers follow the tacit arrangements within a state firm. More on collectivist labour relations see Polterovitch (1996) and Matveenko et al. (1998).

${ }^{15}$ Time constraints $B$ and $H$ are almost surely different in reality, however, further empirical research is required to prove this.

${ }_{16}^{16}$ So-called trudovaya knizhka, i.e. the labour book (see Clarke, 1999).

${ }^{17}$ This is exactly what Barsukova (2000) calls fictitious employment - see Section 1.

${ }^{18}$ In mid 90-s Russia the widespread reaction of managers to periods of a factory downtime was not shedding labour, but rather sending workers to administrative leaves. When facing a menace of layoffs workers preferred rather being on leave without pay and keeping their attachment to the job to being fired from a firm (see Kabalina and Ryjikova, 1998). This can give one another insight into the essence of the time constraint $B$.
} 


$$
L\left(h_{o}, h_{i}, l, \lambda_{1}, \lambda_{2}\right)=U_{o}^{q}\left(W_{o}\left(h_{o}\right)+B_{o}\left(h_{o}\right), w_{i} h_{i}, 1-h_{o}-h_{i}\right)-\lambda_{1} h_{o}-\lambda_{2} h_{i},
$$

where $\lambda_{1}, \lambda_{2}$ are Lagrange multipliers. Since the constraints on $h$ 's are of the form $h_{o}, h_{i} \geq 0$, the sign restriction on Lagrange multipliers claims $\lambda_{1}, \lambda_{2}$ to be non-positive.

It is possible to show that in principle there could exist seven following regimes.

In regime 1 both $\lambda_{1}$ and $\lambda_{2}$ are equal to zero and the individual works in both markets and is not constrained. The first order conditions reduce to $\frac{\partial U_{o}^{q} / \partial l}{\partial U_{o}^{q} / \partial C_{o}}=W_{o}^{\prime}+B^{\prime}$ and $\frac{\partial U_{o}^{q} / \partial l}{\partial U_{o}^{q} / \partial C_{i}}=w_{i}$. Using the implicit function theorem we can obtain interior solution $h_{o}^{*}\left(w_{o}, w_{i}, b_{o}, q\right)$ and $h_{i}^{*}\left(w_{o}, w_{i}, b_{o}, q\right)$.

At this level of generality it is impossible to predict unambiguously the qualitative response of $h_{o}^{*}$ and $h_{i}^{*}$ to variations in $w_{o}, w_{i}, b_{o}$ and $q$. More structure on preferences should first be imposed. We shall consider the case of the logarithmic utility later in this section.

In regime 2 the individual works only in the old sector. This will take place when $\lambda_{1}$ $=0$, and $\lambda_{2}<0$. The first order conditions imply $\frac{\partial U_{o}^{q} / \partial l}{\partial U_{o}^{q} / \partial C_{o}}=W_{o}^{\prime}+B^{\prime}$ and $\frac{\partial U_{o}^{q} / \partial l}{\partial U_{o}^{q} / \partial C_{i}}>w_{i}$. In this regime the solution is $h_{o}^{*}\left(w_{o}, w_{i}, b_{o}, q\right)$ and $h_{i}^{*}=0$.

Regime 3 is the reverse of regime 2 . The individual works only in the informal economy when $\lambda_{1}<0$, and $\lambda_{2}=0$. The first order conditions lead to $\frac{\partial U_{o}^{q} / \partial l}{\partial U_{o}^{q} / \partial C_{o}}>W_{o}^{\prime}+B^{\prime}$ and $\frac{\partial U_{o}^{q} / \partial l}{\partial U_{o}^{q} / \partial C_{i}}=w_{i}$. The labour supply functions solving the worker's maximisation problem are $h_{o}^{*}=0$ and $h_{i}^{*}\left(w_{o}, w_{i}, b_{o}, q\right)$.

Regime 4 refers to individuals who do not work in any market. In this case, $\lambda_{1}<0$ and $\lambda_{2}<0 . h_{o}^{*}=0$ and $h_{i}^{*}=0$ are the solutions of the problem and the worker enjoys maximum leisure.

Regimes 5,6 and 7 refer to the situation when the individual works in any one or both markets but faces an upper-bound constraint in available hours (i.e. her leisure time is 0 ). These regimes do not make economic sense and, thus, are not interesting.

Let us denote the general solution to problem (1a) by $h_{o}^{*}\left(w_{o}, w_{i}, b_{o}, q\right)$ and $h_{i}^{*}\left(w_{o}, w_{i}, b_{o}, q\right)$. Then the maximum value of utility in any of the four regimes above is achieved at

$$
\begin{aligned}
& U_{o}^{*}\left(w_{o}, w_{i}, b_{o}, q\right)= \\
& U_{o}^{q}\left(C_{o}\left(h_{o}^{*}\left(w_{o}, w_{i}, b_{o}, q\right)\right), C_{i}\left(h_{i}^{*}\left(w_{o}, w_{i}, b_{o}, q\right)\right), 1-h_{o}^{*}\left(w_{o}, w_{i}, b_{o}, q\right)-h_{i}^{*}\left(w_{o}, w_{i}, b_{o}, q\right)\right) .
\end{aligned}
$$

\subsection{The worker's choice in the new sector}

Having considered the problem of a choice between the old sector employment and informal activities, we can by analogy write down the problem facing the new sector worker. She has to solve the task:

$$
\begin{array}{ll}
\max _{h_{n}, h_{i}, l} U_{n}^{q}\left(C_{n}\left(h_{n}\right), C_{i}\left(h_{i}\right), l\right) \\
\text { s.t. } & C_{n}=w_{n} h_{n} \\
& C_{i}=w_{i} h_{i} \\
& l=1-h_{n}-h_{i}
\end{array}
$$




$$
h_{n}, h_{i} \geq 0
$$

Again, $q$ describes the heterogeneous aversion to informal work, whereas $h_{n}$ is hours supplied to the new sector, and other variables are as before.

Similarly to the old sector case, the Kuhn-Tucker conditions for (2) define seven major regimes which determine the labour supply/participation in the new and the informal sectors.

The solutions to problem (2), $h_{n}^{*}\left(w_{n}, w_{i}, q\right)$ and $h_{i}^{*}\left(w_{n}, w_{i}, q\right)$, define the maximum value of the utility function $U_{n}^{q}(\bullet)$ :

$$
\begin{aligned}
& U_{n}^{*}\left(w_{n}, w_{i}, q\right)= \\
& U_{n}^{q}\left(C_{n}\left(h_{n}^{*}\left(w_{n}, w_{i}, q\right)\right), C_{i}\left(h_{i}^{*}\left(w_{n}, w_{i}, q\right)\right), 1-h_{n}^{*}\left(w_{n}, w_{i}, q\right)-h_{i}^{*}\left(w_{n}, w_{i}, q\right)\right) .
\end{aligned}
$$

\subsection{The choice of unemployed}

Finally, the problem facing the unemployed is

$$
\begin{array}{ll}
\max _{h_{u}, h_{i}, l} U_{u}^{q}\left(C_{u}\left(h_{u}\right), C_{i}\left(h_{i}\right), l\right) \\
\text { s.t. } & C_{u}=B_{u}\left(h_{u}\right) \\
& C_{i}=w_{i} h_{i} \\
& l=1-h_{u}-h_{i} \\
& h_{u}, h_{i} \geq 0
\end{array}
$$

Where $h_{u}$ is hours spent not working in the informal economy and not leisure (for example, hours spent to look for a new job, etc.); $B_{u}$ is unemployment benefits defined as

$$
B_{u}\left(h_{u}\right)=\left\{\begin{array}{l}
b_{u}, \text { if } h_{u} \geq T \\
0, \text { otherwise. }
\end{array}\right.
$$

Notice, it is assumed that in order to receive the unemployment compensation the worker has to spend some minimum amount of time, $T$, searching for a job. This is a reasonable assumption, since in order to be eligible for benefits the unemployed worker has to bear some time costs while registering at the labour office, checking there periodically, going to interviews, etc.

Again, the Kuhn-Tucker conditions for (3) define the seven regimes determining the labour supply in the informal sector and participation in job search.

The solutions to problem (3), $h_{u}^{*}\left(b_{u}, w_{i}, q\right)$ and $h_{i}^{*}\left(b_{u}, w_{i}, q\right)$, give the maximum value of the utility function $U_{u}^{q}(\bullet)$ :

$$
U_{u}^{*}\left(b_{u}, w_{i}, q\right)=U_{u}^{q}\left(C_{u}\left(h_{u}^{*}\left(b_{u}, w_{i}, q\right)\right), C_{i}\left(h_{i}^{*}\left(b_{u}, w_{i}, q\right)\right), 1-h_{u}^{*}\left(b_{u}, w_{i}, q\right)-h_{i}^{*}\left(b_{u}, w_{i}, q\right)\right) .
$$

\subsubsection{The case of logarithmic utility}

In order to analyse the model further, we first specify a functional form for the utility functions in problems (1a), (2) and (3). Thus, some strong assumptions about preferences of the worker in the economy will be made. However, we need them to be able to draw any qualitative conclusions concerning the impact of parameters of the model on labour supply in each sector.

We also simplify the task somewhat by excluding leisure from the utility function. It is now assumed that the amount of leisure is exogenously given and fixed. Thus, the individual can only distribute her time between different types of work. Such a simplification allows to reduce the number of the regimes considered above. 1991).

It is often convenient to use a logarithmic utility function (see, e.g., Benhabib et al.,

$$
U^{q}=\ln \left(1+W_{\text {off }}\left(h_{\text {off }}\right)\right)+q \ln \left(1+w_{i}\left(1-h_{\text {off }}\right)\right)
$$


Thus, the worker is to choose between employment in the official sector, $h_{\text {off }}$, and

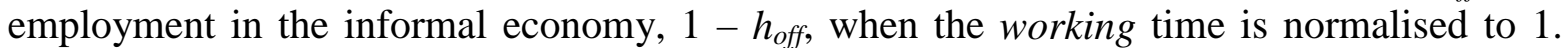
The heterogeneity of workers with respect to informal labour is modelled by factor $q$, which is assumed uniformly distributed on $[0,1]$. The greater $q$ the higher utility is drawn by the individual from working informally.

Let us now consider the worker's choice in already familiar situations.

\subsection{The worker's choice in the old sector}

The worker in the old sector maximises utility

$$
U^{q}=\ln \left(1+W_{o}\left(h_{o}\right)+B_{o}\left(h_{o}\right)\right)+q \ln \left(1+w_{i}\left(1-h_{o}\right)\right) \text {, }
$$

where $W_{o}\left(h_{o}\right)=\left\{\begin{array}{l}w_{o}, \text { if } h_{o} \geq H \\ 0, \text { if } h_{o}<H\end{array}, B_{o}\left(h_{o}\right)=\left\{\begin{array}{l}b_{o}, \text { if } B \leq h_{o} \leq 1 \\ 0, \text { if } 0 \leq h_{o}<B\end{array}\right.\right.$ and $B<H$.

There can be three cases.

1) If the solution, $h_{o}$, were such that $0 \leq h_{o}<B$ then both $W_{o}$ and $B_{o}$ are equal to zero. Then the utility function reduces to $U^{q}=q \ln \left(1+w_{i}\left(1-h_{o}\right)\right)$. It is obvious that workers will choose $h_{o}=0$, and enjoy utility $U_{1}^{o}=q \ln \left(1+w_{i}\right)$.

2) If $B \leq h_{o}<H$ then the worker again receives a zero wage, but can obtain the old sector benefits $B_{o}=b_{o}$. The utility function reduces to

$$
U^{q}=\ln \left(1+b_{o}\right)+q \ln \left(1+w_{i}\left(1-h_{o}\right)\right) .
$$

Again, it is straightforward that the maximum of utility is achieved when $h_{o}=B$. That is workers enjoy utility $U_{2}^{o}=\ln \left(1+b_{o}\right)+q \ln \left(1+w_{i}(1-B)\right)$.

3) Finally, if $H \leq h_{o} \leq 1$ then the worker receives both the wage and the benefits in the old sector. The utility function now is

$$
U^{q}=\ln \left(1+w_{o}+b_{o}\right)+q \ln \left(1+w_{i}\left(1-h_{o}\right)\right),
$$

and the maximum is achieved at $h_{o}=H$. The maximum utility value is

$$
U_{3}^{o}=\ln \left(1+w_{o}+b_{o}\right)+q \ln \left(1+w_{i}(1-H)\right) \text {. }
$$

In Appendix 3 we derive the threshold values of $q$ that determine workers who supply to the old sector as many hours as described in 1), 2) and 3) above. In particular,

$$
\begin{aligned}
& \text { if } q<q_{1}=\frac{\ln \left(1+b_{o}\right)}{\ln \left(1+w_{i}\right)-\ln \left(1+w_{i}(1-B)\right)} \text { then } U_{1}^{o}<U_{2}^{o} \text {; } \\
& \text { if } q<q_{2}=\frac{\ln \left(1+w_{o}+b_{o}\right)-\ln \left(1+b_{o}\right)}{\ln \left(1+w_{i}(1-B)\right)-\ln \left(1+w_{i}(1-H)\right)} \text { then } U_{2}^{o}<U_{3}^{o} \text {; } \\
& \text { and if } q<q_{3}=\frac{\ln \left(1+w_{o}+b_{o}\right)}{\ln \left(1+w_{i}\right)-\ln \left(1+w_{i}(1-H)\right)} \text { then } U_{1}^{o}<U_{3}^{o} \text {. }
\end{aligned}
$$

Different values of parameters $\left(w_{o}, b_{o}, w_{i}, B, H\right)$ make $q_{1}, q_{2}$ and $q_{3}$ correspond to each other in different way. Thus, different solutions can be obtained for the same level of $q$, depending on a particular set of parameters (for example, depending on the value of $B$, the same $q$ will give either $U_{1}^{o}$ or $U_{2}^{o}$ as a solution). We relegate the full analysis of possible situations to the appendix.

Since $q$ is in between 0 and 1 , some restrictions must be put on the threshold levels. These restrictions are also presented in Appendix 3. Beside that, there we show that $q_{1}>1$ and $q_{3}>1$ under some sensible for Russian reality combinations of parameters, and the first case (when a worker supplies zero hours in the old sector) can be eliminated. This rather interesting result implies that an old sector worker facing a choice between work in the 
sector and informal employment will never prefer full-time irregular work. Ultimately, the labour supply function of a worker in the Russian old sector is given by

$$
h_{o}=\left\{\begin{array}{l}
B, \text { if } q_{o} \leq q \leq 1 \\
H, \text { if } 0 \leq q<q_{o}
\end{array},\right.
$$

as determined in the appendix. The threshold level $q_{o}$ is equal to $q_{2}$, i.e.

$$
\frac{\ln \left(1+b_{o}+w_{o}\right)-\ln \left(1+b_{o}\right)}{\ln \left(1+w_{i}(1-B)\right)-\ln \left(1+w_{i}(1-H)\right)} \text {. }
$$

Then the indirect utility function of the worker in the old sector is

$$
U_{o}^{q}=\left\{\begin{array}{l}
\ln \left(1+b_{o}\right)+q \ln \left(1+w_{i}(1-B)\right), \text { if } q_{o} \leq q \leq 1 \\
\ln \left(1+w_{o}+b_{o}\right)+q \ln \left(1+w_{i}(1-H)\right), \text { if } 0 \leq q<q_{o}
\end{array} .\right.
$$

\subsection{The worker's choice in the new sector}

The problem that the worker has to solve once find herself employed in the new sector differs from that for the old sector. It is assumed that the wage in the sector is flexible and the overall income depends on a number of hours actually worked.

The worker maximises utility

$$
U^{q}=\ln \left(1+w_{n} h_{n}\right)+q \ln \left(1+w_{i}\left(1-h_{n}\right)\right) \text {. }
$$

The solution to this problem is $h_{n}=\frac{w_{n}\left(1+w_{i}\right)-q w_{i}}{w_{n} w_{i}(1+q)}$. It is easy to show that $\frac{\partial h_{n}}{\partial w_{n}}>0$, $\frac{\partial h_{n}}{\partial w_{i}}<0$ and $\frac{\partial h_{n}}{\partial q}<0$. Thus, the labour supply in the official sector is positively related to the wage rate in the sector and it negatively depends on the informal wage and the propensity to underground work.

The expression for $h_{n}$ above is correct if some conditions on parameters guarantee that the right hand side of the expression is in between 0 and 1 . However, this is not always the case. In Appendix 3 we derive threshold values for $q$ that determine corner solutions, i.e. when $h_{n}$ is either 0 or 1 . There we also show that the case, when workers do not work in the new sector at all but prefer full time involvement in informal business, is limited on grounds of evidence from Russia. This result is similar to the finding for the old sector worker: having access to a job in the official sector, the worker will hardly sacrifice it for full time irregular activities.

The labour supply of the worker in the new sector is ultimately defined as

$$
h_{n}=\left\{\begin{array}{l}
\frac{w_{n}\left(1+w_{i}\right)-q w_{i}}{w_{n} w_{i}(1+q)}, \text { if } q_{n} \leq q \leq 1 \\
1, \text { if } 0 \leq q<q_{n}
\end{array},\right.
$$

where $q_{n}=w_{n} \frac{1}{w_{i}\left(1+w_{n}\right)}$.

The indirect utility function of the worker in the new sector is as follows:

$$
U_{n}^{q}=\left\{\begin{array}{l}
\ln \left(\frac{w_{n}\left(1+w_{i}\right)+w_{i}}{w_{i}(1+q)}\right)+q \ln q \frac{w_{n}\left(1+w_{i}\right)+w_{i}}{w_{n}(1+q)}, \text { if } q_{n} \leq q \leq 1 \\
\ln \left(1+w_{n}\right), \text { if } 0 \leq q<q_{n} .
\end{array}\right.
$$

\subsection{The choice of unemployed}

Unemployed workers face nearly the same problem that the old sector workers do. The unemployment benefits are a fixed parameter, which does not depend on how much time the worker spends seeking for a new job. However, there exists some lower limit 
constraint that the worker is bound to fulfil if she wants to draw the benefits (it has been discussed earlier in this section). Thus, recall that unemployment benefits can be represented by the function

$$
B_{u}\left(h_{u}\right)=\left\{\begin{array}{l}
b_{u}, \text { if } T \leq h_{u} \leq 1 \\
0, \text { if } 0 \leq h_{u}<T
\end{array},\right.
$$

where $T$ is the minimum amount of time the worker has to devote to job search to receive unemployment compensation. Then the utility function to maximise is

$$
U^{q}=\ln \left(1+B_{u}\left(h_{u}\right)\right)+q \ln \left(1+w_{i}\left(1-h_{u}\right)\right) \text {. }
$$

The worker's labour supply is pinned down by two following cases.

1) If the solution, $h_{u}$, were such that $0 \leq h_{u}<T$ then the worker does not receive any unemployment benefits. Then to maximise utility she chooses $h_{u}=0$ and, thus, drops out of labour force. The utility value she gets is $q \ln \left(1+w_{i}\right)$.

2) If, on the other hand, $T \leq h_{u} \leq 1$ then the worker is still in the labour force and gets benefits $B_{u}=b_{u}$. The maximum of utility is achieved when $h_{u}=T$. That is, such individuals enjoy utility $\ln \left(1+b_{u}\right)+q \ln \left(1+w_{i}(1-T)\right)$.

Again, in Appendix 3 we derive the threshold value of $q$ that determine the workers who either stay in the participation or drop out of it, once unemployed.

The labour supply function of the unemployed worker is then

$$
h_{u}=\left\{\begin{array}{l}
0, \text { if } q_{u} \leq q \leq 1 \\
T, \text { if } 0 \leq q<q_{u}
\end{array},\right.
$$

where $q_{u}=\frac{\ln \left(1+b_{u}\right)}{\ln \left(1+w_{i}\right)-\ln \left(1+w_{i}(1-T)\right)}$. The indirect utility function is

$$
U_{u}^{q}=\left\{\begin{array}{l}
q \ln \left(1+w_{i}\right), \text { if } q_{u} \leq q \leq 1 \\
\ln \left(1+b_{u}\right)+q \ln \left(1+w_{i}(1-T)\right), \text { if } 0 \leq q<q_{u}
\end{array} .\right.
$$

\subsubsection{Discussion of the Model and Its Implications}

The idea of this simple time-allocation model is similar to seminal work by Gronau (1977, 1980). However, instead of the allocation of time between market and home production we closely look at moonlighters supplying labour to the official and informal sectors in the transition economy. This view is different from that of Matveenko et al. (1998), who consider old sector workers moonlighting in the new sector, but similar to Commander and Tolstopiatenko (1997), focusing on moonlighting in informal firms.

We consider three time-allocation problems because in each state of the traditional transitional trichotomy (old sector employment, new sector employment and unemployment) workers have different opportunities for moonlighting. Their decision to supply labour underground stems from some personal characteristics of an individual. Heterogeneous labour is defined through some factor or propensity to work informally that varies across workers. In practice, this factor can not necessarily reflect the actual propensity or motivation for such work but can instead be affiliated to costs or opportunities to engage in secondary informal employment. ${ }^{19}$ Depending on this propensity individuals can take different decisions about their informal labour supply in each of possible states. External factors such as the actual level of wages and benefits determine some threshold levels for the propensity. Therefore, changes in the factors impact the distribution of workers across fulltime and part-time work. Below we consider some implications for hours of work and workers' behaviour in more detail.

${ }^{19}$ Clarke (2000) points to an uneven distribution of such opportunities across individuals. 


\subsubsection{Implications for hours of work}

We have shown that the institutional peculiarities of the Russian economy (such as, e.g., some additional non-wage benefits unique for the old sector) can lead some workers to get employed only fictitiously (the terminology of Barsukova, 2000). These workers will earn only the old sector benefits, but not its wage. That is, in fact, most of their time they will spend working informally.

The model implies that any increase in the informal rate of income will distort the supply of hours away from the regular sectors. In the new sector each individual will decide to supply fewer hours. In the old sector where the possible options are discrete the increase in the underground wage will make more workers choose fictitious employment. An increase in the amount of fringe benefits in the old sector will take the same effect. ${ }^{20}$ This conclusion supports the point of Commander et al. (1996b) who show that the smaller the relative monetary wage in the primary sector the stronger the workers' incentives "to reduce effort, subject to a minimum effort requirement, and to allocate as much of their time as possible to secondary work". In Appendix 3 we show that by tightening the minimum time requirement $B$ the old sector can induce more workers to work for wage, but not fictitiously.

\subsubsection{Who will work full time in the informal sector?}

It is interesting that the evidence from Russia suggests that some threshold levels do not satisfy the restrictions placed on $q$ (see Appendix 3). That is, it suggests a variant of the model where choices of full-time informal employment are eliminated for the old and new sector workers. Only unemployed workers can prefer full involvement in irregular activities. This is consistent with the stylised fact that major flows to inactivity take place through unemployment.

At the beginning of the paper we have also seen that the evidence from Eastern Europe witnesses the probability of direct shifts from employment to out-of-labour-force to be nearly twice as high as the probability of such shifts in Russia. Our model can provide a clue to this fact: the practices adopted in the official sectors of the Russian economy may exclude choices of full-time underground work. In Russia the official sector workers may face more opportunities for moonlighting than in CEE countries (e.g. fictitious employment). They do not face a trade-off between formal and informal work.

\subsubsection{Comparing threshold values and utilities}

Having determined the three threshold levels for the propensity of old sector, new sector and unemployed workers, we should compare them to understand how a worker with the same level of $q$ would behave in different states.

In Appendix 3 we make such a comparison of $q_{o}, q_{n}$ and $q_{u}$. It is difficult to say, in which way these values will correspond to each other in a general case. One has to know the parameters of the model, i.e. $w_{o}, w_{i}, w_{n}, b_{o}, b_{u}, B, H$, and $T$, to draw any inference. Using some evidence from Russia reported by other authors (Clarke, 1998; Kolev, 1998; Roshchin and Razumova, 1999; Rutkowski, 1999, among others) we suggest that the likely relation is $q_{n}<q_{u}<q_{o}{ }^{21}$

This implies that all the full-time new sector workers would never choose fictitious employment, if they turned to be in the old sector. On the other hand, all fictitious old sector workers who spend much of their time in the irregular sector and earn only benefits in the

\footnotetext{
${ }^{20}$ This is because with an increase in benefits the opportunity to work the minimum possible amount of time for higher compensation becomes more attractive for workers. More of them will give up the old sector wage for the informal one provided they still maintain access to benefits.

${ }^{21}$ That is, more workers moonlight in the new sector than in the old one. Intuitively, this might be explained by the fact that many new sector firms co-exist in the formal and informal economies at once. Their employees work at the same place producing both registered and non-registered output. Effectively, they officially earn moderate salaries, but may receive much more in "black" cash. Moonlighting in this case would imply just working at the same place but for "shadow" remuneration.
} 
formal economy, will moonlight whenever they are in the new sector. Such workers will also choose full-time informal work if they become unemployed, while the workers who work full time in the new sector will never do that. The behaviour of workers moonlighting in the new sector or working time $H$ in the old sector cannot be predicted precisely if they get laid off: they can either choose full-time informal work or not do that depending on a particular value of their $q$.

The comparison of $q$ 's, however, does not allow to say what the workers would do if they had an option of changing their current state. We should compare utilities of workers and unemployed with the same level of $q$ to obtain an answer.

In general, as with threshold values of $q, U_{o}^{q}, U_{n}^{q}$ and $U_{u}^{q}$ can relate to each other in different way. In Appendix 3 we make a comparison between the utilities for a single set of parameters likely for Russian reality. We use this set later in this work to simulate the dynamic model. The implication of the analysis is that for a few people with low values of $q$ (for example, full-time workers) relation $U_{u}^{q}<U_{o}^{q}<U_{n}^{q}$ holds. That is, for a worker with low $q$ new sector opportunities always make her better off than when she is in the old sector. Such a worker is at her worst when she is unemployed. For workers with higher $q$ 's, however, $U_{u}^{q}<U_{n}^{q}<U_{o}^{q}$ is satisfied. Such workers would never voluntarily prefer the new sector work to the old sector work, if they had such a choice.

This implication is consistent with VCIOM (1993-1999) survey data showing that many respondents indeed preferred state sector jobs to work in private firms, despite the latter provided a higher level of wages than the former did (Fig.1.6).

\subsubsection{Developing an idea}

To sum up, we have seen that the model provides a number of interesting implications that are important for reallocation of workers between different states in transition. Further, we would like to focus, in particular, on the finding that an unemployed worker may choose working full time in the irregular sector. This provides an insight into the drop in participation rates in Russia and other transition countries observed over the last decade. To develop this important conclusion we now turn to the dynamic model of transition that draws upon the time allocation model. We follow the Blanchard's (1997) model of labour reallocation in transition augmented to include the informal sector along with a number of other essential innovations.

\subsection{The Dynamic Model of Transition with an I nformal Sector}

The first model suggests that some proportion of workers prefer full-time informal work to receiving unemployment compensation once they found themselves unemployed. This in turn makes one think of the situation when few workers leave the labour force and do not participate in job search in the official sectors. Thus, as it has been noted in Section 1, the informal sector can play a significant role in labour force reallocation during economic transformation, not to mention the opportunities it creates for moonlighters.

We proceed by considering an OST-type dynamic model ${ }^{22}$ with the old and the new sectors extended to include the underground sector.

\subsubsection{The Main Assumptions}

The characteristics of the sectors are as described in the time-allocation model. It is also assumed that the work in the informal sector is always available and the sector's extent depends only on a number of workers wishing to work there. However, not all of the workers are willing to get a job in the informal sector. Their desire or ability to get that job is described by the parameter $q$ in the time-allocation model.

${ }^{22}$ The model itself fits the flow approach to labour markets as developed by Blanchard and Diamond (1992). 
Workers in the model are assumed to face the same opportunities as before. They can combine employment in one of the official sectors with underground employment, but they cannot be simultaneously employed in the two official sectors.

The transition is viewed as reallocation of labour from the old to the new sector.

At the beginning of transition the economy is dominated by the old sector firms. They pay wages and benefits on the same terms as in the previous model. Following Commander and Tolstopiatenko (1996), we assume that these firms do not invest. This could happen because either insiders have enough power to extract all surplus or some part of revenue is defalcated or wasted.

Firms in the new sector operate more effectively, they set flexible wages as before and invest their profits. We abstract from accumulation of physical or human capital in this model. All investments are in fact go into new job creation.

Contrary to many other OST studies, we assume that job destruction rates in the old sector, $\lambda \in[0,1]$, and in the new sector, $\gamma \in[0,1]$, are the same. Both sectors fire their workers at the same rate. Such job break-up separations result from firm specific shocks (such as changes in relative demand, in technology, etc.) and constitute a part of a natural labour turnover process. Boeri (1999) notes that empirical evidence for countries of Central and Eastern Europe suggests that separation rates from state and private firms are roughly comparable. However, the state sector is more notable for quits, which are comparatively rare in private units. In his model two different parameters are allowed for job destruction in the old and new sectors, i.e. $\gamma \neq \lambda$. Kapelyushnikov and Aukutsionek (1994) and Kapeliushnikov (1997) report similar results for Russia. Richter and Schaffer (1996), however, estimate that average job destruction rates for Russian state-owned and de novo enterprises in 1993-94 were $6.2 \%$ and $6.1 \%$ of total employment, respectively. Thus, the case when $\gamma=\lambda$ cannot be ignored.

Since the job destruction rates in the new and the old sector are the same, the rate of the old sector decline depends on the job creation rate in the sector, $\eta \in[0,1]$. This rate is given exogenously, but it is assumed that the government can affect its level.

Ultimately, the basic mechanism implied by the model is as follows.

The old sector is shrinking because of job break-ups and workers leaving it for the new sector. However, it still generates jobs for unemployed workers. The new sector is growing and it can also create new vacancies.

Workers in the old sector can either be laid off and become unemployed or can quit voluntarily for jobs in the new sector. Workers in the new sector can only be fired and become unemployed. Direct shifts of workers from employment to inactivity are not considered as suggested by the time-allocation model. However, workers can leave the labour force if they are unemployed. Informal sector workers cannot be directly employed in the official sectors, but they can come back to participation and register as unemployed.

The level of wages in the old sector is given as well as is the informal wage, whereas firms in the new sector determine the wage basing on efficiency wage considerations: they set wages at such a level that the value of being in the old sector for a worker is always lower than the value of being in the new sector. This condition is necessary in order for old sector workers to find work in the new sector more attractive.

Once the wage rate and thereby the profit rate in the new sector is determined, the new sector firms can work out a number of job vacancies to create. The latter impacts the exit rate from unemployment and the old sector and determine the dynamic process which describes how the economy evolves over time.

The flows between full-time employment in the model are shown in Fig.2.17. 
Now we can get round to considering the model in detail. We start by outlining the main features of building blocks of the model and then in subsections 2.2.8-2.2.10 bring the blocks together.

\subsubsection{Workers}

It is assumed that the overall number of workers (working age population) in the dynamic model is normalised to 1 . However, this is not to say that the labour force is equalised to 1 . This assumption is essentially different from other OST models with the important exception of Boeri (1999), that all imply the constant participation rate.

We will assume that each period of time a worker gets to know her personal level of $q$. This is modelled as if the worker were to draw the value of $q$ from the uniform distribution on $[0,1]$. After that the worker decides how much labour to supply informally in a particular situation. Only the worker knows her level of $q$. Both other workers and firms do not have any idea about it.

Let us assume for analytical simplicity that decisions about job search and moonlighting are separated, i.e. workers do not plan moonlighting for the future. They will think of a particular job as a full-time one. Getting a place in one of the sectors at the beginning of the period, the workers face some possibilities to change it at the end of the period. The workers who will leave the sector voluntarily or involuntarily are chosen randomly. They cannot reverse the will or necessity to separate. Then their $q$ 's become revealed bringing around some additional opportunities. Now the workers can start moonlighting depending on circumstances and their propensity expressed by such parameters as $B, H, T$ in the previous model and their current $q$. Thus, moonlighting in this model can be seen as a spontaneous phenomenon within a particular period of time. It can happen only after workers already know their future for the next period. ${ }^{23,24}$

As before, the threshold values of the propensity to work underground in different states are defined as

$$
\begin{aligned}
q_{o} & =\frac{\ln \left(1+b_{o}+w_{o}\right)-\ln \left(1+b_{o}\right)}{\ln \left(1+w_{i}(1-B)\right)-\ln \left(1+w_{i}(1-H)\right)}, \\
q_{n} & =w_{n} \frac{1}{w_{i}\left(1+w_{n}\right)}, \\
q_{u} & =\frac{\ln \left(1+b_{u}\right)}{\ln \left(1+w_{i}\right)-\ln \left(1+w_{i}(1-T)\right)},
\end{aligned}
$$

where all parameters are as in subsection 2.1. The law of change for the new sector wage, $w_{n}$, will be derived later.

The time allocation model describes the behaviour of the worker in any state of the economy apart from the informal one, since we deemed the latter as a kind of a supplementary sector. Some workers, however, can choose to get employed full-time in this sector. This happens if given their current $q$ their utility of being registered unemployed and

\footnotetext{
${ }^{23}$ We assume that workers do not form expectations about their $q$ 's or that they are just biased expecting $q$ to be 0 .

${ }^{24}$ This is a strong assumption that, in fact, implies that workers solve two different utility maximisation problems. The first one is to maximise utility over time without taking into account moonlighting possibilities. Another one is to maximise utility within a period of time when $q$ 's are known and moonlighting is considered. Since workers each period draw their $q$ 's and do not form expectations, their search behaviour is determined by maximisation of the life-time utility as in the Shapiro and Stiglitz (1984) model. This utility is just a function of the wage and/or benefits that are due to the full-time worker. This essentially simplifies the problem since then, for example, before $q$ 's are revealed, for any worker the utility of being in the new sector will be greater than the utility of being in the old sector, provided that wages in the former are higher. This was not the case in the time-allocation problem, though. We leave the assumption for the time being, but expect to change it in future research.
} 
holding part-time irregular business is too low. After such workers quit the pool of unemployed, they draw their $q$ 's again and may want to come back to participate. However, if some entry barriers exist only part of such workers will be able to begin search for a job in the official sectors. Other workers will stay attached to their irregular jobs. In this sense the informal sector is a partly absorbing state. We make the process of quitting the irregular economy explicit later on when consider the workings of the informal sector.

\subsubsection{The Old Sector}

The old sector firms pay its workers wage $w_{o}$ on the same terms as in the timeallocation model. ${ }^{25}$ They also have to pay payroll taxes at rate $\tau_{o}$. Both the wage rate and the tax rate are assumed exogenously given. ${ }^{26}$

Apart from the wage, the firms provide fringe benefits $b_{o}$ that can be expressed in monetary terms. It is assumed that provision of these benefits comes at zero cost. Thus, $b_{o}$ is in line with the type of benefits discussed in subsection 2.1. They are not such social benefits as subsidised housing or kindergartens that were also widespread in the state enterprises of pre-reform Russia. The terms of provision of the benefits are as in subsection 2.1.

While in the old sector the worker faces three possibilities: she can move to the new sector with probability $\pi_{n}$, lose work in the old sector with probability $\lambda$, or stay employed in the old sector.

The worker's value of being in the old sector can then be written as:

$$
r V_{o}=w_{o}+b_{o}+\pi_{n}\left(V_{n}-V_{o}\right)+\lambda\left(V_{u}-V_{o}\right)+\frac{\partial V_{o}}{\partial t},{ }^{27}
$$

where $r$ is the interest rate, $V_{n}, V_{u}$ are the worker values of being employed in the new sector and being unemployed, respectively. ${ }^{28}$ The arbitrage equation states that the return on being employed in the old sector is equal to the wage and benefits received in the old sector plus the expected gain from changing to the new sector minus the expected loss from getting unemployed plus the change in the value of being employed in the old sector over time.

The old sector is assumed to generate vacancies for $p_{o} U$ unemployed workers, where $p_{o}$ is the probability of being employed in the old sector when unemployed. ${ }^{29}$ Job

\footnotetext{
${ }^{25}$ That is a worker has to work at least $H<1$ hours to earn wage $w_{o}$.

${ }^{26}$ The absence of investments would imply that the before tax wage is equal to the average product per worker if all workers were to work full-time. This is an assumption made in Commander and Tolstopiatenko (1996). In our model, however, workers can moonlight. Thus, the principles of wage setting in the old sector as described in the time-allocation model imply that the wage rate is in between the average product per worker and the average product per hour worked in the old sector. These two products are equal if all workers work in the sector full-time. Otherwise, the product per worker is less than the product per hour.

${ }^{27} \mathrm{We}$ assume that quits and layoffs are independent events and that $\lambda+\pi_{n}<1$.

${ }^{28}$ Given that decisions about job search and moonlighting are separated, we consider only the sum of the wage and fringe benefits as a worker's current value in the Bellman equation. Looking for a future job workers compare only full-time values (see footnote 24). The change in the value does not take into account moonlighting or changes in $q$. Thus, moonlighting is indeed a sort of an additional opportunity in the model. The draws of $q$ give the worker a chance to achieve in each period some higher level of utility. This chance is, however, unexpected. Otherwise, in the situation when workers plan moonlighting, they would form expectations of their future levels of $q$. The Bellman equation would be different. Then, in order to completely link the previous and the current models we should consider the indirect utility value depending on worker's $q$ as described in subsection 2.1. This would make the dynamic model too complex. One of possibilities to circumvent this difficulty is to look at the utility value for the marginal worker only. However, we leave this problem for further research. In this work we consider only full-time wages as current values in the arbitrage equations for workers in all sectors.

${ }^{29}$ Many authors (e.g. Clarke, 1999; Kapeliushnikov, 1997) have pointed out that a large proportion of activity of the Russian labour market mainly involves "churning", and only a very small proportion involves transition to new created jobs. This is particularly true of the old sector where workers are hired at places that other workers have left. In this model we can assume that jobs cease to exist when workers quit. Then creation of new jobs can be treated as replacing part of those jobs, i.e. churning.
} 
creation in the old sector can be possible because of external subsidies, for example from the government, since firms themselves do not invest in our model.

Now the balance equation for the old sector employment which incorporates all outflows from and inflows into the old sector can be given by:

$$
\dot{N}=p_{o} U-\left(\lambda+\pi_{n}\right) N,
$$

where $U$ is the number of workers unemployed.

The possibilities of direct shifts to the informal sector are excluded both in the old sector and in the new sector as we noted earlier.

\subsubsection{The New Sector}

Following the tradition of the OST literature we assume that the new sector pays the efficiency wage and firms are constrained by their labour demand curves.

The asset value of being employed in the new sector for the worker can then be written as

$$
r V_{n}=w_{n}+\gamma\left(V_{u}-V_{n}\right)+\frac{\partial V_{n}}{\partial t},
$$

where $w_{n}$ - the new sector hourly wage $\mathrm{e}^{30} ; \gamma$ - the exogenously given probability of losing work. The equation implies that the return on being employed in the new sector equals the sector's wage less the expected loss from losing the job plus the change in the value of being in the new sector over time.

The nature of the more effective new sector in transition assumes an advantage of the new sector work compared to the old sector work. This implies that workers in the old sector want to get employed in the new sector while workers in the new sector will not leave it voluntarily for the old sector. Therefore, the possibility of moving to the old sector for the new sector worker is excluded from the arbitrage equation above.

This advantage is also expressed by the efficiency wage condition:

$V_{n}=V_{o}+c$,

where $c$ is some constant. That is, firms in the new sector set the level of wages in order the return on working in new enterprises to be always greater than the old sector return. ${ }^{31,32}$

The new sector job creation is one of the key issues in the model. The rate $J$ at which new jobs are created is determined by

$$
J=\alpha\left(k-w_{n}\left(1+\tau_{n}\right)\right),
$$

where $k$ is the product per hour worked in the new $\operatorname{sector}^{33} ; \tau_{n}$ - the payroll tax rate; $\alpha$ - some constant in between 0 and 1 reflecting the general state of the economy. Ruggerone (1996) calls $\alpha$ the reactivity of new jobs creation to profitability. Blanchard (1997) notes that $\alpha$ is in fact very important for the development of transition: the more various constraints and adjustment costs facing the new sector the lower is $\alpha$. The logic here is as follows. If an economic environment is favourable then the probable value of $\alpha$ is close to 1 , which

\footnotetext{
${ }^{30}$ All the working time within a period is normalised to 1 as postulated in subsection 2.1 . So, $w_{n}$ is the wage of a full-time worker.

${ }^{31}$ This is different from the assumption often made in the OST literature. There it is often assumed that the new sector pays some premium over the unemployment benefit level. However, in the case of Russia where the system of unemployment compensation has been practically absent, condition (5) is more realistic.

${ }^{32}$ This assumption must hold for a full-time worker before she knows her $q$, i.e. when she considers herself a full-time employee. We must also assume that at least the value of being unemployed is less than both the value of being in the old sector and the value of being in the new sector. Otherwise, workers would prefer to stay unemployed and will not search for jobs in the official sectors.

${ }^{33}$ In Blanchard's (1997) and some other models, $k$ is the average product per worker. In our model, firms make their investment after analysing their profits which depend on hours actually worked but not numbers of workers employed. This is because some workers can moonlight. The essence of the vacancy creation equation, however, is as in the Blanchard's model.
} 
implies that firms can use all their profits (the product per hour less the hourly wage rate less taxes) for investment, i.e. new job creation. Otherwise, if the economy is highly regulated or even corrupted the profits of new firms might be taken away through excessive regulation, taxation, corruption (e.g. bribing), etc. This has been the case of a number of transition countries, and Russia in particular (see Johnson et al., 1997). In such a situation the value of $\alpha$ is much lower than 1 , and opportunities for job creation are scanty.

Let the overall number of vacancies be $J=v_{u}+v_{o}$, where $v_{u}$ and $v_{o}$ are the vacancies created for the unemployed and old sector workers, respectively.

If $\pi_{n}$ and $p_{n}$ are the probabilities of transition from the old sector and unemployment to the new sector (the probabilities of finding a job), then they could be expressed as ratios of a number of available job vacancies to the particular pool of job-seekers: $\pi_{n}=\frac{v_{o}}{N}$ and $p_{n}=\frac{v_{u}}{U}$. This is a standard in the matching functions literature interpretation of transition probabilities as functions of market tightness. $^{34}$

For simplicity we will assume that the number of vacancies created for the old sector workers and for unemployed is proportional to the relative size of a particular pool of jobseekers, i.e. $v_{o}=\frac{N}{N+U} J$ and $v_{u}=\frac{U}{N+U} J$. This, in turn, implies $\pi_{n}=p_{n}=\frac{J}{N+U} \cdot 35,36$

Then the law of development of the new sector is

$$
\dot{E}=p_{n} U+\pi_{n} N-\gamma E \text { or } \dot{E}=J-\gamma E,
$$

where $U$ is, again, the number of workers unemployed.

\subsubsection{The Informal Sector}

We see the nature of the informal sector as preventing direct shifts from there to both official sectors. This condition could result from the assumption of deterioration of human capital of underground workers or from their time involvement at informal jobs. In this respect underground workers are worse off than the unemployed, because the latter can be employed in the informal sector part-time (see subsection 2.1) and can perform search in the official sectors.

A worker, however, can return to unemployment when her $q$ is revealed and she finds it smaller than $q_{u}$ (i.e. the informal work does not attract such an individual any more to the degree that she would spend all her working time underground). Such a worker receives a chance to get an official job through, for example, registering at an employment office and getting necessary training. However, we will assume that not all workers with $q$ smaller than $q_{u}$ are successful in quitting the irregular economy. Entering the unemployment from nonparticipation could be more difficult compared to being laid off in the official sectors. Conditions of registration with the employment office can be much less attractive for such

\footnotetext{
${ }^{34}$ Since the transition probabilities are functions of market tightness the corresponding matching functions have constant returns to scale. For some discussion on the relevance of constant returns see Pissarides (1990).

${ }^{35}$ Boeri (1999) assumes matching technologies to be the same for employed and unemployed job-seekers. He also notes that empirical evidence suggests that for countries like Poland the mean of the distribution of joboffers for employed and unemployed job-seekers is almost identical.

${ }^{36}$ This expression is correct in case the old sector workers are as effective in job search as unemployed workers. If they are less effective (since they have to produce in the old sector), then the transition probability in the sector could be $\pi_{n}=\frac{v_{o}}{\mu N}$, where $\mu$ denotes search effectiveness in the old sector. The transition probabilities become $\pi_{n}=p_{n}=\frac{J}{\mu N+U}$. Brixiova (1997) examines the impact of search effectiveness on the optimal path of transition - see the literature review in Section 1.
} 
workers. ${ }^{37}$ The level of bureaucracy and regulation can also play some role in making the return more problematic. Therefore, given the level of the economy "friendliness", $\alpha$, introduced above, we will assume that only fraction $\alpha q_{u}$ of irregular workers can pop up in the official economy again.

Accordingly, the full-time informal employment follows:

$\dot{I}=p_{u} U-\alpha q_{u} I$,

where $p_{u}$ is the proportion of unemployed workers moving underground. Recall that direct shifts from official sectors underground are not considered.

Since workers plan their future before they know their $q$ 's, the value of being in informal employment is just

$$
r V_{i}=w_{i} \text {. }
$$

This arbitrage equation states that the return on being in the informal sector is equal to the rate of informal income.

\subsubsection{Unemployment}

In the three previous subsections we have seen that workers become unemployed when they are either laid off in one of the official sectors or willing to quit the informal sector. The worker can change her unemployment state when she gets employed in the formal economy or does not want to stay in participation. We will assume that unemployed workers first look for a job in the new sector (as most profitable), then, if not successful, in the old sector. Then the value of being unemployed is:

$$
r V_{u}=b_{u}+\eta\left(1-p_{n}\right)\left(V_{o}-V_{u}\right)+p_{n}\left(V_{n}-V_{u}\right)+\frac{\partial V_{u}}{\partial t},
$$

where $\eta\left(1-p_{n}\right)$ is the probability of moving into the old sector, $p_{o}$, and $\eta$ is the job creation rate in the old sector. In this arbitrage equation the return on being unemployed includes unemployment benefits plus the expected gain from changing into the new or the old sectors plus the change in the value of being unemployed over time.

The unemployed workers draw their $q$ 's after they sought for jobs in the formal economy and knew their future (see subsection 2.2.2). It is assumed that those lucky enough to get an official job will not quit the official economy even if their $q$ 's are greater than $q_{u}$. However, the part of unsuccessful in search individuals can leave participation for irregular jobs. Denoting by $p_{u}$ the proportion of moving into the irregular sector it equals $\left(1-p_{n}\right)(1-\eta)\left(1-q_{u}\right)$.

The flows in and out of unemployment determine its dynamics:

$$
\dot{U}=\lambda N+\gamma E+\alpha\left(1-q_{u}\right) I-\left(\eta\left(1-p_{n}\right)+p_{n}+\left(1-p_{n}\right)(1-\eta)\left(1-q_{u}\right)\right) U,
$$

where the first three terms on the right hand side are inflows from the formal and informal sectors, other terms describe outflows.

\subsubsection{The Government}

We will consider two variants of the model.

In the first variant we do not allow for fiscal externalities. The government is deemed implicit - unemployment benefits, taxes in the old and in the new sector are all exogenously given parameters.

\footnotetext{
${ }^{37}$ For example, Layard and Richter (1995) report that to get benefits a redundant worker in Russia must register within 2 weeks of loosing her job. First three months such a worker is entitled for her last monthly unindexed wage as benefits. Then the level of benefits is gradually scaled down. The whole period of the entitlement is 15 months. Other unemployed workers (in our model - those who come back from underground) are entitled only for benefits at the minimum wage level over the first 12 months after the registration.
} 
In the second variant the government is explicitly present. Unemployment benefits and job creation in the old sector are financed through payroll taxation. ${ }^{38}$ As Commander and Tostopiatenko (1996) and Boeri (1999) we have also postulated the presence of statutory contribution rates, $\tau_{o}$ and $\tau_{n}$, that vary across the two official sectors. Then the government budget constraint is:

$$
\left(b_{u}+\eta\left(1-p_{n}\right)\right) U=\tau_{n} w_{n} S E+\tau_{o} w_{o} q_{o} N .
$$

The term on the left hand side of (7) is the amount of benefits paid plus the number of created jobs in the old sector. ${ }^{39}$ On the right hand side, $w_{n} S E$ is the wage bill in the new sector when moonlighting is taking into account; $S$ is the actual number of hours supplied to the new sector ${ }^{40} ; q_{o} N$ is the number of the old sector workers being paid. Notice that the benefits of the old sector, $b_{o}$, are not included in the government budget constraint. This is because $b_{o}$ reflects other institutional features of the economy and has nothing to do with social security compensation.

Following Boeri (1999) it can be reasonable to assume that the payroll contribution rate in the new sector, $\tau_{n}$, is the only variable that can be adjusted in order to balance in each moment in time the government budget. ${ }^{41}$ That is

$$
\tau_{n}=\frac{\left(b_{u}+\eta\left(1-p_{n}\right)\right) U-\tau_{o} w_{o} q_{o} N}{w_{n} S E} .
$$

Later when simulating the model we consider both cases with implicit and explicit government in turn.

Having laid out the main blocks of the model we now move to the new sector wage determination.

\subsubsection{Wage Determination and Employment Creation in the New Sector ${ }^{42}$}

Collecting together all the arbitrage equations we get the following system:

$$
\begin{aligned}
& r V_{o}=w_{o}+b_{o}+\pi_{n}\left(V_{n}-V_{o}\right)+\lambda\left(V_{u}-V_{o}\right)+\frac{\partial V_{o}}{\partial t}, \\
& r V_{n}=w_{n}+\gamma\left(V_{u}-V_{n}\right)+\frac{\partial V_{n}}{\partial t}, \\
& r V_{i}=w_{i} \\
& r V_{u}=b_{u}+\eta\left(1-p_{n}\right)\left(V_{o}-V_{u}\right)+p_{n}\left(V_{n}-V_{u}\right)+\frac{\partial V_{u}}{\partial t} .
\end{aligned}
$$

We have assumed that firms in the new sector set their wage $w_{n}$ at such a level that $V_{n}=V_{o}+c$. This in turn implies that $\frac{\partial V_{n}}{\partial t}=\frac{\partial V_{o}}{\partial t}$. Then subtracting the first equation in (9) from the second we get

\footnotetext{
${ }^{38}$ Clarke (1998) reports: “... with low levels of benefit and few benefit recipients, many regions [in Russia M.B.] have substantial funds available for active employment policy. However, most of this money is used to subsidise existing jobs..." (p.47). In our model job creation in the old sector is equivalent to hiring people on existing positions left by other workers.

${ }^{39}$ It is implicitly assumed that the cost of creating an old sector vacancy is normalised to 1 .

${ }^{40}$ We derive the expression for $S$ later when consider the results of the model's simulation.

${ }^{41}$ Boeri (1999, p.27) writes: "Subsidies [i.e. positive taxes - M.B.] to state enterprises did not look at all as a control variable. As discussed in Schaffer (1998), subsidies to enterprises in these countries [CEE - M.B.] took mainly the form of tax arrears allowed by weak tax collection administrations or by governments fearing domino effects originated by the interlocking of banks and firms." At the same time, unemployment benefits cannot be a control variable either, since "in Russia...there are no national standards for the provision of social assistance...It is often claimed that in Russia...there is virtually no unemployment benefit system in place." (ibid., pp. 42-43).

${ }^{42} \mathrm{We}$ assume in this subsection that government is implicit.
} 


$$
r\left(V_{n}-V_{o}\right)=w_{n}-w_{o}-b_{o}+\gamma\left(V_{u}-V_{n}\right)-\pi_{n}\left(V_{n}-V_{o}\right)-\lambda\left(V_{u}-V_{o}\right) .
$$

Substituting for $V_{n}$ yields

$$
c\left(r+\gamma+\pi_{n}\right)=w_{n}-w_{o}-b_{o}+(\gamma-\lambda)\left(V_{u}-V_{o}\right) \text {. }
$$

Since $\gamma=\lambda$ by assumption, we can solve equation (10) for $w_{n}$ without solving system (9) for $V_{o}, V_{n}$, and $V_{u}$ ( $V_{i}$ is constant and does not influence other values).

Equation (10) then becomes

$$
w_{n}=w_{o}+b_{o}+c\left(r+\gamma+\pi_{n}\right) \text {, }
$$

or, substituting for $\pi_{n}$,

$$
w_{n}=w_{o}+b_{o}+c\left(r+\gamma+\frac{J}{N+U}\right) \text {. }
$$

Replacing the wage in equation (6) by its value from (11), and solving out gives both the new sector wage and employment creation as a function of employment in the old sector and unemployment

$$
w_{n}=\frac{\alpha c k}{\alpha c\left(1+\tau_{n}\right)+N+U}+\frac{(N+U)\left(w_{o}+b_{o}+c(r+\gamma)\right)}{\alpha c\left(1+\tau_{n}\right)+N+U}
$$

and

$$
J=\frac{\alpha(N+U)}{\alpha c\left(1+\tau_{n}\right)+N+U}\left(k-\left(w_{o}+b_{o}+c(r+\gamma)\right)\left(1+\tau_{n}\right)\right) .
$$

The highest wage a firm can pay and not make losses is $\frac{k}{\left(1+\tau_{n}\right)}$, i.e. the hourly product adjusted for taxes; $\left(w_{o}+b_{o}+c(r+\gamma)\right)$ is the lowest wage the firm may want to pay, the wage that corresponds to zero job creation rate in the new sector. If $k$ is less than $\left(w_{o}+b_{o}+c(r+\gamma)\right)\left(1+\tau_{n}\right)$ then the new sector will never take off. So, we shall assume that

$$
k \geq\left(w_{o}+b_{o}+c(r+\gamma)\right)\left(1+\tau_{n}\right) \text {. }
$$

In that case, $\frac{\partial w_{n}}{\partial N}<0, \frac{\partial w_{n}}{\partial U}<0$ and $\frac{\partial J}{\partial N}>0, \frac{\partial J}{\partial U}>0$ (see Appendix 4), i.e. the wage rate is a decreasing function of the employment in the old sector and unemployment, while new sector employment creation is an increasing function of the old sector employment and the unemployment rate.

Let us now sum up the workings of this part of the model.

New sector job creation depends on the profit rate, which in turn depends on the wage. The wage rate is decreasing in the number of workers looking for a job. Thus, other things being equal, higher employment in the old sector and/or higher unemployment lead to higher job creation in the new sector.

\subsubsection{Dynamics}

Combining all the dynamic equations and substituting for $\pi_{n}, p_{n}, p_{o}$ and $p_{u}$ we obtain the following non-linear system describing the behaviour of the economy:

$$
\begin{aligned}
& \dot{N}=\eta\left(1-\frac{J(N, U)}{N+U}\right) U-\left(\lambda+\frac{J(N, U)}{N+U}\right) N, \\
& \dot{E}=J(N, U)-\gamma E, \\
& \dot{U}=\lambda N+\gamma E+\alpha q_{u} I-\left(\eta\left(1-\frac{J(N, U)}{N+U}\right)+\frac{J(N, U)}{N+U}+(1-\eta)\left(1-\frac{J(N, U)}{N+U}\right)\left(1-q_{u}\right)\right) U, \\
& \dot{I}=(1-\eta)\left(1-\frac{J(N, U)}{N+U}\right)\left(1-q_{u}\right) U-\alpha q_{u} I .
\end{aligned}
$$


Summing up all the equations we get the consistency condition $\dot{N}+\dot{E}+\dot{U}+\dot{I}=0$ since $N+E+U+I=1$.

The system (14) is in the steady state equilibrium when in addition to satisfying (12) and (13), $\dot{N}=\dot{E}=\dot{U}=\dot{I}=0$. There are one trivial steady state $\left(N^{*}=0, E^{*}=0, U^{*}=0, I^{*}=0\right)$ and at least one non-trivial. The analytical solution of this system is rather complicated, therefore we solve it numerically.

The model generates at each point in time flows from employment in the old sector to the new sector and unemployment, from unemployment to both the official sectors and the informal economy and flows from underground to unemployment (Fig.2.17). The time or speed of transition is viewed as a number of periods needed to reach a steady state where the new sector prevails over the old sector and involves a significant part of the labour force. Contrary to other authors (among them Aghion and Blanchard, 1994; Boeri, 1999; Castanheira and Roland, 2000) we do not eventually see the system to settle down with disappearance of the old sector.

\subsubsection{Introducing Search Effectiveness}

When performing simulations we will also look at the influence of $\mu$ - search effectiveness in the old sector (see footnote 36 ). It is easy to check that after introducing $\mu$ the equations (12), (13) and system (14) become:

$$
\begin{aligned}
& w_{n}(N, U)=\frac{\alpha c k}{\alpha c\left(1+\tau_{n}\right)+\mu N+U}+\frac{(\mu N+U)\left(w_{o}+b_{o}+c(r+\gamma)\right)}{\alpha c\left(1+\tau_{n}\right)+\mu N+U}, \\
& J(N, U)=\frac{\alpha(\mu N+U)}{\alpha c\left(1+\tau_{n}\right)+\mu N+U}\left(k-\left(w_{o}+b_{o}+c(r+\gamma)\right)\left(1+\tau_{n}\right)\right)
\end{aligned}
$$

and

$$
\begin{aligned}
& \dot{N}=\eta\left(1-\frac{J(N, U)}{\mu N+U}\right) U-\left(\lambda+\frac{J(N, U)}{\mu N+U} \mu\right) N, \\
& \dot{E}=J(N, U)-\gamma E, \\
& \dot{U}=\lambda N+\gamma E+\alpha q_{u} I-\left(\eta\left(1-\frac{J(N, U)}{\mu N+U}\right)+\frac{J(N, U)}{\mu N+U}+(1-\eta)\left(1-\frac{J(N, U)}{\mu N+U}\right)\left(1-q_{u}\right)\right), \\
& \dot{I}=(1-\eta)\left(1-\frac{J(N, U)}{\mu N+U}\right)\left(1-q_{u}\right) U-\alpha q_{u} I,
\end{aligned}
$$

respectively. All the results for signs of the derivatives of (15) and (16) and the consistency condition for (17) hold.

Before moving further to the results of model's simulation and drawing conclusions, we summarise the main points of the two models in this section.

\subsubsection{Summing Up}

We presented in this section two models relevant to Russian transition.

The first model is a standard static utility maximisation problem with time allocation between two states - official employment or unemployment and informal activity. It incorporates some distinct institutional features of the Russian economy and helps to look from a new angle at the problem of moonlighting in Russia. The point of the model that has not been considered before in the literature is that the decision of an individual to moonlight can depend on a parameter varying across workers and reflecting her personal propensity to underground work (e.g. motivation, personal contacts, etc.).

The time-allocation model leads into an OST-type dynamic model that introduces the explicit informal sector. The model is notable for considering the old sector hirings while levelling the job destruction rates in the old and new sectors. The last fact is supported by the 
empirical evidence from Russia. Another innovative feature of the model is that the new sector firms base their wage setting decisions on the wage and benefit levels in the old sector rather than on the level of unemployment benefits. The latter has been extremely low in Russia and hardly constituted a footing for the traditional assumption of OST models.

\section{Simulation and Interpretation of the Dynamic Model of Transition}

This section proceeds through the analysis of the dynamic model from Section 2. We start by describing the choice of values for the parameters and then turn to numerical simulations of the model. The last subsection discusses and summarises the results.

\subsection{Choosing the Parameters}

In the simulations that follow we are going to keep values of some parameters fixed all the time and vary the others.

In particular, we normalise the old sector wage, $w_{o}$, to 1 , and let the informal wage, $w_{i}$, be 2.75 and the time constraint in the old sector, $H$, be 0.75 (see Appendix 3 for explanation). We also put the interest rate, $r$, to be $10 \%$, and the difference between the values of being in the old and new sector employment, $c$, to be 1 . Job destruction rates in the old and the new sectors are both taken equal to 6\%. This is consistent with estimates obtained by Richter and Schaffer (1996) for Russian state owned and de novo enterprises (see Section 2) in 1993-1994.

Thus, for all various cases considered later we keep $w_{o}=1, w_{i}=2.75, H=0.75$, $r=0.1, c=1, \lambda=\gamma=0.06$.

Other parameters are not kept constant. We will look at deviations from their benchmark values. The latter are as follows:

$B=0.25, T=0.65, b_{u}=0.5, \quad b_{o}=0.75, \tau_{o}=0.1, \tau_{n}=0.1, \alpha=0.3, \eta=0.1$, $\mu=1, k=2.4, q_{u}=0.63, q_{o}=0.76$.

This choice is somewhat arbitrary and the values should be treated accordingly. However, we think that the assigned values are likely to describe Russian reality well enough.

The lower time constraint in the old sector, $B$, is chosen to be 0.25 as a simple average of 0 and 0.5 (we expect it to be lower than $H$, but $H$ is definitely higher than 0.5 as suggested in Appendix 3). The time constraint for the unemployed, $T$, is seen to be a bit lower than the constraint in the old sector, $H$. Anyway it is still quite significant to reflect the high time costs borne by the registered unemployed (again, see the discussion in Appendix $3)$.

The level of unemployment benefits, $b_{u}$, is chosen as $50 \%$ of the old sector wage. This could seem to be a high value. For example, Boeri (1999) in the context of his model treats the value of benefit replacing $35 \%$ of the wage earned in old sector as already very high. However, recalling that Russian state enterprises are notable for a very low level of wages, the 50\% replacement ratio looks plausible. Moreover, Rutkowski (1999) reports that the ratio of the average unemployment benefit to the average wage was 30\% in 1998 in Russia. We shall see that in our model the wage rate in the new sector is roughly as high as about twice the wage in the old sector. Thus, if we assign equal weights to wages in the old and the new sector then the average wage will be approximately 1.5 . That is, unemployment benefits replace about the third of the average official wage.

The fringe benefit in the old sector, $b_{o}$, is equal to 0.75 . It is taken to be higher than the unemployment benefit level, but lower than the old sector wage. The actual level of this benefit can be a topic for separate empirical research.

The payroll tax rates in the old, $\tau_{o}$, and the new, $\tau_{n}$, sectors are both viewed as 0.1 . Schaffer and Turley (2000) study tax administration in transition economies, and report that 
the actual social security tax to GDP ratio was $9.9 \%$ for Russia in $1997 .{ }^{43}$ In their research the social security contributions are treated as a payroll tax. The authors also estimate the normalised social security tax yield to be 10\% of GDP in 1997.

The degree of regulation or corruption in the economy, $\alpha$, is put equal to 0.3 ( $\alpha=1$ implies an economy free of corruption and where regulations are not much of a burden to the new sector). Reversing and re-scaling in [0,1] the EBRD (1999) score of the average investment climate yields an index of approximately $0.3-0.4$, where a higher value implies the better climate. Reversing the Vostroknoutova's (2000) index of weakness of institutions for Russia gives roughly 0.35 . We take the lower possible estimate as a basic value.

The parameter that has a direct influence on the speed of transition in our model is the rate of old sector job creation, $\eta$. By assumption the job destruction rates are the same in the old and the new sector and given exogenously. So, there are two variables that endogenously influence the speed of transition and determine the actual size of the old sector. They are the new sector creation of vacancies for old sector workers, $\frac{\mu N}{\mu N+U} J(N, U)$, and the probability of outflow from unemployment to the old sector. The latter depends on both $\eta$ and $J(N, U)$. It is assumed that the government has a direct influence on the magnitude of $\eta$ through subsidisation of the old sector. We put $\eta=0.1$, however, this value could be understated. By the definition of the probability of outflow from unemployment to the old sector it cannot be greater than $\eta$ (see (14)). However, for example, Foley (1997a) estimates the probability of transition from unemployment to the state sector to be 0.347 in 1992-1993 in Russia. We shall see later the effect of the increase in the value of $\eta$ up to 0.9 .

With regard to search effectiveness, $\mu$, we start by assuming that the old sector workers are as effective in job search as the unemployed, i.e. $\mu=1$. Many authors have pointed to job-to-job flows as a significant part of labour turnover in the Russian economy (see, e.g., Clarke, 1998; Commander et al., 1996a; Gimpelson and Lippoldt, 1997). This suggests that employed workers are in fact very successful in on-the-job search. It might even be the case that unemployed workers are less effective in finding a job than the presently employed. So, putting $\mu$ equal to 1 is fully justified. However, we will also look at the effect of lower $\mu$ when employed workers are less effective in seeking for jobs than unemployed ones. $^{44}$

We also put the productivity of the new sector $k$ to be 2.4. If we assume that only wage earners in the old sector produce and that all profits are appropriated by insiders, then the average effective product per hour in the sector is $\frac{w_{o}\left(1+\tau_{o}\right)}{H}$. Dividing $k$ by this value we obtain the productivity differential of about 1.8 between the new and the old sector. This is a value used in calibrations by Aghion and Blanchard (1994).

Finally, the parameters values above imply the threshold values in the time-allocation model to be $q_{u}=0.63$ and $q_{o}=0.76$ (see subsection 2.2.2). The former value means that $37 \%$ of the unemployed workers unsuccessful in getting a job will leave for the informal sector. The latter value implies that $24 \%$ of workers in the old sector would be employed just fictitiously - they would work the minimum amount of time, $B$, to get the old sector benefits. The threshold value for full-time employment in the new sector, $q_{n}$, depends on the current wage rate in the sector. So, it varies with the wage and job creation in the new sector.

\footnotetext{
${ }^{43}$ This ratio is roughly four times less than the statutory social security tax rate which was 39.5\% in 1997 (see Schaffer and Turley, 2000).

${ }^{44} \mathrm{We}$ leave the case with less successful in search unemployed workers for future research.
} 


\subsection{Testing the Model}

Now we can get round to the results of simulations that have been run with Scientific WorkPlace. ${ }^{45}$

The initial values for the employment variables are taken as $N(0)=1, E(0)=U(0)=$ $I(0)=0$. That is, at the beginning of transition all the employment is in the old sector. The new sector, full-time informal employment and unemployment are absent.

We consider two variants of the model - with implicit and explicit government - in turn. First we focus only on major dynamic patterns leaving aside implications for moonlighting and the actual size of the informal economy. The latter we discuss in subsection 3.2.1.2.

The time scale that is used could be viewed as measured in years. However, we prefer to address the time unit as a period rather than a year, since we are not aiming to draw any conclusions regarding the actual duration of the transition process. We rather suggest looking at the relative length of transformation period in each of the cases considered compared to the benchmark case.

\subsubsection{The Case with Implicit Government}

\subsubsection{Looking at major dynamics}

The benchmark set of parameters gives us a transition picture depicted in Figures 3.1 to 3.6 .

The old sector is slowly declining while the new sector is slowly growing (Fig.3.1). It takes about 25 periods for the system to settle down. The share of the old sector in the economy is positive, it does not disappear completely. The unemployment rate ${ }^{46}$ monotonically increases and reaches the highest value of about $18 \%$ of labour force (Fig.3.2).

Full time informal employment is growing since people leave the labour force as soon as they find themselves unemployed, are unlucky in getting a new job and their propensity to irregular job is high enough. Some workers, however, turn back to participation. Overall, there is a major decline in participation rate ${ }^{47}$, which amounts to $20 \%$ after 20 periods.

The new sector wage is roughly twice the old sector wage (Fig.3.5). It grows as the pool of job seekers becomes smaller. The old sector is shrinking, workers leave it for the new sector jobs, other are being laid off. Unemployment causes some people to move underground. Thus, the disciplining device described by Shapiro and Stiglitz (1984) slackens and wages creep up, depressing the profit rate of new firms and bringing the job creation rate down (Fig.3.6).

However, this scenario is not unique. Other values of parameters produce a dynamic picture similar to the benchmark case at the start of transition but getting more different over time. Looking at the effects of variations in the value of a separate parameter is very useful to get some insight into possible qualitative changes in the dynamic pattern.

\subsection{The effect of a change in productivity}

Fig. 3.7 to 3.10 present the case when the productivity of the new sector is $125 \%$ of its productivity in the benchmark case.

Transition now is much quicker - it takes about 10 periods. The share of the new sector is about $80 \%$ of the initial employment. The old sector dwindles away to nearly nothing (Fig.3.7). Unemployment grows quickly at the beginning of transformation, reaches

\footnotetext{
${ }^{45}$ Scientific WorkPlace Version 3.00 Build 1069.

${ }^{46}$ It is calculated as $U /(N+E+U)$, i.e. as a part of labour force, but not population.

${ }^{47}$ It is calculated as $(N+E+U) /(N+E+U+I)$.
} 
a peak of about 9-10\% and then decreases to settle down at the level of 8\% (Fig.3.8). Such a pattern is different from one depicted in Fig.3.2. Recall, that the unemployment rate is calculated as the ratio of unemployment to labour force (not population). Thus, the pattern is explained by the behaviour of the people who left participation for the informal economy.

The full-time informal economy first grows fast enough as the old and the new sectors shed labour and unemployment increases. However, since the new sector is highly productive, it keeps on generating much more new working places than in the benchmark case. It hires more unemployed people including those getting back from out-of-labourforce. Thus, the participation rate recovers a bit after the sharp fall (which was, however, less deep than in the first scenario) at the beginning of transition (Fig.3.10). Hence, the informal economy declines somewhat as soon as it reaches a peak after about 8 periods (Fig.3.9).

\subsection{The effect of a change in search effectiveness}

Following Brixiova (1997) we consider the case when the old sector workers are not as effective in job search as the unemployed. Fig.3.11 to 3.14 show the dynamics when the effectiveness of the on-the-job search in the old sector is just $10 \%$ of the level in the benchmark set of parameters.

Transition is noticeably slower. Both the rate of growth of the new sector and the rate of old sector recession is moderate. After 30 periods of time the system has not yet converged (Fig.3.11). The new sector now has troubles with hiring from the old sector since fewer workers are able to effectively look for a job. This pushes wages up preventing high job creation rates. However, the new sector is as smooth in dealing with unemployed workers as in the benchmark case. The unemployment rate is of the same magnitude too (compare Fig.3.12 and 3.2). The lower size of the new sector implies fewer layoffs and does not increase the number of jobless workers.

The full-time informal employment and the reduction in participation rate fall into step with the unemployment rate. Their patterns resemble the benchmark case (Fig.3.13 and 3.14 , respectively).

\subsection{A change in the speed of transition}

Let us look now at an economy in which the government is able to maintain a high hiring rate in the old sector. This, obviously, leads to the slower decline rate of old enterprises and keeps employment up.

In Fig.3.15 we can see that the speed of transition is a bit higher than in the case with low job search effectiveness considered before. However, transition is still slow and the system is only about to settle down by the end of the $30^{\text {th }}$ period.

The new sector, however, is more buoyant in this case. It does not face difficulties in attracting old sector workers, and its growth helps to avoid high unemployment (Fig.3.16). The latter fact means the lower size of the informal sector (Fig.3.17) and a moderate fall in participation (Fig.3.18).

This observation provides an interesting policy implication. Maintaining the old sector employment does not prevent the new sector from growing (compare Fig.3.1 and $3.15)$, although slows the transition down. We will turn back to this issue later in subsection 3.2.2.

\subsection{Changes in $q_{u}$}

Now we consider changes in the level of unemployment benefits. This has a direct impact on the threshold value $q_{u}$ and, thus, determines the exit rate from unemployment to non-participation.

By increasing the level of social compensation for unemployed workers up to $75 \%$ of the old sector wage, the government can retain more workers in the labour force. Now on average only $14 \%$ of jobless workers unlucky in finding a job will go full-time underground each period. 
The main consequence of such a governmental policy is, of course, the lower extent of the full-time irregular sector (Fig.3.21) and a smaller drop in participation rate (Fig.3.22). This is achieved partly by means of increasing unemployment (Fig.3.20). However, more unemployment has a positive impact on new sector wages, since by an efficiency wage mechanism they are not growing faster and keep job creation in the sector at a higher level. As a result, the new sector slightly gains in employment (compare Fig.3.19 and 3.1).

The same result can be achieved by varying the time constraint $T$, while leaving the level of benefits unchanged. If, for example, the government provides more employment offices and/or makes the procedure of registration as unemployed less time-consuming ${ }^{48}$, the outcome for the economy will be as when benefits are increased. We show that the same level of $q_{u}$ is achieved by decreasing $\mathrm{T}$ by about $23 \%$ down to 0.5 .

Fig.3.23 to 3.26 show the effect of a decrease in the level of unemployment compensation. Bringing benefits down to a meagre amount of $10 \%$ of the old sector wage can result in an enormous reduction in participation (Fig.3.26) and the flowering of the shadow economy (Fig.3.25).

The official part of the economy is shrinking, but with the new sector eventually prevailing (Fig.3.23) and an unemployment rate of about 16\% (Fig.3.24). Note, that transition is also a very slow process in this setting. Moreover, the new sector starts declining after booming first 20 periods. This can lead to an output fall provoked by the new sector adjustment.

\subsection{Changes in regulation}

Similarly to providing better conditions for unemployed, the government can affect the value of $\alpha$ reflecting the investment climate in the economy and the absence of the excessive burden of regulation. Bringing this parameter up to a level of 0.9 implies not only a faster transition (Fig.3.27 shows a convergence after 15-20 periods), but also the lower size of the irregular sector (compare Fig.3.29 and 3.3). The participation also suffers much less and erodes by about $8 \%$ (Fig.3.30).

An improvement in the investment climate, obviously, makes new firms spend less on bribes, etc., raises their job creation rates and hastens transformation. The new sector crowds out the informal economy somewhat, keeping more workers in participation, hiring them quickly and preventing their shifts underground.

\subsection{New sector taxation}

Taxes exert an adverse impact on new sector investment and job creation, since they depress profit rates. An increase in the level of new sector taxation hampers its growth significantly, slows down the transition, increases unemployment and the amount of irregular activities.

Ultimately, the new sector is only slightly bigger than the old one (Fig.3.31), whereas nearly two thirds of the initial employment is spread between unemployment (Fig.3.32) and the informal economy (Fig.3.33). The drop in participation is notable (Fig.3.34).

\subsection{Changes in old sector benefits}

The effect of an increase in the old sector benefits can be even worse than the effect of excessive taxation of the new sector.

More benefits in the old sector increase its attractiveness for workers in the economy. To lure them away from old enterprises the new firms have to set higher wages squeezing their own profit rates and narrowing down investment. The economy suffers a long transition that in fact fails, since eventually the state sector prevails, while the level of employment falls dramatically (Fig.3.35). Unemployment is skyrocketing (Fig.3.36) along with the share of the informal sector (Fig.3.37). The rate of population activity is extremely low (Fig.3.38).

${ }^{48}$ See Appendix 3 for some discussion on this issue. 
This simple example shows how detrimental, in principle, can be the practices adopted in the old sector of the Russian economy. Note also that the threshold value $q_{o}$ becomes smaller as benefits increase. In the case we just considered only $68 \%$ of old sector workers actually work for wages, while the rest in fact just work for benefits the minimum possible amount of time. So, the change in the level of benefits, above all, depletes the supply of hours to the formal economy. Therefore, now it is time to recall moonlighters and look behind the major dynamic patterns.

\subsubsection{Recalling moonlighting}

Up till now we have been concerned with the changes in the patterns of the official and informal employment dynamics as well as in evolution of unemployment and the participation rate in our model. However, variations in some parameters considered above have direct implications for the moonlighters since they change the threshold values in the time-allocation model. Each period workers can choose moonlighting after they decide their affiliation for the next period. Such workers shift part of their time away from official sectors. This entails a difference between sectors' shares in total employment and their shares in total output (including informal output). To see it more clearly we have to derive functions of the supply of hours to each sector.

\subsection{The total supply of hours in each sector}

The actual labour supply in the old sector is easily derived if we revisit the time allocation model. Remember that at each moment of time there are a proportion of workers, $q_{o}$, who supply $H$ hours each and a proportion of workers, $\left(1-q_{o}\right)$, who supply $B$ hours each. Thus, the total hours in the old sector are $\left(q_{o} H+\left(1-q_{o}\right) B\right) N$. Accordingly, the old sector workers will work $\left(q_{o}(1-H)+\left(1-q_{o}\right)(1-B)\right) N$ hours underground.

Similarly, the unemployed workers will supply $q_{u} T U$ hours to search and $q_{u}(1-T) U$ hours to irregular activities.

Deriving the total supply of hours in the new sector is a little bit tricky.

At each moment of time, a proportion $q_{n}=w_{n} \frac{1}{w_{i}\left(1+w_{n}\right)}$ of the new sector employees spends all the working time in the sector, i.e. they supply 1 hour each to the new sector. The remaining part supply $\frac{w_{n}\left(1+w_{i}\right)-q w_{i}}{w_{n} w_{i}(1+q)}$ hours each to the new sector and $\left(1-\frac{w_{n}\left(1+w_{i}\right)-q w_{i}}{w_{n} w_{i}(1+q)}\right)$ hours each to the informal economy (see subsection 2.1.1.2.2). Both these quantities depend on the actual value of worker's $q$. Then, these workers supply $\int_{w_{n} \frac{1}{w_{i}\left(1+w_{n}\right)}}^{1} \frac{w_{n}\left(1+w_{i}\right)-q w_{i}}{w_{n} w_{i}(1+q)} d q$ hours in the new sector all together. Accordingly, they supply $\int_{w_{n} \frac{1}{w_{i}\left(1+w_{n}\right)}}^{1}\left(1-\frac{w_{n}\left(1+w_{i}\right)-q w_{i}}{w_{n} w_{i}(1+q)}\right) d q$ hours underground.

Recall that the wage rate in the new sector is determined by equation (15). So, substituting its value in the integrals above, we get two functions of total labour supply of new sector moonlighting workers

$$
S(N, U)=\int_{\frac{w_{n}(N, U)}{w_{i}\left(1+w_{n}(N, U)\right)}}^{1} \frac{w_{n}(N, U)\left(1+w_{i}\right)-q w_{i}}{w_{n}(N, U) w_{i}(1+q)} d q
$$


and

$$
\begin{array}{r}
L(N, U)=\int_{\frac{w_{n}(N, U)}{w_{i}\left(1+w_{n}(N, U)\right)}}^{1}\left(1-\frac{w_{n}(N, U)\left(1+w_{i}\right)-q w_{i}}{w_{n}(N, U) w_{i}(1+q)}\right) d q= \\
=1-\frac{w_{n}(N, U)}{w_{i}\left(1+w_{n}(N, U)\right)}-S(N, U),
\end{array}
$$

in the new sector and the irregular economy, respectively (see Appendix 4 for the derivation of explicit functions $S(N, U)$ and $L(N, U)$ ).

The total supply of hours in the new sector, hence, is $\left(S(N, U)+\frac{w_{n}(N, U)}{w_{i}\left(1+w_{n}(N, U)\right)}\right) E$.

Bringing together the hours of employed and unemployed workers spent in the informal economy and adding full-time underground employment we obtain the total size of the informal economy measured in man-hours:

$$
\left(q_{o}(1-H)+\left(1-q_{o}\right)(1-B)\right) N+q_{u}(1-T) U+L(N, U) E+I .
$$

\subsection{The benchmark case}

The benchmark set of parameters gives us the dynamics drawn in Fig.3.39 to 3.41.

It is easy to see that the old sector employees work in the irregular sector part of the time that they could have in principle worked in the old sector (Fig.3.39). The vertical distance between two curves at each moment of time shows the total number of hours distorted away from the old sector.

Similarly, the growth of the new sector (Fig.3.40) is essentially overstated if it is measured in numbers employed, since there are workers who combine work there with informal work. The hours lost by the new sector are represented again by the vertical distance between two curves.

Such substitution of hours is a notable feature of the Russian reality - as we have noted in Section 2 many new sector firms in fact co-exist in both the official and the informal sectors. Their workers devote only part of their working time to producing the officially registered output. The remaining time they work at the same place for the informal sector.

The additional labour supply coming from moonlighters in the official sectors sufficiently increases the size and, hence, output of the informal sector (Fig.3.41). The vertical distance between the two curves shows the number of hours gained by the irregular sector in addition to those spent by full-time informal workers. If moonlighters are as productive in the informal economy as full-time irregular workers then the upper curve in Fig.3.41 represents the evolution of the irregular output.

Now we can look at the consequences of some institutional changes that the government is capable of bringing about.

\subsection{Changes in old sector institutions}

In subsection 3.2.1.1.7 we considered the impact of a positive change in the level of old sector benefits. Remember, it was the case when the transition essentially failed.

Such a change in benefits decreases the threshold value $q_{o}$ and makes more workers get employed fictitiously in the old sector (they will work only time B). Fig.3.42 to 3.44 show the effect of this on the hours spent in the official sectors and the informal economy.

The actual supply in the old sector is at even greater odds with the potential supply of hours implied by numbers employed (Fig.3.42) than in the benchmark case.

The growth of total informal hours is more dynamic (Fig.3.44). However, the hours of full-time informal employment are also growing faster since the new sector job creation is 
depressed by high wages that the sector has to pay in response to high $b_{o}$. Hence, more unemployed workers leave the labour force.

Another possible institutional change concerns the time constraint $B$ in the old sector. If it is tightened enough, i.e. $B$ becomes closer in value to $H$, the threshold value $q_{o}$ becomes greater than 1 . This implies that all the workers in the old sector will work time $H$, i.e. there will be no fictitiously employed. In that case the patterns of the actual supply of hours in the old sector and the potential supply of hours implied by employee numbers are more close to each other (Fig.3.45). This leads the shape of total informal hours to resemble closely the trend of hours of full-time informal workers (Fig.3.47). To put it another way, the evolution of irregular output is governed by the number of full-time workers. There are no major changes in patterns of employment in the new sector compared to the benchmark case (Fig.3.46 and 3.40).

\subsection{Changes in institutions regulating unemployment}

Finally, we turn again to institutions influencing the behaviour of the unemployed. Earlier we have already considered the case with changes in the value of $q_{u}$, affecting the exit rate from unemployment to underground. In subsection 3.2.1.1.4 we noted that the same values of $q_{u}$ can be achieved by varying either $T$ or $b_{u}$ holding all other parameters fixed. This implies that both such manipulations will bring about the same pattern of unemployment (see Fig.3.48 and 3.50). However, implications for the supply of hours underground will be different.

If the government, for example, just reduces time costs of search, not making any changes to the level of benefits, the total supply of hours to the informal economy will increase compared to the beginning of transition (Fig.3.49). This is because unemployed workers enjoy more time for informal activities. Notice that initially the total supply of hours increases in the wake of the increase in the general level of unemployment. After some time, however, the new sector is outmanoeuvring the irregular sector (Fig.3.19 and 3.21), since the former keeps on generating places for workers coming from the latter. Hence, the supply of informal hours is somewhat declining after reaching a peak.

Fig.3.51 shows the effect of an increase in unemployment benefits, holding the time constraints fixed. Now, the total supply of informal hours is less than in the beginning of transition. The initial drop in the old sector employment leads to the fall in informal hours supplied by the old sector moonlighters. They are not compensated by the increase in the informal hours supplied by jobless workers. Therefore, informal hours first decrease. Then their pattern follows the scenario described in the previous paragraph. The only exception is that now the growth in the new sector cancels out completely the small gains in informal hours obtained while the unemployment was quickly increasing.

Thus, we can see that different measures taken by the government have the same effect on the official statistics but impact differently the informal economy. However, in both cases just considered, the total change in informal hours was in the narrow range of $2 \%$. This cannot be a number to worry about.

\subsubsection{The Case with Explicit Government}

Up till now we have assumed that any government budget balance can be financed and has no feedback on the economy. However, the debate originated by Burda (1993), Aghion and Blanchard (1994) and Chadha and Coricelli (1994) has shown that too high or too slow a speed of transition can have an adverse effect on the outcome of transformation itself if the fiscal budget is introduced in models explicitly.

For example, Aghion and Blanchard (1994) and Blanchard (1997) argue that if the speed of old sector closure is too high, the positive effect on new sector wages can be reversed by the negative effect of the additional fiscal burden on new firms. Indeed, the faster the old sector sheds labour the faster the growth of unemployment. More workers 
claim benefits and the higher taxes have to be levied on the new sector since the old sector tax base is eroding. It can be the case that the adverse effect of taxation outbalances the disciplining device of high unemployment and, thus, brings transition to a halt.

On the other hand, Chadha and Coricelli (1994) also argue that too slow a speed of transition can be detrimental as well. If higher tax rates in the old sector make it restructure faster then lowering the tax pressure on the sector can slow down the transition. This can happen because the government may wish to prevent a rapid rise in unemployment, and may stop pushing the old sector by high taxes and bring their level down. This in turn could be harmful for the new sector if it hires workers from the unemployment pool. The lower level of new sector employment the lower rate of human capital accumulation in the Chadha's and Coricelli's model, and eventually the economy may well end up specialising in the old sector good. ${ }^{49}$ Transition will fail again.

The reasonable question then arises - what is the optimal speed of transition? The answer can be obtained if in addition to the government budget constraint some kind of an objective function of the social planner is introduced. It can be the total output of the economy net of costs (Burda, 1993; Brixiova, 1997) or the life-time utility of consumers (Castanheira and Roland, 2000). The optimal speed is that at which the social planner maximises her objective function.

In this work we do not attempt to give our answer on the tricky question of the optimal speed. However, we introduce the government budget to look at the fiscal externalities effect.

\subsubsection{A last bit of algebra}

As we introduced in Section 2, the budget of the government is determined by

$$
\left(b_{u}+\eta\left(1-\frac{J(N, U)}{\mu N+U}\right)\right) U=\tau_{n} w_{n}(N, U) S(N, U) E+\tau_{o} w_{o} q_{o} N,
$$

where $\frac{J(N, U)}{\mu N+U}=p_{n}$.

Then the tax rate in the new sector can be represented as:

$$
\tau_{n}(N, U, E)=\frac{\left(b_{u}+\eta\left(1-\frac{J(N, U)}{\mu N+U}\right)\right) U-\tau_{o} w_{o} q_{o} N}{w_{n}(N, U) S(N, U) E} .50
$$

Together with (15) and (16) and the expression for $S(\bullet)$ it determines the wage setting and job creation behaviour of new sector firms. Note, that ultimately both $w_{n}(\bullet)$ and $J(\bullet)$ and $S(\bullet)$ become functions of $N, U$ and $E$, but not only of $N$ and $U$. This essentially complicates the system.

The results of numerical simulations are discussed below.

\subsubsection{Derailment of transition}

The benchmark set of parameters makes already a case for transition derailment.

Fig.3.52 shows that after about 10 periods the fiscal pressure on the new sector becomes too serious, $\tau_{n}$ gets too high (Fig.3.58), which leads to negative job creation rates (Fig.3.57) and the collapse of the system after 25 periods. Too high a speed of the old sector decline quickly generates high levels of unemployment (Fig.3.53) that has to be financed through the unemployment benefit system. The old sector is too small already but the new sector is not yet strong enough to cope with such unemployment. High taxes both lead to

\footnotetext{
${ }^{49}$ See the literature review in Section 1.

${ }^{50}$ We follow Boeri (1999) who suggests that the new sector tax rate is the only variable that can be adjusted see subsection 2.2.7.
} 
lower wages (Fig.3.56) and reverse the development of new firms. Transition eventually fails.

However, if the government changes $\eta$, i.e. the rate of old sector job creation (which is also financed through payroll taxation), namely increases subsidies to the old sector, then transition succeeds as shown in Fig.3.59 to 3.65. The major dynamic patterns of all variables of interest are similar to ones considered, for example, in Fig.3.13 to 3.18.

The new sector tax rates stabilises (Fig.3.65) and firms develop smoothly.

\subsubsection{Never too slow a transition}

What if the government increases subsidies to the old sector even more? That is, what if job creation rates in old enterprises are higher than those in the case depicted in Fig.3.59 to 3.65 ?

Fig.3.66 to 3.72 illustrate that transition will definitely become slower. However, it will converge after more than 25-30 periods.

Increasing $\eta$ leads to a decrease in the share of the informal economy. If, for instance, $\eta=1$ then full-time irregular employment will be completely absent in the model. At the same time, transformation of the official sectors will still succeed. It does not derail but just becomes very slow.

Such a result is explained by the way hirings in the new sector are made. Maintaining the level of the old sector does not hamper the new sector growth because it then accepts more workers directly from the old sector but not from unemployment. This situation was just impossible in the earlier OST studies that postulate hirings from the unemployment pool.

\subsection{Discussing and Summarising the Findings}

Having considered a number of possible cases now we can sum up our findings.

The analysis of the model shows that it helps to explain many stylised facts mentioned in Section 1 and supports the initial hypotheses.

\subsubsection{Explaining Stylised Facts}

As we can see the model generates the dynamic patterns consistent with the real development of the Russian economy, especially at the beginning of transition. It captures the decline in the state employment and the rise in private employment (Fig.1.5), the growth of unemployment (Fig.1.2 and 1.3), the upsurge in the share of the informal sector (Fig.1.8) and the drop in participation (Fig.1.4). The basic model also reflects the behaviour of private sector wages, that have been growing faster than wages in the state sector (Fig.1.6).

The model suggests that the decline in participation rates, which has been observed not only in Russia but in other countries of Central and Eastern Europe over the last decade, can be associated with a shift of some workers into the informal economy. For all the sets of parameters the decline in participation takes place and the growth of the shadow sector is notable. The moonlighting practices in the old and the new sectors can make matters even worse. As we have seen, if an account is made of the hours spent by moonlighters underground the relative size of the informal sector is even greater compared to the size of the old or the new sector.

The evidence from Central and Eastern Europe does not show a uniform upheaval of informal economies in all the transition countries (Fig.1.7). By contrast, in such countries as Russia and Ukraine the irregular sector has been growing markedly (Fig.1.8). In the light of our model we suggest that such a difference can in part be explained by moonlighting, which is widespread in countries of the former Soviet Union to a much greater extent than in CEE countries. ${ }^{51}$

${ }^{51}$ Clarke et al. (1998) argue that "contrary to the popular stereotype, secondary employment is not a mass phenomenon" in Russia (p.128). However, they note that "the largest growth in the sphere of secondary labour 
In our model the transition starts with moonlighting workers in the old sector supplying less hours than they are officially supposed to. However, the specific institutional arrangements that allow them to do so did not emerge at one moment. Some amount of time had to pass before such practices were adopted. We suggest that the more rapid growth of the informal economy in 1990-1992 (see Fig.1.8) and more severe output decline rates in the same years (Fig.1.1) in Russia reflect both the adoption of those practices and such shifts of part of hours away from the old sector to the irregular economy.

As we noted earlier in subsection 3.2.1.2.2. the evolution of total informal hours can be treated as the evolution of informal output. Then Fig.3.41, 3.44, 3.49 and 3.51 indicate that there could be a minor decline at the beginning of transition in the size of the informal sector. This is associated with the decrease in hours supplied by moonlighters because of the closure of old sector enterprises. The data of Johnson et al. (1997) does not show any minor negative change in the size of the Russian irregular economy since 1989. However, the more recent study of Lackó (2000) indicates a minor short decrease in the share of hidden economy in Russia (see Table 1) in 1993. Thus, our model offers an explanation to this observation.

The evolution of official output in Russia has until recently resembled the L-type rather than the U-type transition curve mooted by the seminal work of Aghion and Blanchard (1994). For various sets of parameters our model generates different trends as shown in Fig.3.73 to 3.75. It is obvious that an argument for the L-type curve can easily be made.

Our model is less successful in explaining the trend of officially registered unemployment (Fig.1.3). The major patterns suggested by simulations are rather similar to the unemployment consistent with the ILO definition (Fig.1.2). On the one hand, an explanation to this fact might be the evidence by Clarke (1999, p.250) who reports that much more unemployed turn to the Federal Employment Service in Russia in the hope to find a job than actually register to get benefits. That is, much more people, than just the officially registered unemployed, spend their time looking for a job through employment offices. Thus, our model does not that bad, producing trends similar to the ILO-type unemployment trajectory. On the other hand, it might be the case that not only the time-constraints and the level of benefits are important for the decision of people to register with employment offices. Clarke (1999) also points out that the Employment Service cannot provide a full range of information about the existing vacancies, and only about $10 \%$ of people use it as a channel of information (p.210). Thus, other factors than benefits might be important to push an individual to register. We leave this issue for other work.

\subsubsection{Policy Implications}

The analysis of the simulations reveals several interesting points that can be very useful for deriving policy implications. We consider all of them in turn.

\subsubsection{Unemployment benefits}

The straightforward implication that follows from both the time-allocation and the dynamic model is that the level of unemployment benefits should not be brought too much down. If unemployed workers face a problem of allocation of time between more lucrative informal work and registering at the employment office for tiny benefits, they could well prefer the former and leave the labour force altogether. The dynamic model shows that low benefits can lead to a dramatic fall in participation and hamper the growth of the new sector. To avoid such troubles the government should either maintain a relatively high level of unemployment compensation or make benefits more accessible for jobless workers. Too much regulation or insufficient infrastructure making the turn for help to the employment

activity is in subsistence production, which we do not include within secondary employment" (ibid.). In our model, as you remember, the informal sector above all comprises subsistence activities, i.e. we take account of secondary jobs ignored by Clarke et al. (1998). 
office too time-consuming can distort workers away from the official economy. This point is consistent with the large observed difference between the level of registered unemployment and the level reported by labour force surveys in Russia. Many of those who are not registered but report themselves unemployed may in fact work in the informal sector. Clarke (1998) and Commander and Yemtsov (1995) also point to this problem. Moreover, as the authors report, many registered unemployed hold an informal or secondary job as well.

The policy of high unemployment benefits was criticised by Boeri (1999) who argues that higher benefits facilitate filling the unemployment pools with workers not actively seeking jobs and working most of the time informally. The high benefits were also viewed as disrupting the new sector job creation, since they were deemed to provide floors for new sector wages. We can readily contest this point arguing that if benefits are too low, the new sector could base their wage decisions on the old sector wages. Then increasing benefits does not directly influence the profitability of the new sector. However, it is the timeallocation option that makes a good case for more generous benefits.

\subsubsection{Old sector benefits}

In the setting of the dynamic model it is the high old sector benefits that are indeed hazardous for the economic transformation. In the case when the old sector compensation is deemed to be a wage floor for the new sector, any increase in the benefits undermines the abilities of new firms to take off.

The high level of such benefits is also extremely detrimental for it causes the share of fictitious workers or "dead souls" (see Clarke, 1998) to increase. It distorts the old sector hours away in favour of the irregular sector.

The prohibition against the old sector practices of supporting the labour book (see Section 2), as a bright example of such benefits, should bring more workers into official employment.

\subsubsection{Timing and the outcome of transformation}

High taxes, lower job search effectiveness in the old sector, the high level of corruption, higher old sector job creation rates, etc. - they all unambiguously slow the transition process down. We show that they also influence the eventual outcome of the transformation - transition can end up with a still significant share of the old sector. The actual restructuring of old enterprises was left beyond of the scope of this research, but in the situations when the old sector survives additional measures would have to be undertaken to reform the less productive sector.

Interestingly, the setting of the model supports the finding of previous OST studies that too fast a transition may lead to derailment because of fiscal externalities. Those studies warn also against a too slow transition, since it prevents the successful growth of the new sector and the accumulation of human capital within it (Chadha and Coricelli, 1994). However, the most important theoretical result of this work shows that in the presence of onthe-job search, supporting the old sector cannot be dangerous for the eventual outcome. Transition will slow down but will never derail if the new sector is able to hire workers directly from old enterprises.

\subsubsection{The size of the informal sector}

Finally, the model suggests that the increase in the share of the informal economy depends on the probability of outflow from unemployment to jobs in the official sectors. The higher the probability the lower the speed of the informal sector growth. This is consistent with the observation of Lackó (2000) who finds that lower increases in ratios of the hidden economy in former communist countries were associated with larger increases in the share of the private economy in the course of transition. The explanation offered by our model is that the brisk new sector implies higher recruiting rates and, thus, larger outflows from unemployment. This prevents people from supplying there labour underground. 
The evidence from Russia as documented by Foley (1997a) has seen the reemployment probability decline by $24 \%$ from 1992 to 1996 . This led to an increase in longterm unemployment (see Fig.1.9). Fig.1.8 indicates that the informal economy was growing over that period, which again supports the finding of our work.

The important implication that one can infer from this result is that active labour market policies stimulating job creation can be not only very useful for employment per se, but may prevent the growth of the informal sector. ${ }^{52}$

At this point we stop the discussion of various implications and proceed to the next section which concludes.

\section{Conclusions and Perspectives}

We have suggested in this work a way of thinking about Russian transition.

In Section 1 we presented a number of stylised facts, many of which were left unexplained by the important strand of the literature on transition called the OST studies. This literature is aimed at providing a theoretical footing for processes of labour reallocation widely observed in Central and Eastern European countries and the former Soviet Union republics. We gave a brief overview of nearly all bright examples of this line of the research. They lack consideration of moonlighting and informal employment - the two phenomena that gained importance in transition economies over the last decade. Both moonlighting and informal employment have been particularly rampant in Russia.

To develop an economic model suitable to describing the Russian reality, in Section 2 , two models were put forward.

The first model is a time-allocation model with secondary job holding in the informal economy. It draws upon the well-developed theory of allocation of time originated by Becker (1965) and revisited by Gronau (1977). The model considers the choice of heterogeneous workers separately in the old and the new sector and when they are unemployed. Effectively, all the three states can provide a worker with different incentives or possibilities to moonlight. In particular, we take account of additional non-wage benefits that constitute an important part in workers' motivation as pointed out by Commander et al. (1996b).

The model suggests that low direct flows from employment to inactivity in Russia compared to CEE countries may be explained by practices adopted in the official sectors of the Russian economy, in particular, by fictitious employment (Barsukova, 2000). Under values of the model's parameters estimated by other authors, the choices of full-time underground work can be excluded from consideration for employed workers. However, unemployed workers can still prefer full-time informal work. This is consistent with the stylised fact that major flows to inactivity take place through unemployment. This finding provides an insight into the drop in participation rates in Russia and other transition countries observed during 90-s. We develop this issue in the dynamic model.

The second model is an OST-type dynamic model with reallocation of workers between the old, new and informal sectors. The model differs from many previous OST studies in a number of aspects. In particular, it explicitly considers three sectors instead of two, treats the old sector compensation as a floor to new sector wages, and allows for old sector hirings and on-the-job search. It also takes account of moonlighting practices and builds on the finding of the first model that unemployed workers can prefer full-time informal work.

\footnotetext{
${ }^{52}$ Boeri and Garibaldi (2001) arrive at a similar conclusion while looking at links between shadow activities and unemployment.
} 
Section 3 presents the OST model simulations. They show that the model is consistent with a number of stylised facts presented in Section 1. In particular, it describes the growth of the private (new) sector, the decline of the state (old) sector, growing unemployment, informal employment, the drop in participation, etc. It also makes a case for L-type output evolution observed in Russia. The model provides useful implications for labour market policies maintaining employment, policies affecting the level of unemployment benefits and old sector benefits. Contrary to the Boeri's (1999) conclusion that too high unemployment benefits may lead to high inactivity among population, we argue that too low benefits push more workers to choose full-time informal work. This results from the time-allocation option of workers. It is also shown that contrary to the argument of some authors (e.g. Chadha and Coricelli, 1994) too slow a transition will never lead to derailment because of fiscal externalities if on-the-job search is allowed. This is an important theoretical result.

This work provides a very good point of departure for future research. The recent studies by Boeri $(1999,2000)$ and Castanheira and Roland (2000) show that issues of resource reallocation in transition are still of great interest and leave spacious room for future improvements.

In the dynamic model we assumed that workers do not plan moonlighting in advance when choosing work in a particular sector. However, there is another point of view. For example, Popov (1999) notes that movement of a worker from one job to another may be caused not by wages but by opportunities for incidental non-wage earnings. Incorporating this fact into the model would be an interesting theoretical development of our work.

Another challenging task would be to empirically verify statements of both models presented in this work.

With regard to the time-allocation model, the informal/home production labour supply functions can be estimated. This can be accomplished in a way similar to the studies of informal economies in Western countries, such as Lemieux et al. (1994) and Lacroix and Fortin (1992) who estimate irregular labour supply functions for Quebec City, Canada, or Krishnan (1990) who estimates labour supply functions of moonlighters in the USA. There are few similar studies for transition countries as well - Foley (1997a,b), Kolev (1998), and Roshchin and Razumova (1999) try to estimate labour supply functions in the secondary job market in Russia. However, they do not take account of home production, despite the fact that the data set they use - RLMS ${ }^{53}$ - allows them to do so.

The most recent work by Juraida and Terrell (2000) outlines the way the validity of the dynamic model can be explored. They use micro- and macroeconomic data from the Czech Republic to check if the OST models (in particular, the Aghion and Blanchard one) concentrate on the empirically most important job reallocation flows. They also examine relationships between the flows suggested by the theory.

Thus, by following the authors above we should expect to obtain further interesting results related to our topic. We hope that our work has contributed to an understanding of the issues of transitional labour reallocation, but future research is needed to make its conclusions sound more strongly.

${ }^{53}$ A detailed report of the technology of the RLMS sample can be found in Swafford (1997). 


\section{Appendix 1 (Figures)}

Stylised Facts

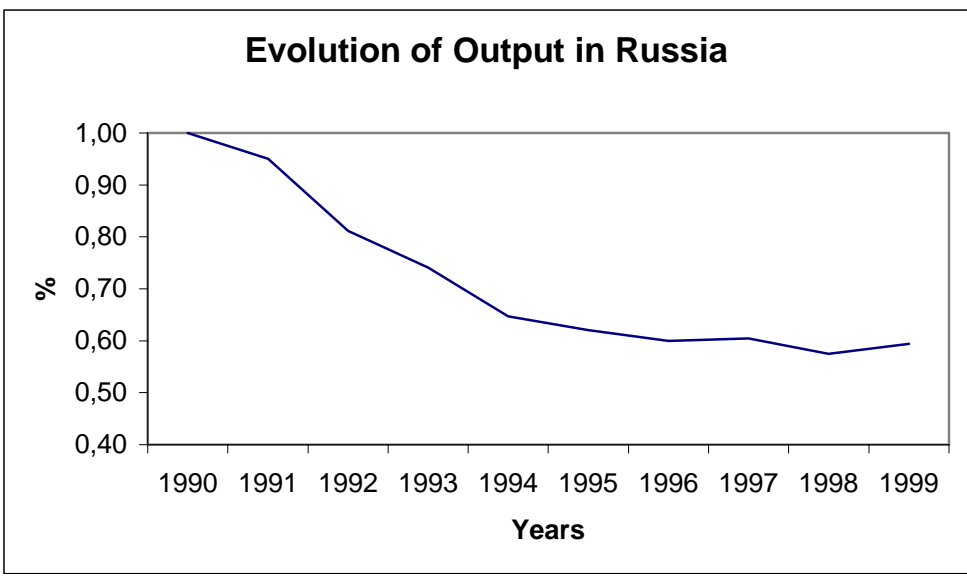

Figure 1.1 Evolution of real GDP 1990=100\% (Sources: IMF, 2000)

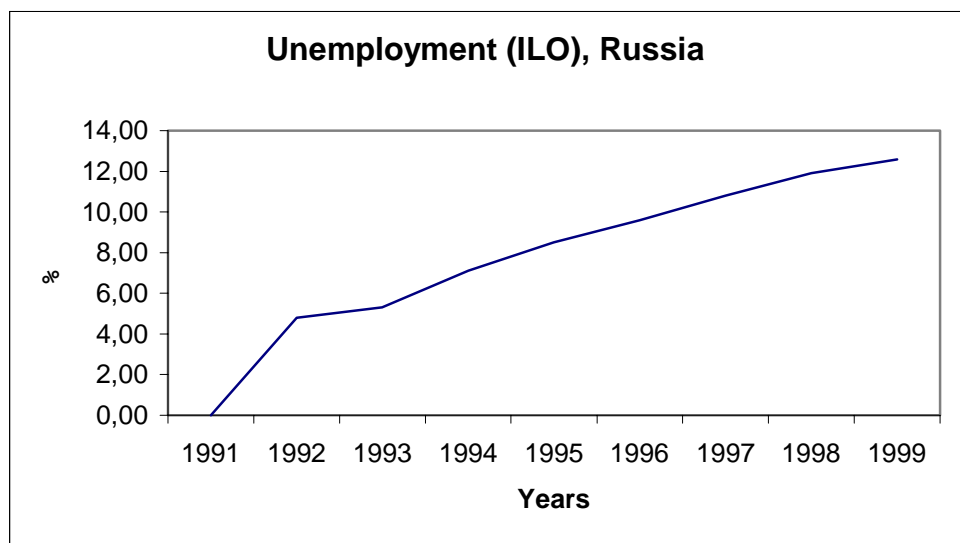

Figure 1.2 ILO type unemployment (Sources: EBRD Transition Report, 1999;

Russian Economic Trends n. 1, 2001)

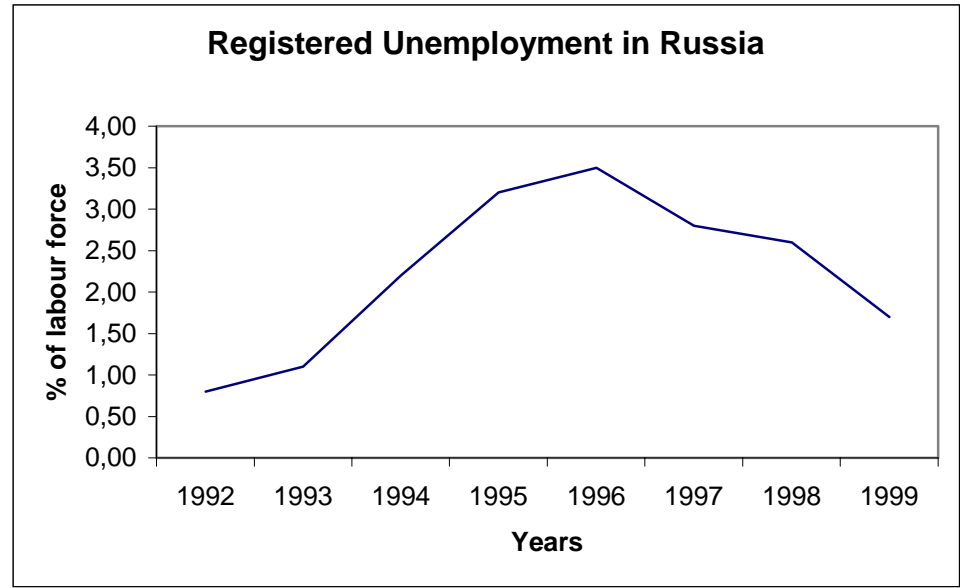

Figure 1.3 Registered unemployment (Sources: IMF, 2000) 


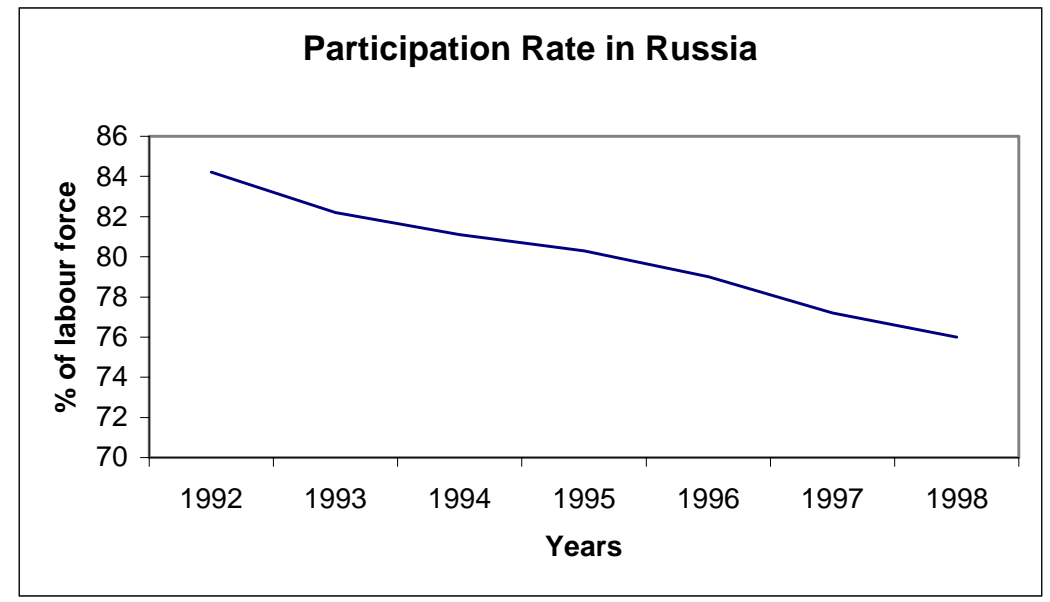

Figure 1.4 Decline in participation rate in Russia (Sources: Goskomstat, 1999)

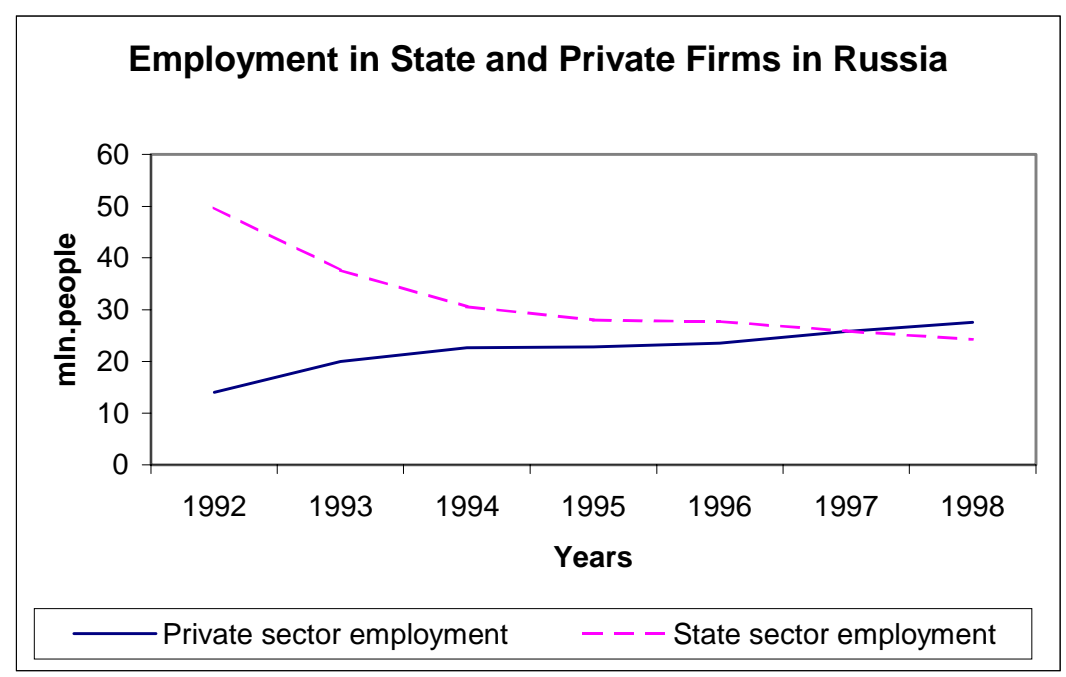

Figure 1.5 Employment in sectors with different types of ownership (Sources: Goskomstat, 1999)

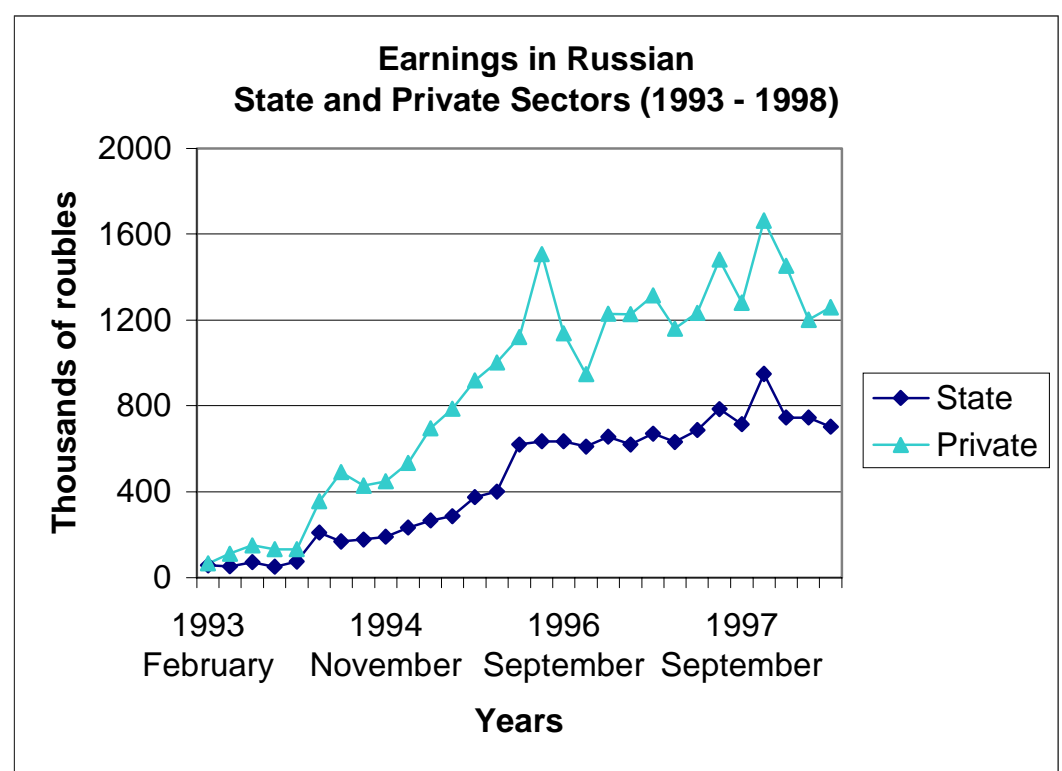

Figure 1.6 Earnings in sectors with different types of ownership (Source: VCIOM, 1993-1999) 


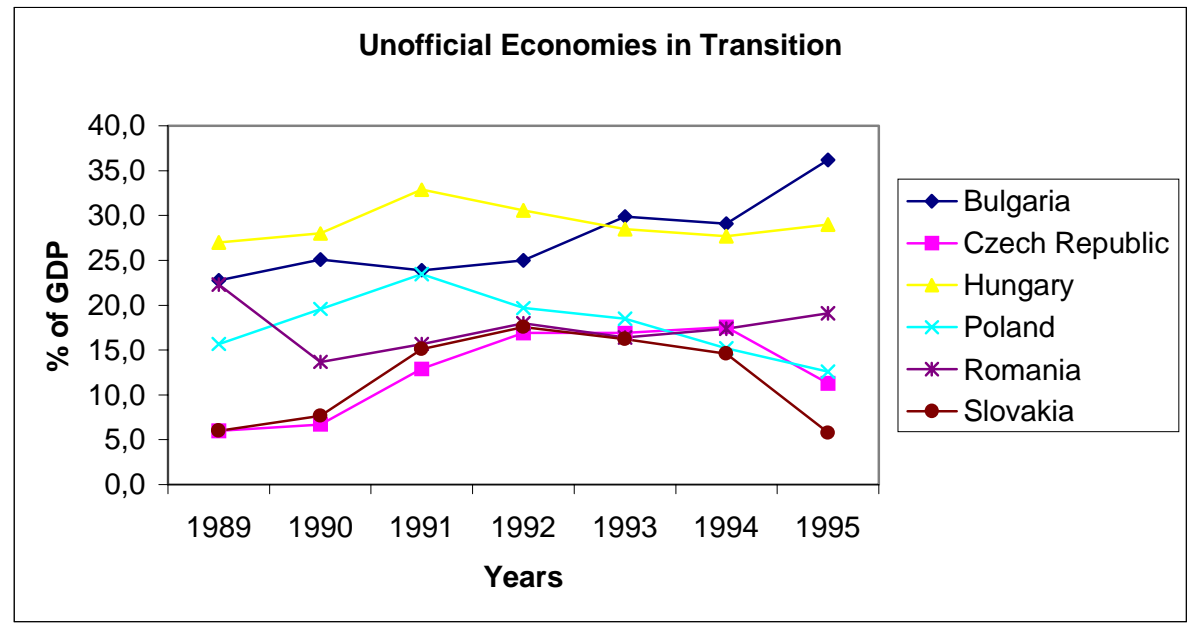

Figure 1.7 Informal sector in selected European transition countries (Source: Johnson et al., 1997)

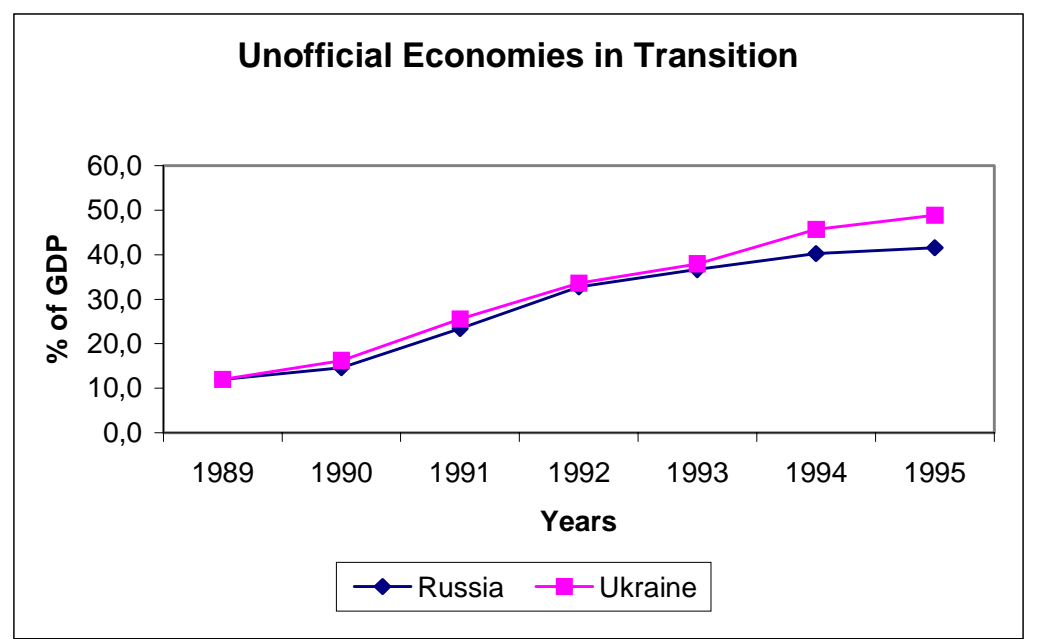

Figure 1.8 Informal sector in selected FSU countries (Source: Johnson et al., 1997)

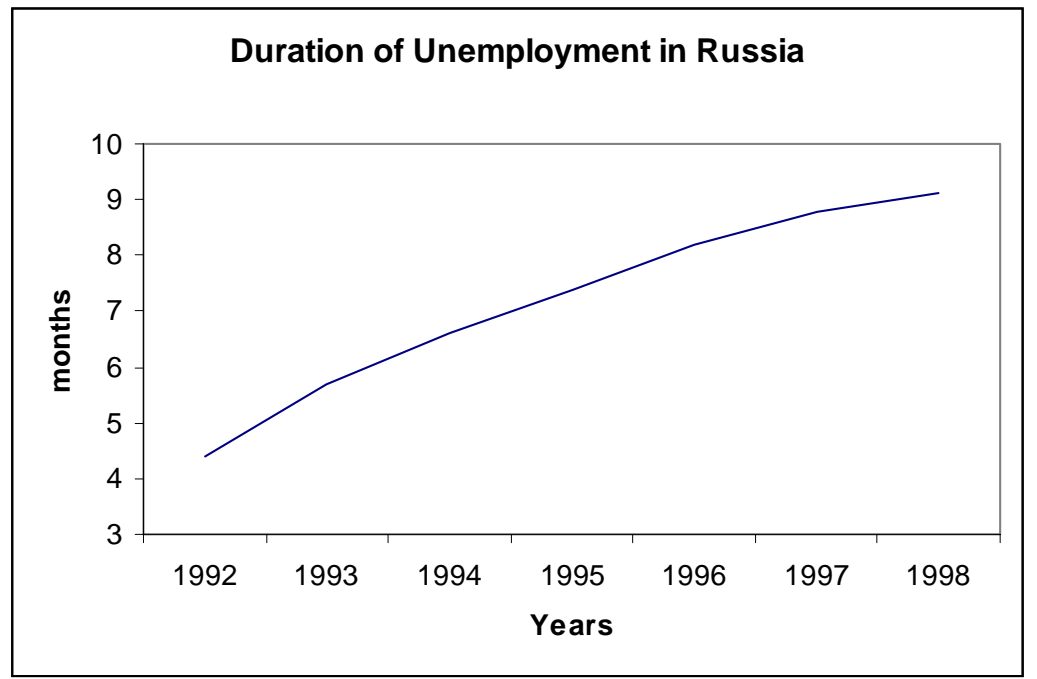

Figure 1.9 Average duration of unemployment (Source: Goskomstat, 1999) 
Appendix 1 (Figures - continued)

Aghion-Blanchard (1994) Benchmark Model of Transition (simulation)

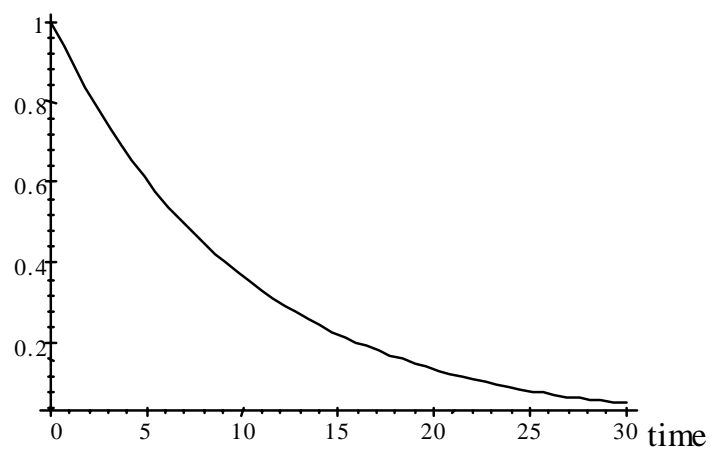

Figure 1.10 State sector employment

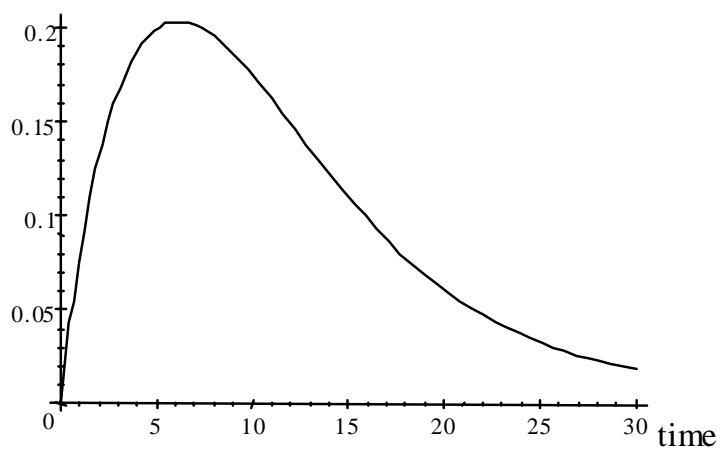

Figure 1.12 Unemployment

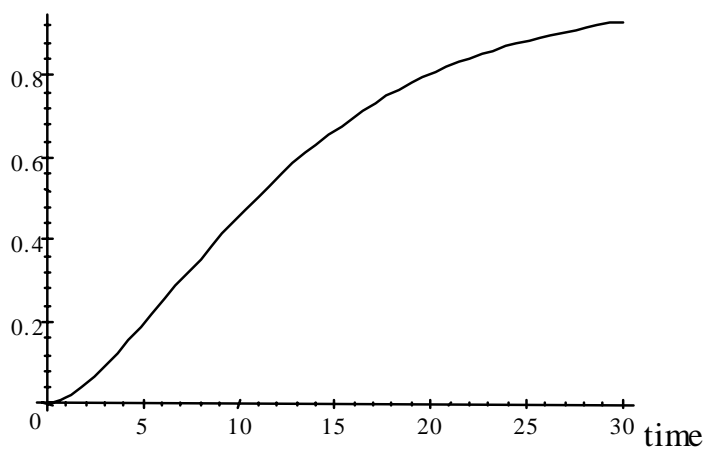

Figure 1.11 Private sector employment

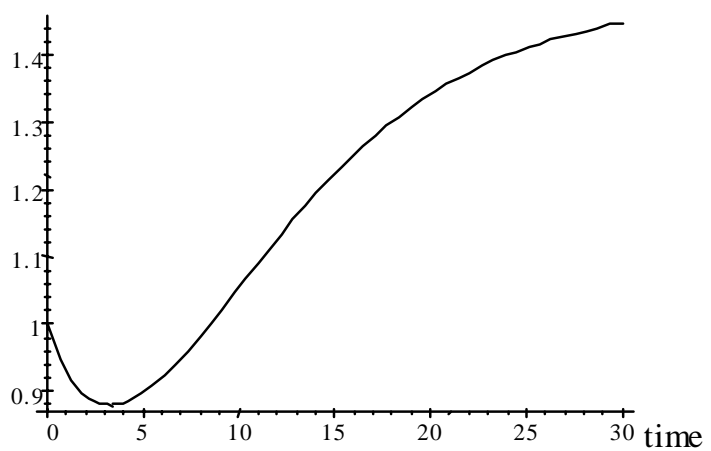

Figure 1.13 Evolution of output

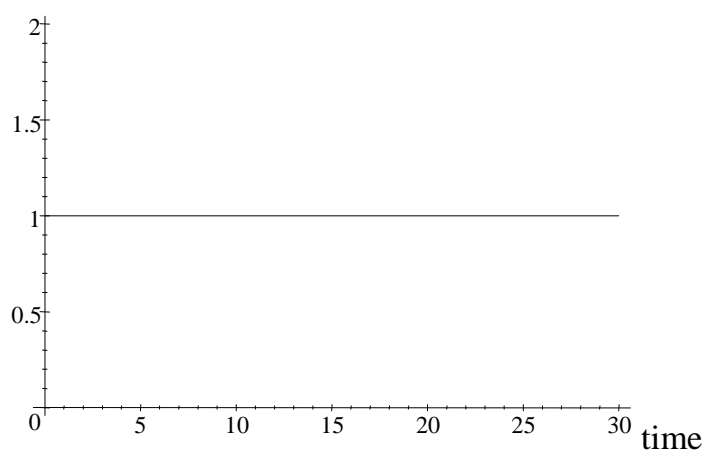

Figure 1.14 Participation rate 


\section{Appendix 1 (Figures - continued)}

The Time-Allocation Model
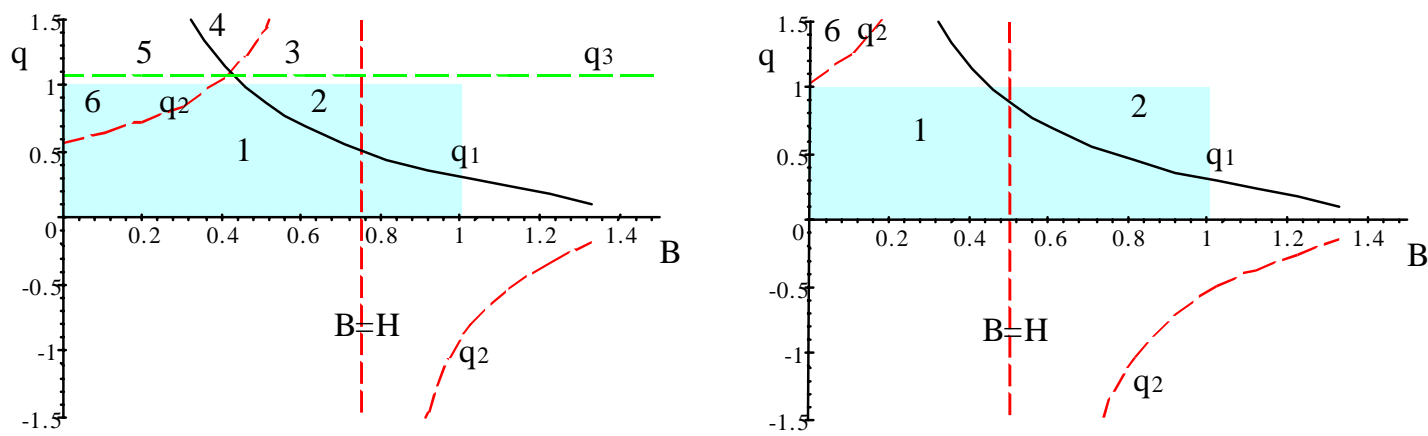

Figure 2.1 $w_{o}=1, b_{o}=0.5, w_{i}=2.75, H=0.75$

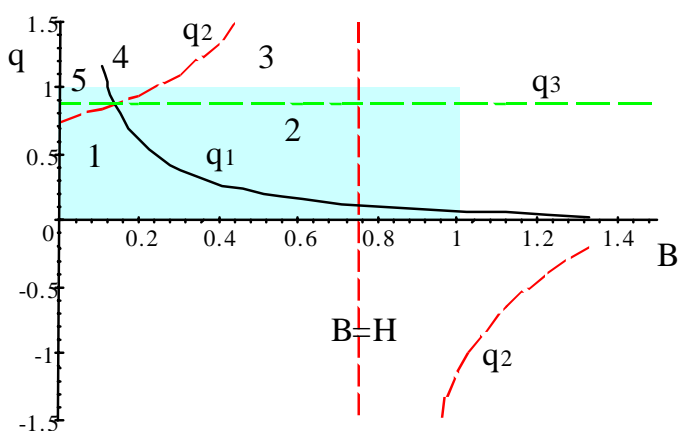

Figure 2.3 $w_{o}=1, b_{o}=0.1, w_{i}=2.75, H=0.75$

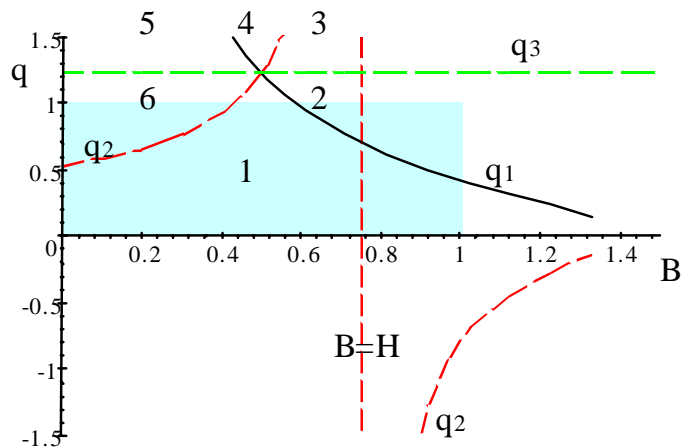

Figure 2.5 $w_{o}=1, b_{o}=0.75, w_{i}=2.75, H=0.75$
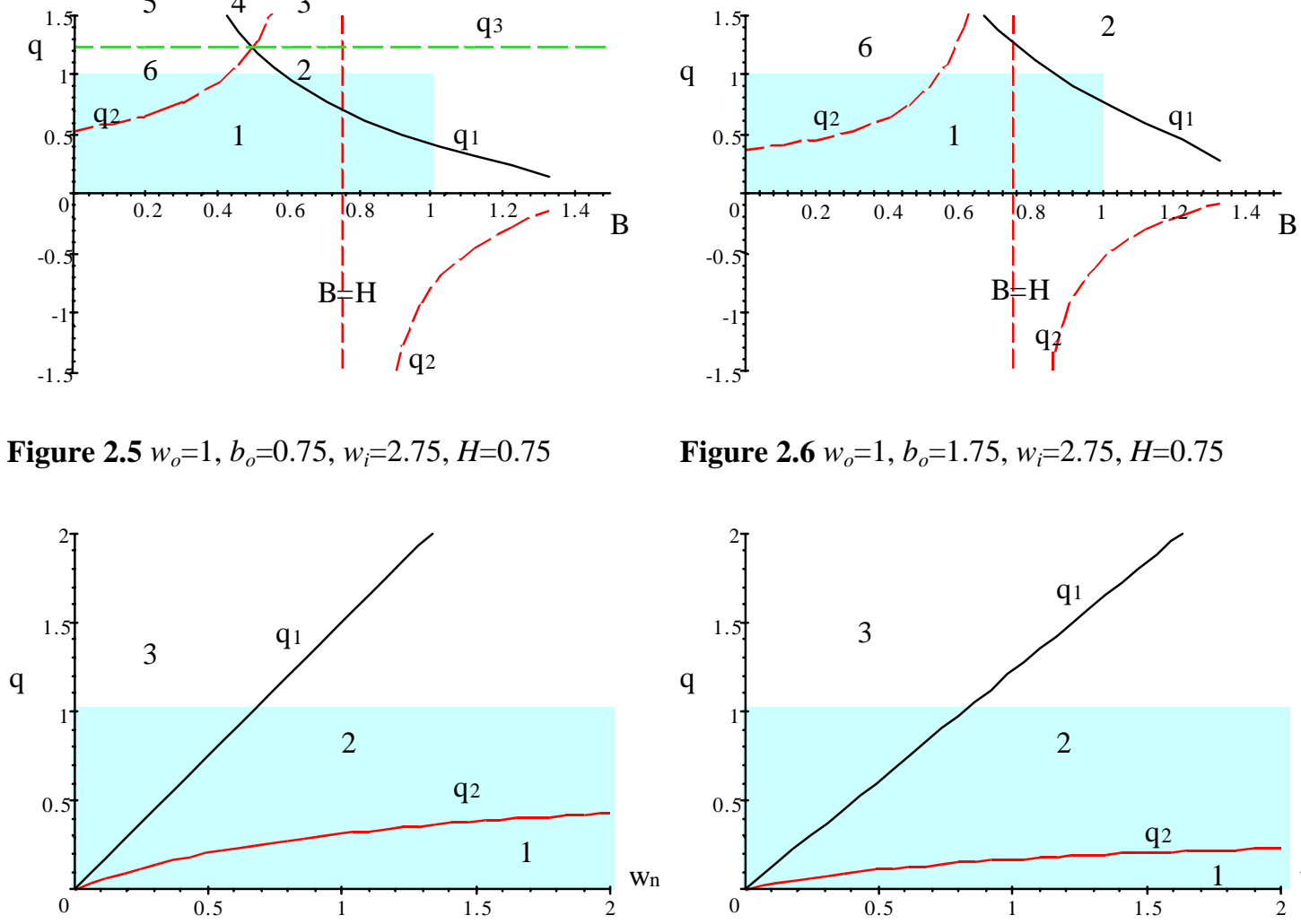

Figure 2.6 $w_{o}=1, b_{o}=1.75, w_{i}=2.75, H=0.75$

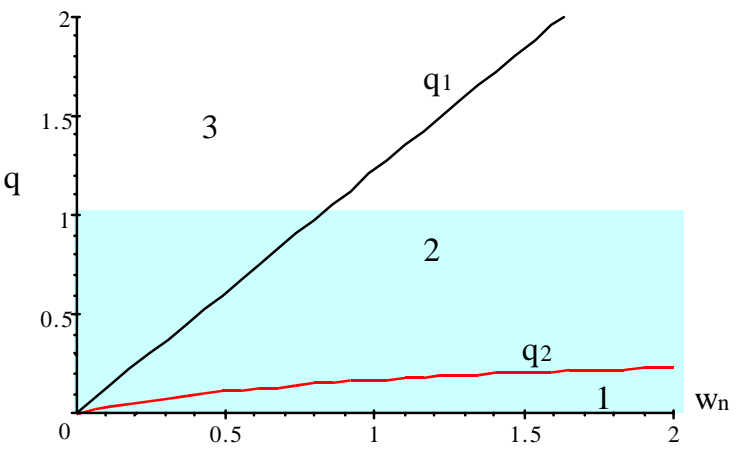

Figure $2.7 w_{i}=1.5$

Figure $2.8 w_{i}=2.75$ 


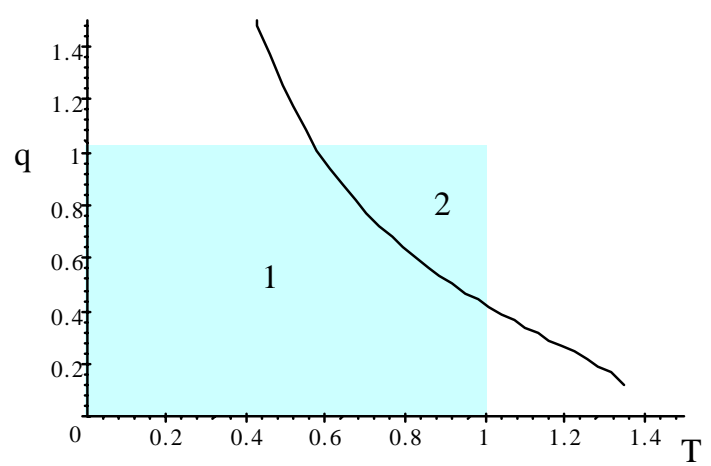

Figure $2.9 w_{i}=2.75, b_{u}=0.75$

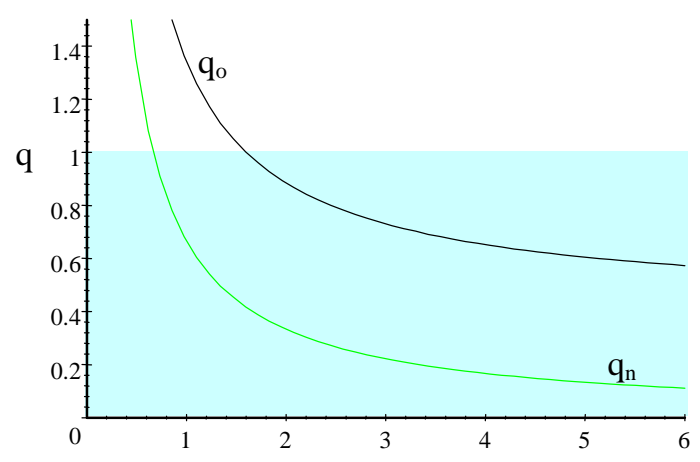

Figure 2.11 $w_{o}=1, b_{o}=0.75, B=0.25$

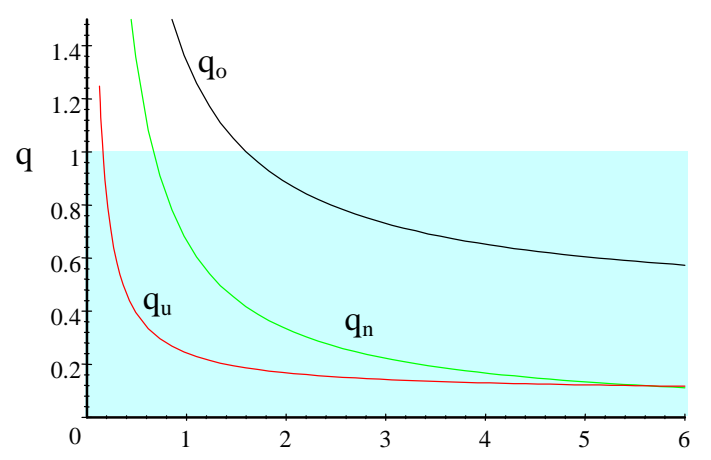

Figure 2.13 The case when, e.g., $w_{o}=1, b_{o}=0.75$, $b_{u}=0.1, w_{n}=2, H=0.75, B=0.25, T=0.65$

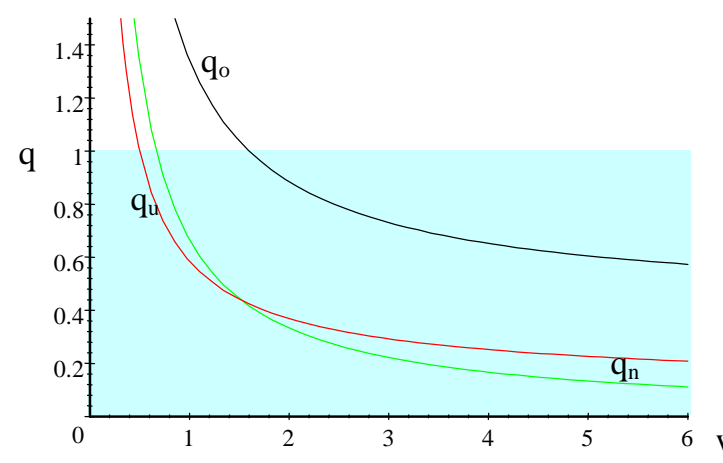

Figure 2.15 The case when, e.g., $w_{o}=1, b_{o}=0.75$, $b_{u}=0.5, w_{n}=2, H=0.75, B=0.25, T=1$

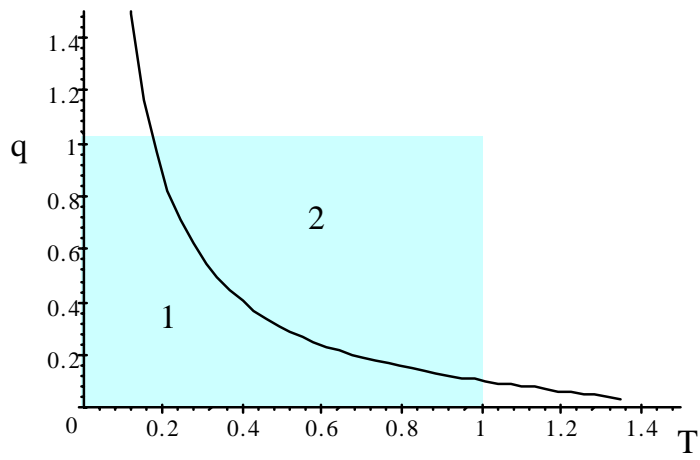

Figure 2.10 $w_{i}=2.75, b_{u}=0.15$

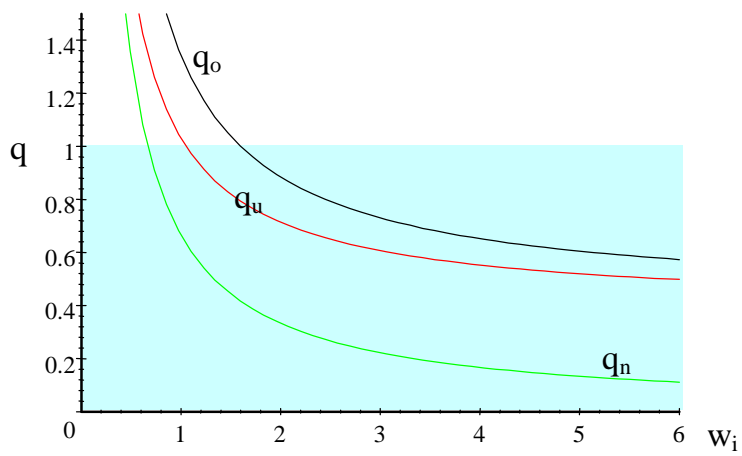

Figure 2.12 The case when, e.g., $w_{o}=1$, $b_{o}=0.75, b_{u}=0.5, w_{n}=2, H=0.75, B=0.25, T=0.65$

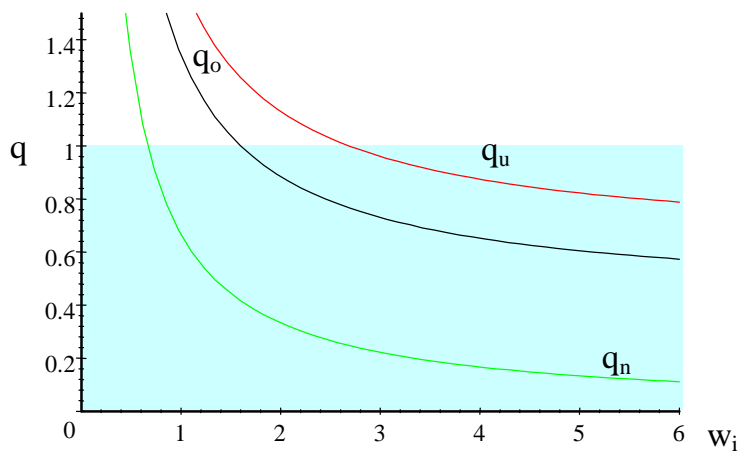

Figure 2.14 The case when, e.g., $w_{o}=1$, $b_{o}=0.75, b_{u}=0.9, w_{n}=2, H=0.75, B=0.25, T=0.65$

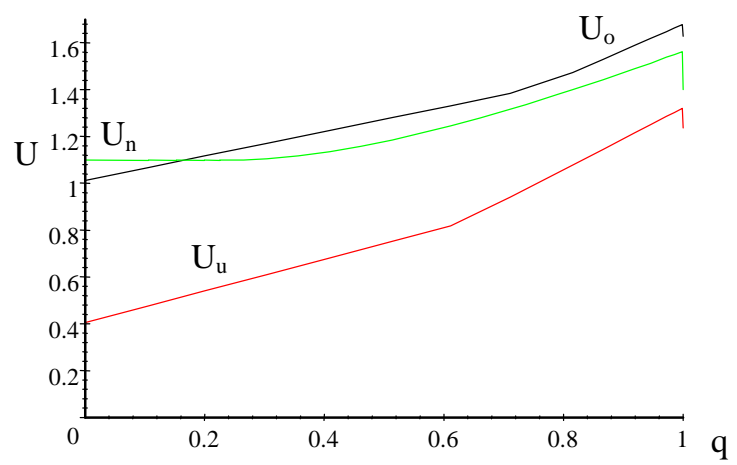

Figure 2.16 Utility functions when $w_{o}=1, b_{o}=0.75$, $b_{u}=0.5, w_{n}=2, H=0.75, B=0.25, T=0.65$ 
Flows in the Dynamic Model

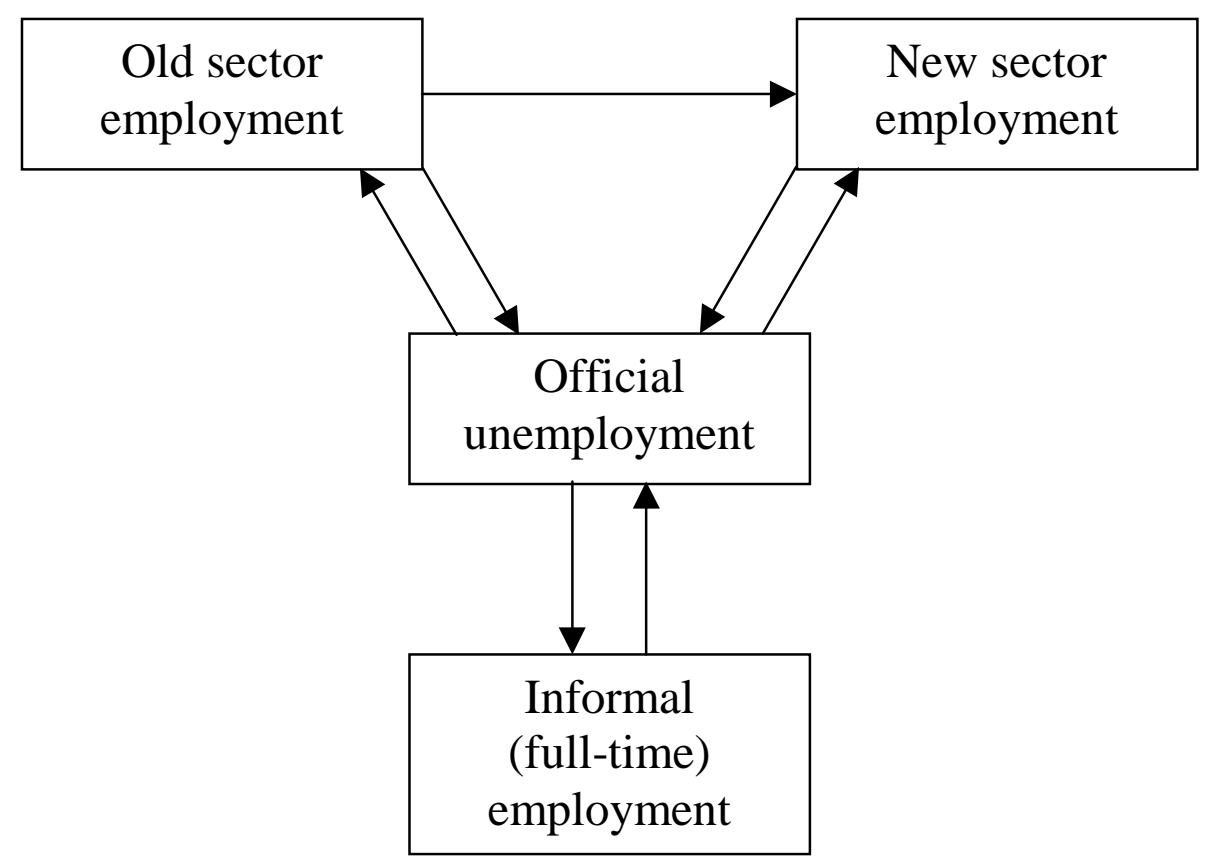

Figure 2.17 


\section{Appendix 1 (Figures - continued)}

\section{Simulations of the Dynamic Model}

The benchmark set of parameters: $w_{o}=1, \tau_{o}=0.1, \tau_{n}=0.1, b_{o}=0.75, b_{u}=0.5, w_{i}=2.75, B=0.25, H=0.75$, $T=0.65, k=2.4, c=1, r=0.1, \lambda=\gamma=0.06, \alpha=0.3, \mu=1, \eta=0.1, q_{u}=0.63, q_{o}=0.76$

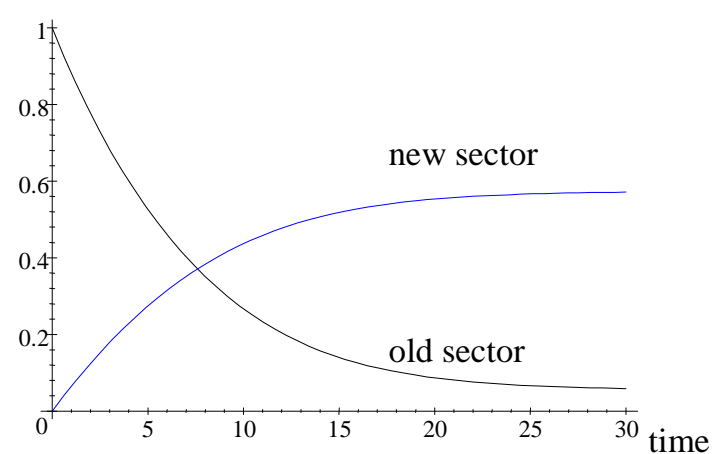

Figure 3.1 Old and new sector employment

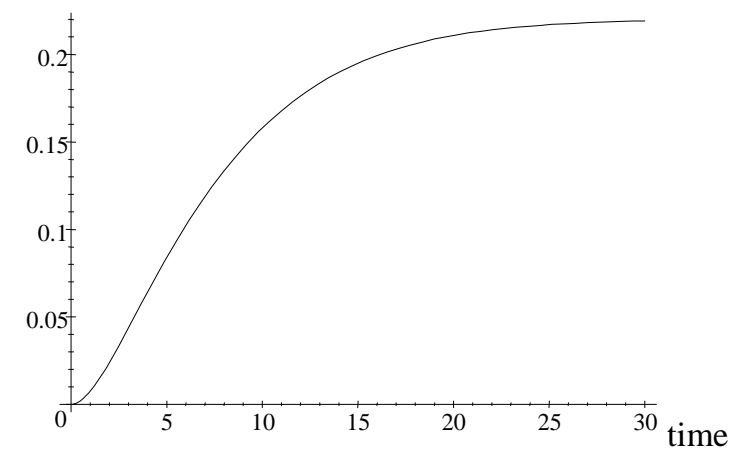

Figure 3.3 Informal sector employment (full-time)

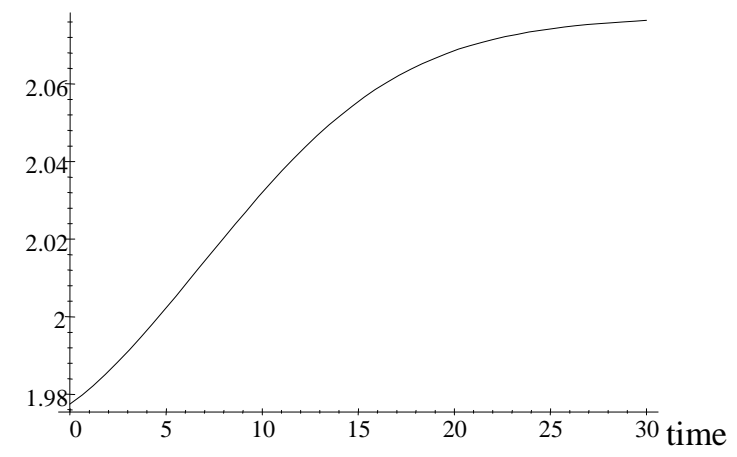

Figure 3.5 Wage in the new sector

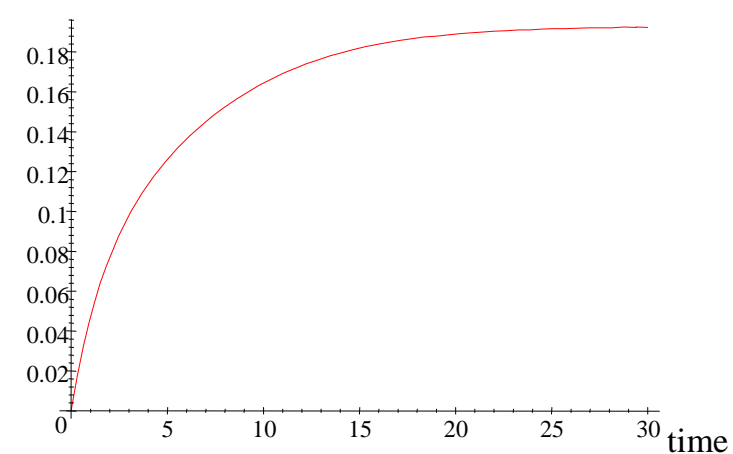

Figure 3.2 Unemployment rate

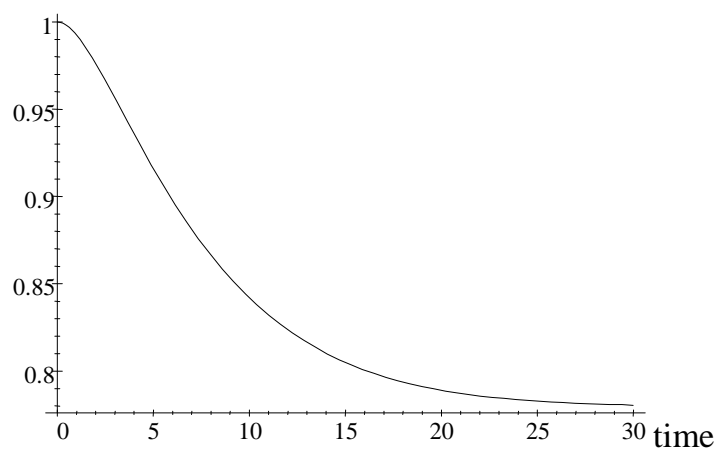

Figure 3.4 Participation rate

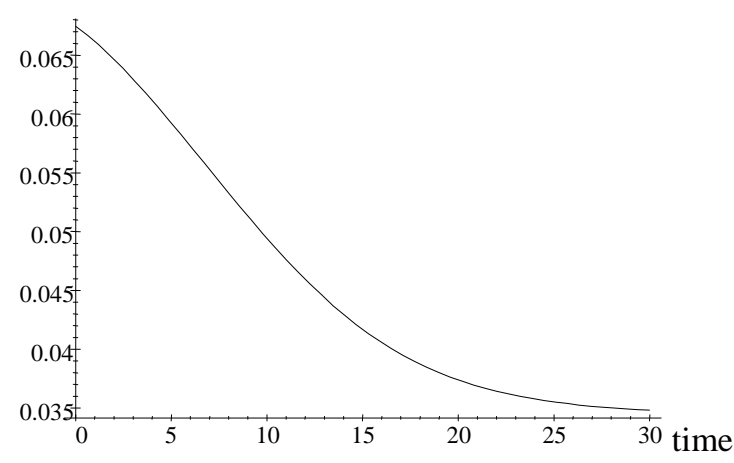

Figure 3.6 Job creation in the new sector 
The set of parameters: $w_{o}=1, \tau_{o}=0.1, \tau_{n}=0.1, b_{o}=0.75, b_{u}=0.5, w_{i}=2.75, B=0.25, H=0.75, T=0.65, \boldsymbol{k}=\mathbf{3}$, $c=1, r=0.1, \lambda=\gamma=0.06, \alpha=0.3, \mu=1, \eta=0.1, q_{u}=0.63, q_{o}=0.76$

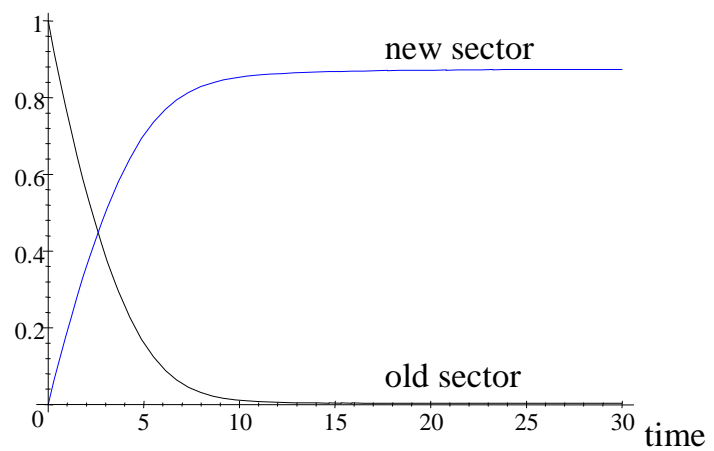

Figure 3.7 Old and new sector employment

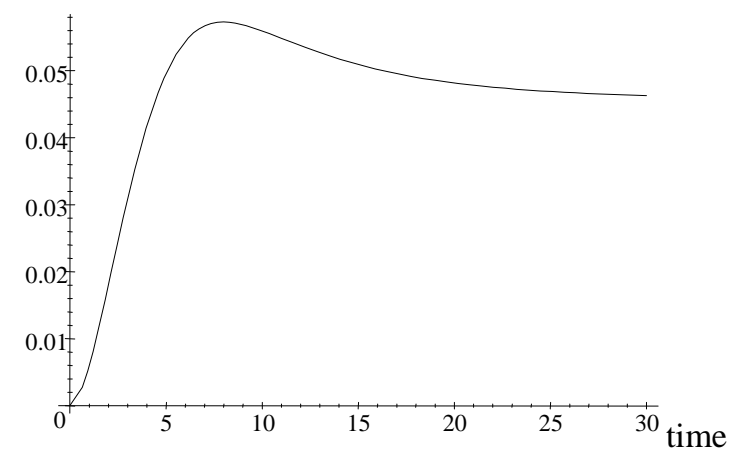

Figure 3.9 Informal sector employment (full-time)

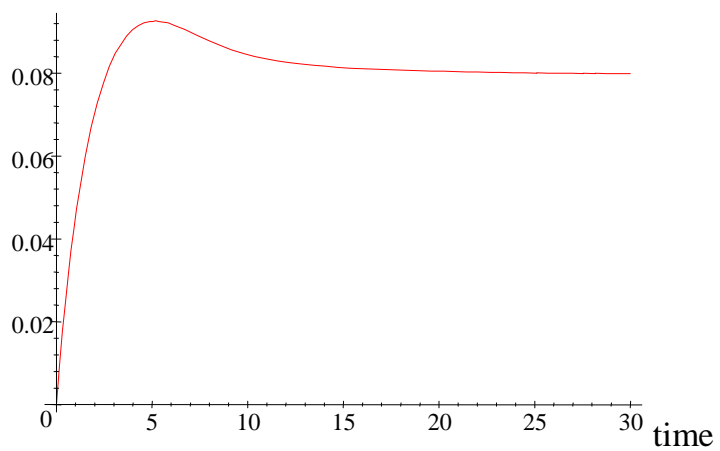

Figure 3.8 Unemployment rate

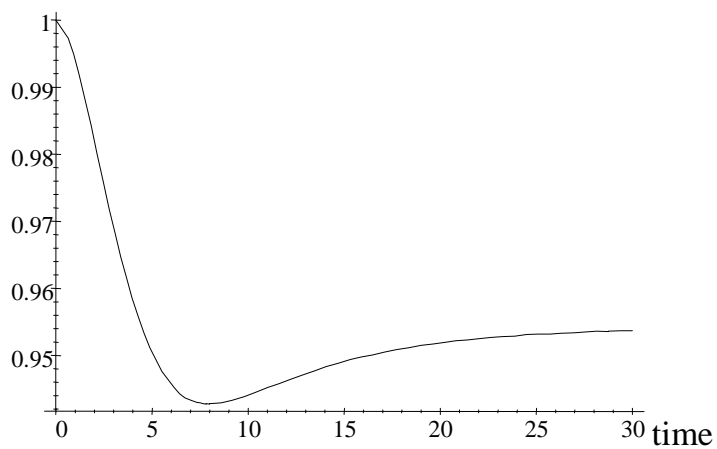

Figure 3.10 Participation rate

The set of parameters: $w_{o}=1, \tau_{o}=0.1, \tau_{n}=0.1, b_{o}=0.75, b_{u}=0.5, w_{i}=2.75, B=0.25, H=0.75, T=0.65, k=2.4$, $c=1, r=0.1, \lambda=\gamma=0.06, \alpha=0.3, \boldsymbol{\mu}=\mathbf{0 . 1}, \eta=0.1, q_{u}=0.63, q_{o}=0.76$

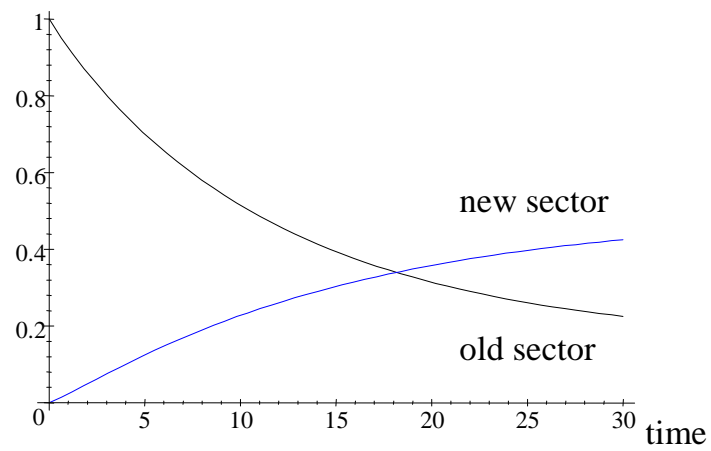

Figure 3.11 Old and new sector employment

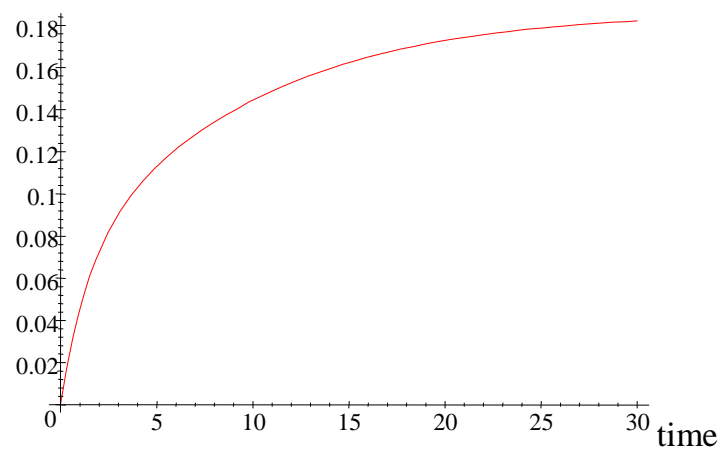

Figure 3.12 Unemployment rate 


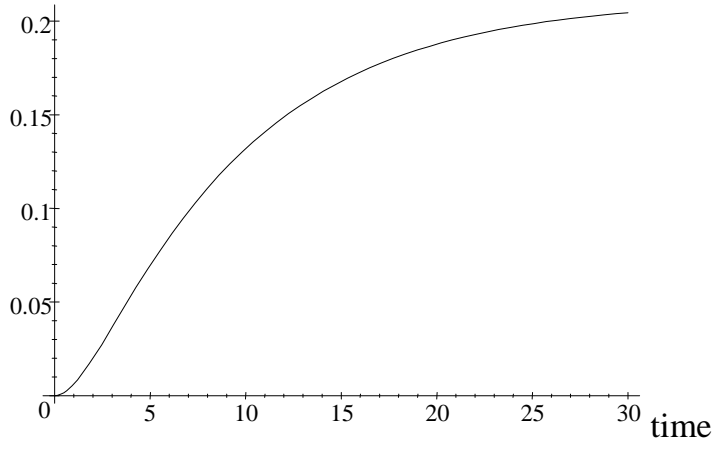

Figure 3.13 Informal sector employment (full-time)

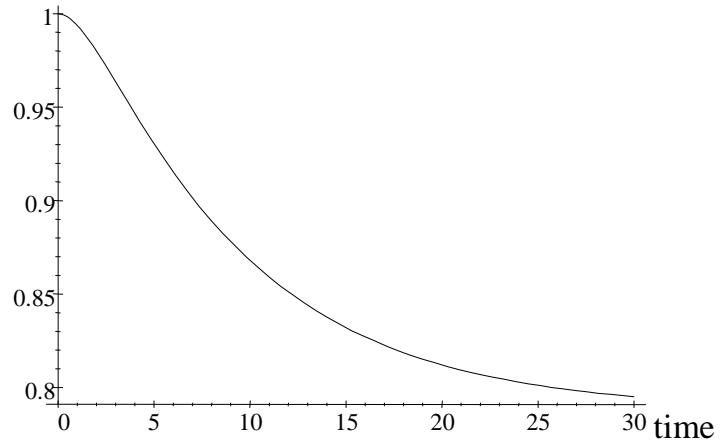

Figure 3.14 Participation rate

The set of parameters: $w_{o}=1, \tau_{o}=0.1, \tau_{n}=0.1, b_{o}=0.75, b_{u}=0.5, w_{i}=2.75, B=0.25, H=0.75, T=0.65, k=2.4$, $c=1, r=0.1, \lambda=\gamma=0.06, \alpha=0.3, \mu=1, \eta=0.5, q_{u}=0.63, q_{o}=0.76$

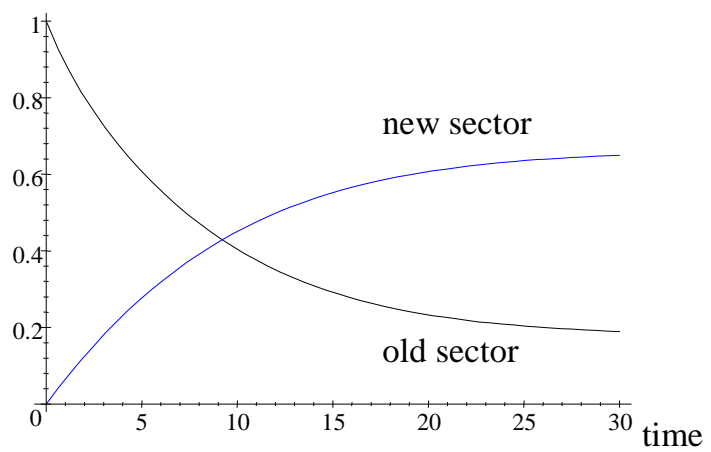

Figure 3.15 Old and new sector employment

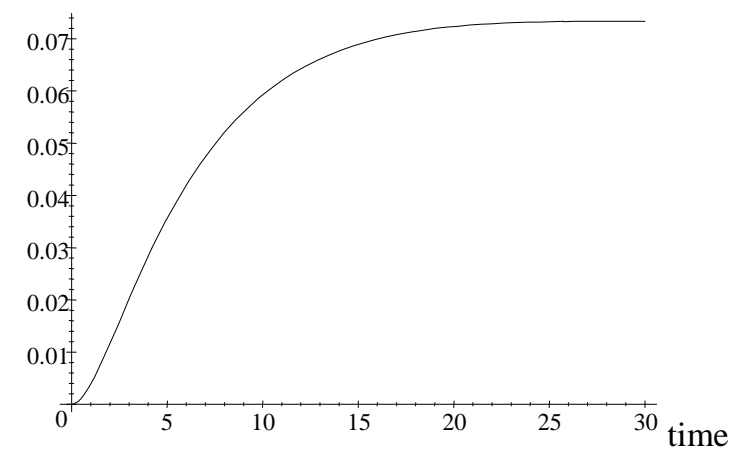

Figure 3.17 Informal sector employment (full-time)

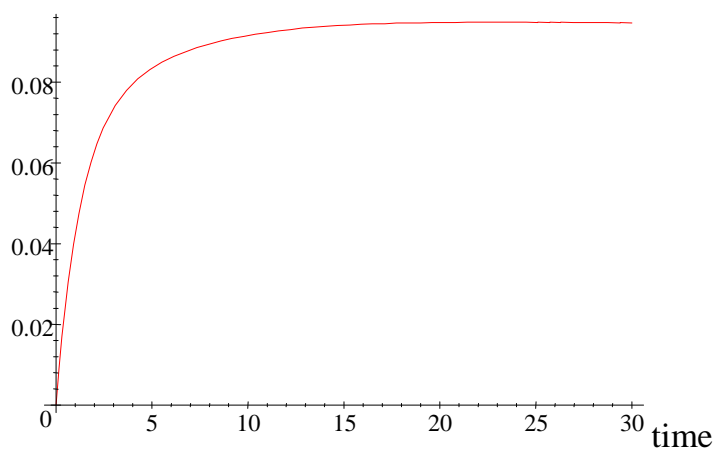

Figure 3.16 Unemployment rate

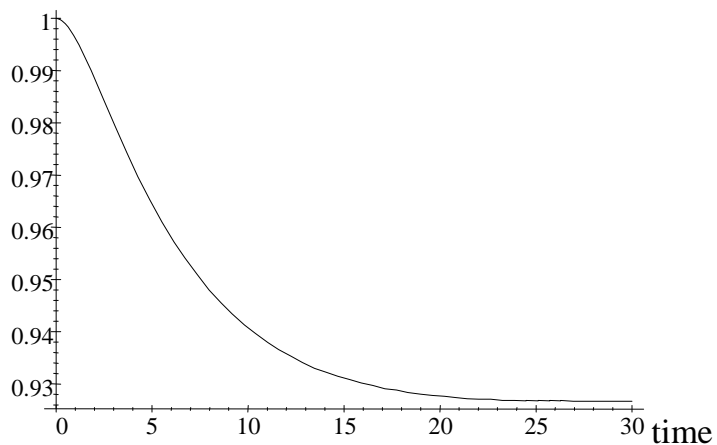

Figure 3.18 Participation rate 
The set of parameters: $w_{o}=1, \tau_{o}=0.1, \tau_{n}=0.1, b_{o}=0.75, w_{i}=2.75, B=0.25, H=0.75, k=2.4, c=1, r=0.1$, $\lambda=\gamma=0.06, \alpha=0.3, \mu=1, \eta=0.1, q_{o}=0.76, \boldsymbol{q}_{u}=\mathbf{0 . 8 6}\left(\boldsymbol{T}=\mathbf{0 . 5}, b_{u}=0.5\right.$ or $\left.T=0.65, \boldsymbol{b}_{u}=\mathbf{0 . 7 5}\right)$

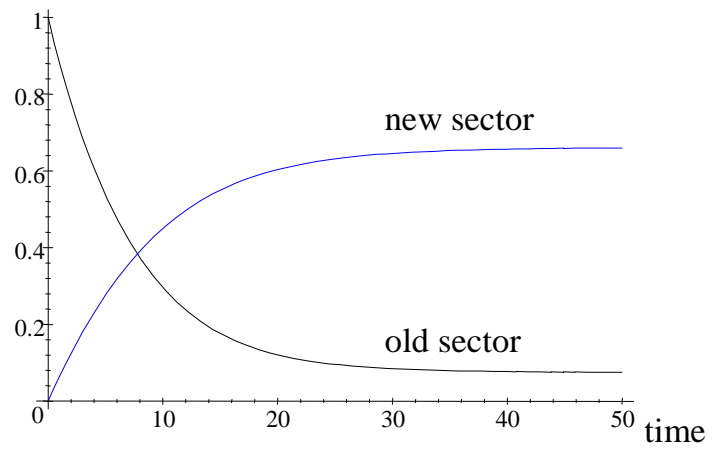

Figure 3.19 Old and new sector employment

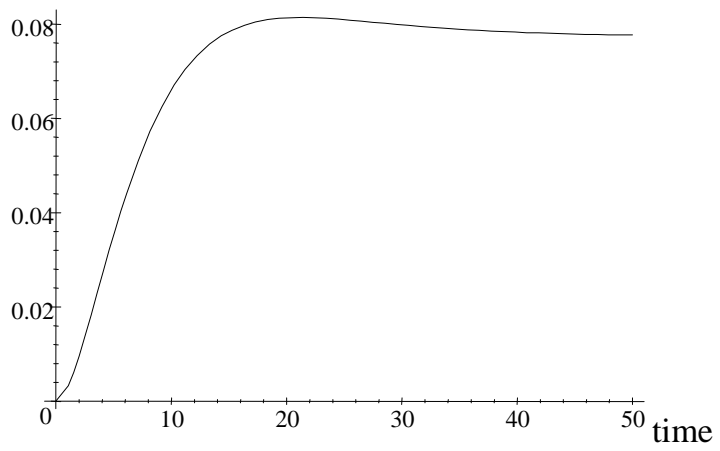

Figure 3.21 Informal sector employment (full-time)

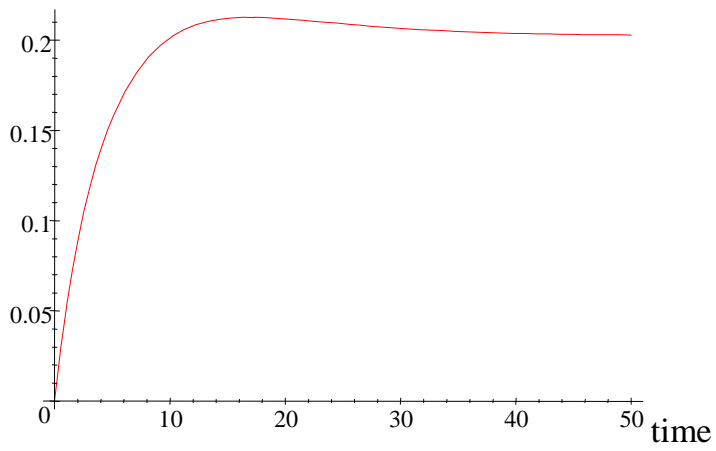

Figure 3.20 Unemployment rate

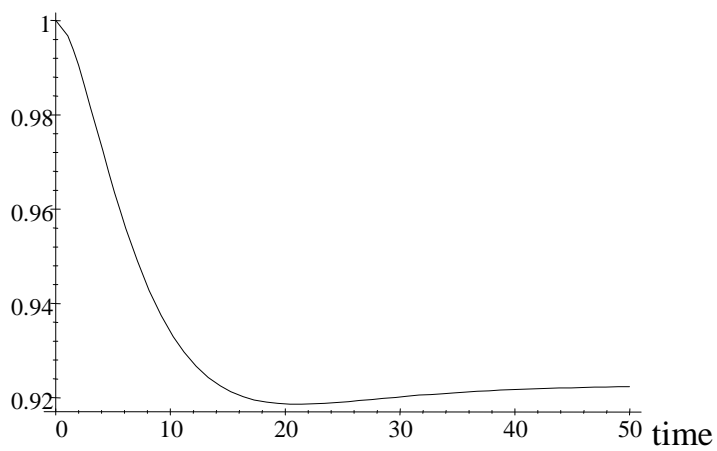

Figure 3.22 Participation rate

The set of parameters: $w_{o}=1, \tau_{o}=0.1, \tau_{n}=0.1, b_{o}=0.75, w_{i}=2.75, B=0.25, H=0.75, k=2.4, c=1, r=0.1$, $\lambda=\gamma=0.06, \alpha=0.3, \mu=1, \eta=0.1, q_{o}=0.76, \boldsymbol{q}_{u}=\mathbf{0 . 1 4}\left(T=0.65, \boldsymbol{b}_{u}=\mathbf{0 . 1}\right)$

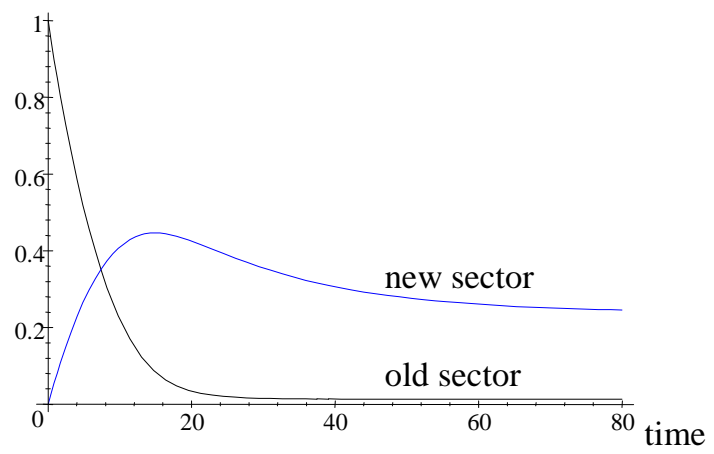

Figure 3.23 Old and new sector employment

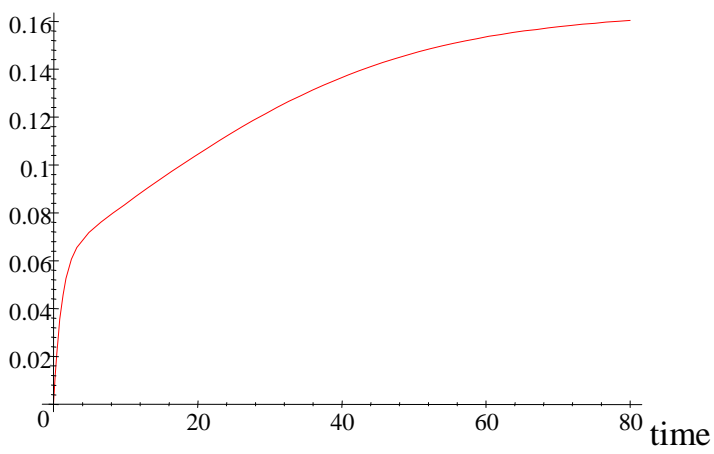

Figure 3.24 Unemployment rate 


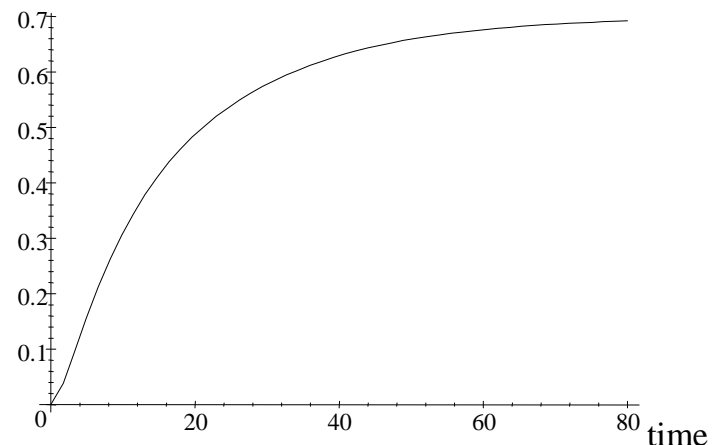

Figure 3.25 Informal sector employment (full-time)

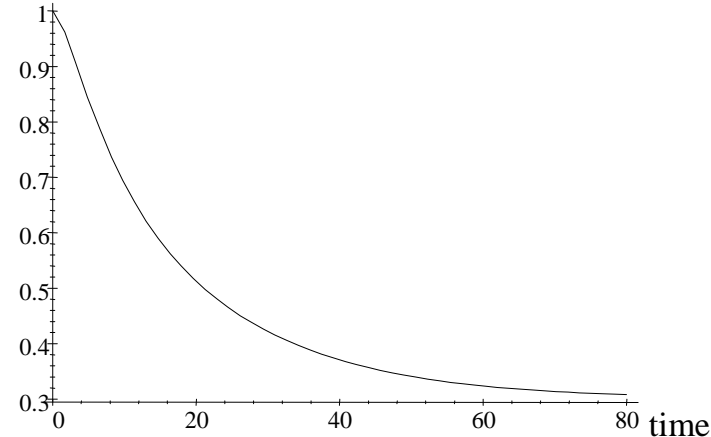

Figure 3.26 Participation rate

The set of parameters: $w_{o}=1, \tau_{o}=0.1, \tau_{n}=0.1, b_{o}=0.75, b_{u}=0.5, w_{i}=2.75, B=0.25, H=0.75, T=0.65, k=2.4$, $c=1, r=0.1, \lambda=\gamma=0.06, \alpha=0.9, \mu=1, \eta=0.1, q_{u}=0.63, q_{o}=0.76$

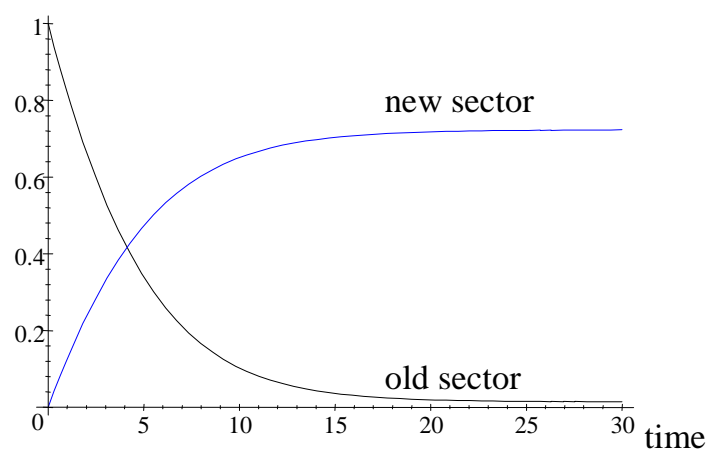

Figure 3.27 Old and new sector employment

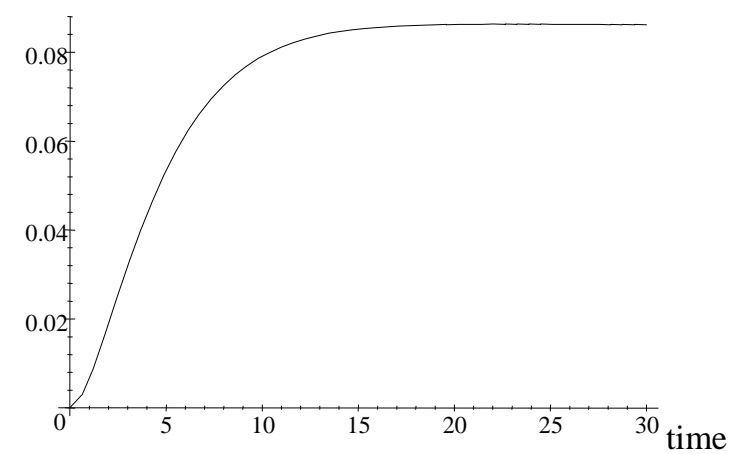

Figure 3.29 Informal sector employment (full-time)

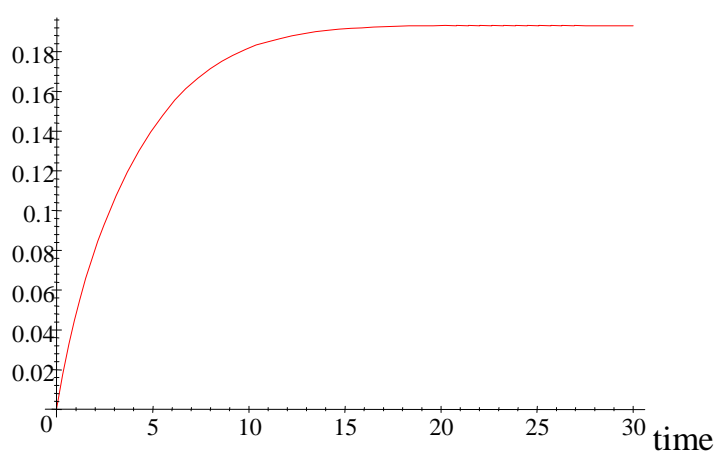

Figure 3.28 Unemployment rate

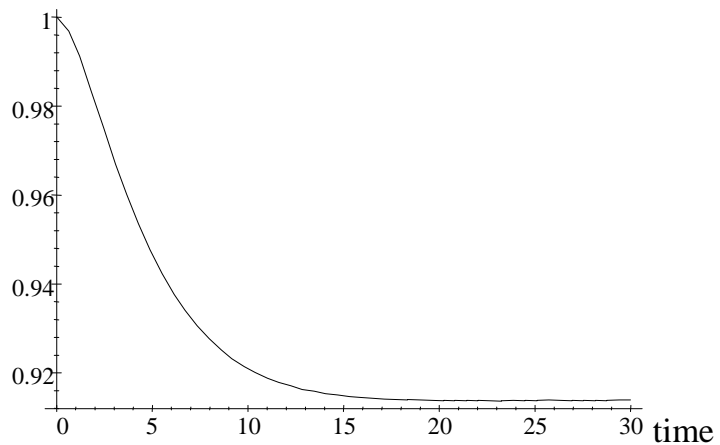

Figure 3.30 Participation rate 
The set of parameters: $w_{o}=1, \tau_{o}=0.1, \tau_{\boldsymbol{n}}=\mathbf{0 . 2}, b_{o}=0.75, b_{u}=0.5, w_{i}=2.75, B=0.25, H=0.75, T=0.65$, $k=2.4, c=1, r=0.1, \lambda=\gamma=0.06, \alpha=0.3, \mu=1, \eta=0.1, q_{u}=0.63, q_{o}=0.76$

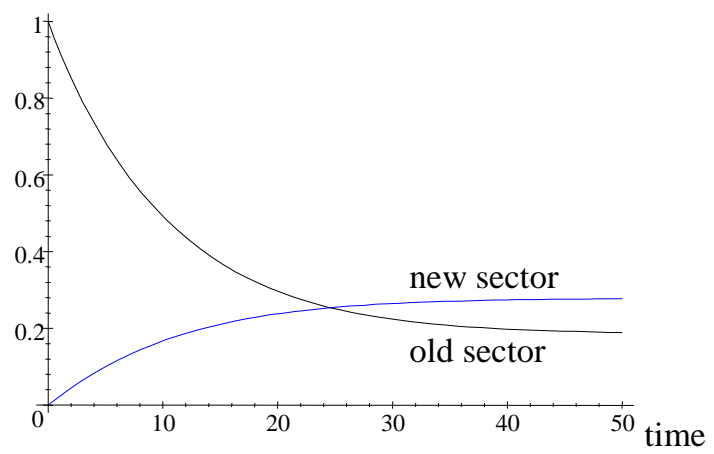

Figure 3.31 Old and new sector employment

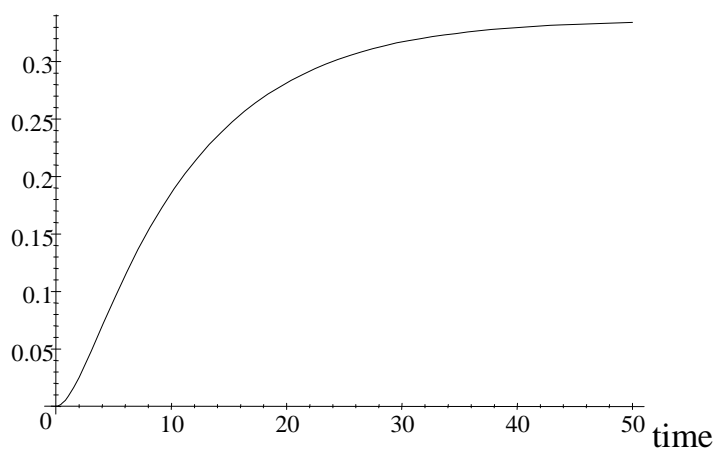

Figure 3.33 Informal sector employment (full-time)

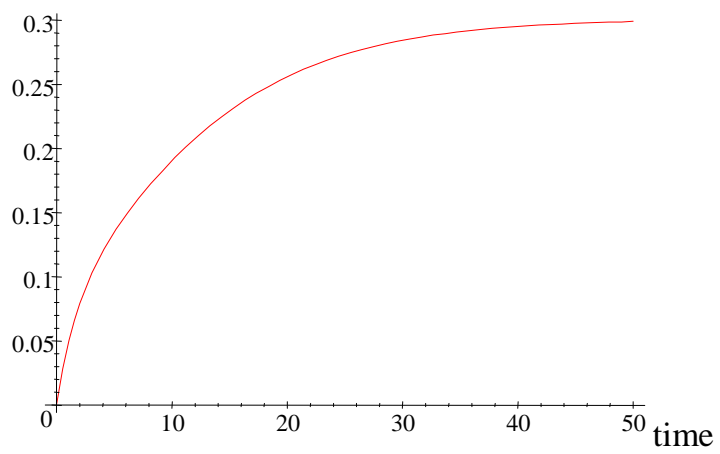

Figure 3.32 Unemployment rate

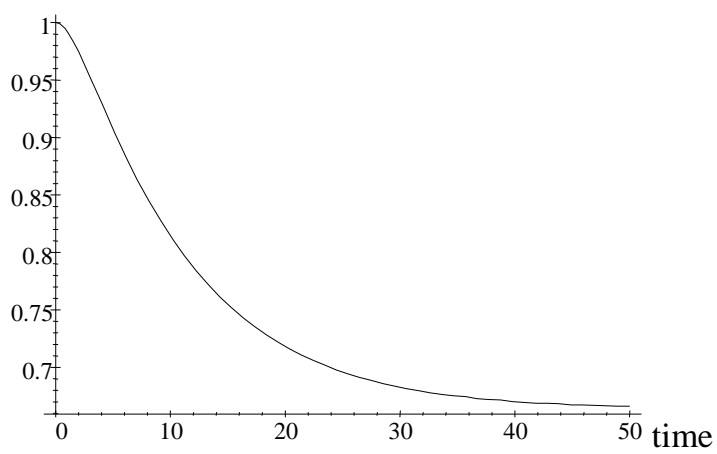

Figure 3.34 Participation rate

The set of parameters: $w_{o}=1, \tau_{o}=0.1, \tau_{n}=0.1, \boldsymbol{b}_{\boldsymbol{o}}=\mathbf{1}, b_{u}=0.5, w_{i}=2.75, B=0.25, H=0.75, T=0.65, k=2.4$, $c=1, r=0.1, \lambda=\gamma=0.06, \alpha=0.3, \mu=1, \eta=0.1, q_{u}=0.63, \boldsymbol{q}_{o}=\mathbf{0 . 6 8}$

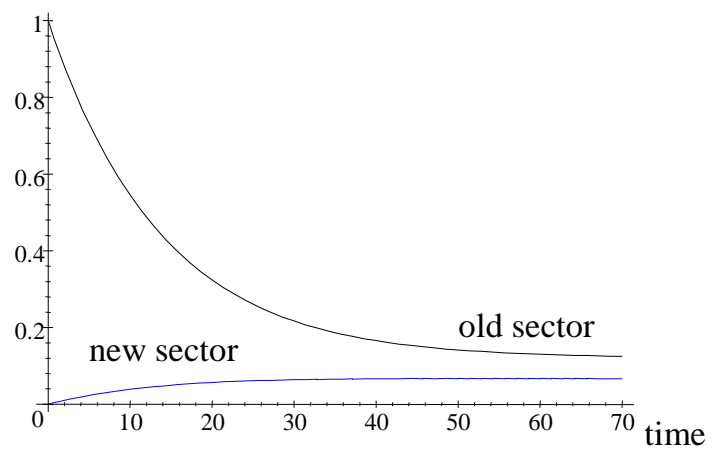

Figure 3.35 Old and new sector employment

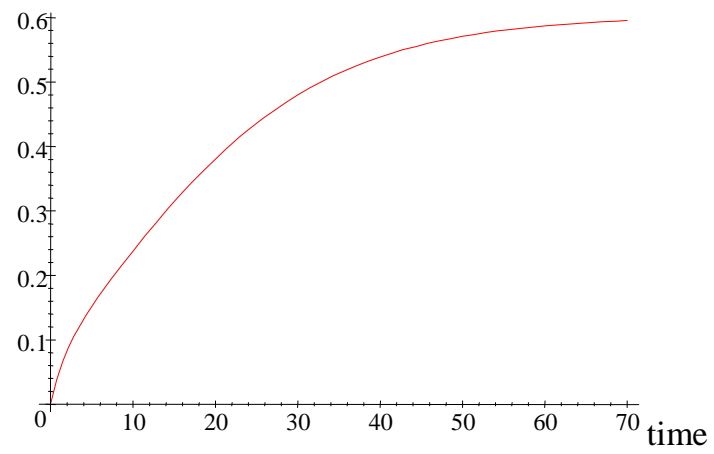

Figure 3.36 Unemployment rate 


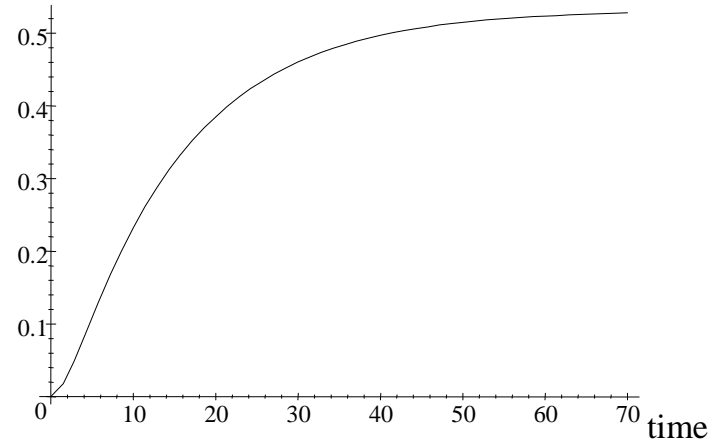

Figure 3.37 Informal sector employment (full-time)

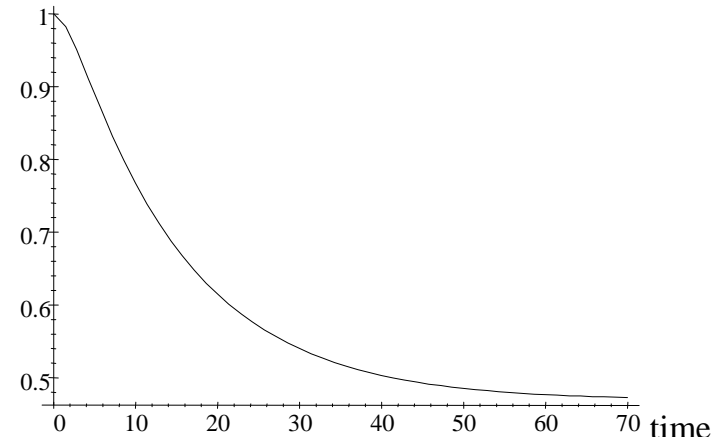

Figure 3.38 Participation rate

The benchmark set of parameters: $w_{o}=1, \tau_{o}=0.1, \tau_{n}=0.1, b_{o}=0.75, b_{u}=0.5, w_{i}=2.75, B=0.25, H=0.75$, $T=0.65, k=2.4, c=1, r=0.1, \lambda=\gamma=0.06, \alpha=0.3, \mu=1, \eta=0.1, q_{u}=0.63, q_{o}=0.76$

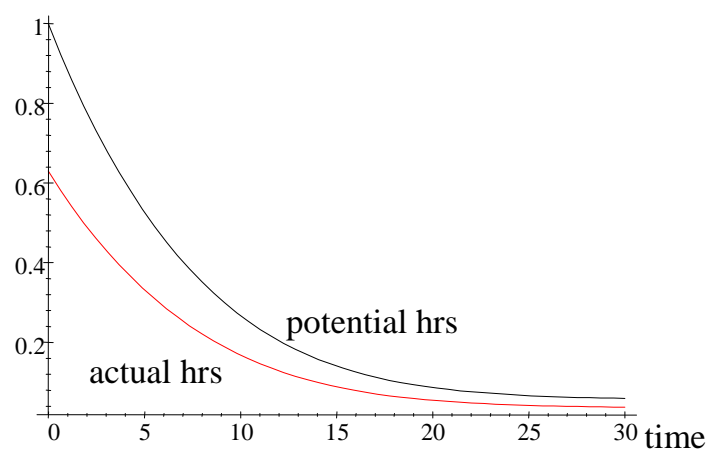

Figure 3.39 Potential and actual hours in the old sector

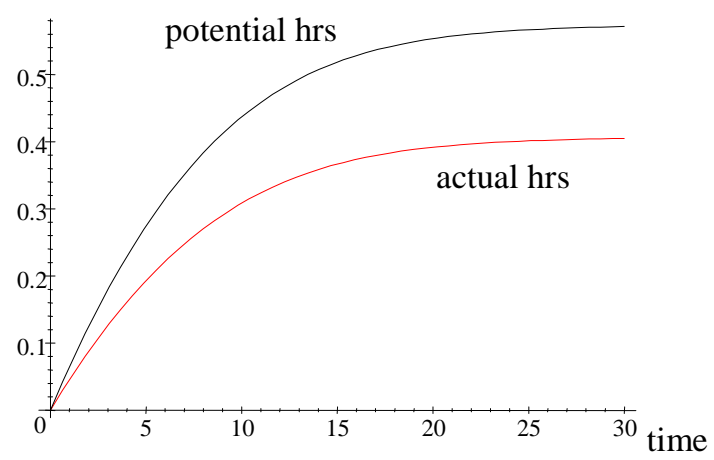

Figure 3.40 Potential and actual hours in the new sector

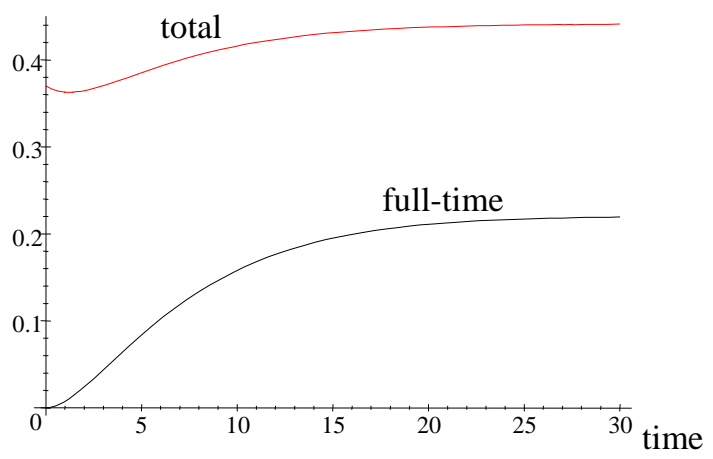

Figure 3.41 Total informal hours and hours of full-time informal workers 
The set of parameters: $w_{o}=1, \tau_{o}=0.1, \tau_{n}=0.1, \boldsymbol{b}_{\boldsymbol{o}}=\mathbf{1}, b_{u}=0.5, w_{i}=2.75, B=0.25, H=0.75, T=0.65, k=2.4$, $c=1, r=0.1, \lambda=\gamma=0.06, \alpha=0.3, \mu=1, \eta=0.1, q_{u}=0.63, q_{o}=\mathbf{0 . 6 8}$

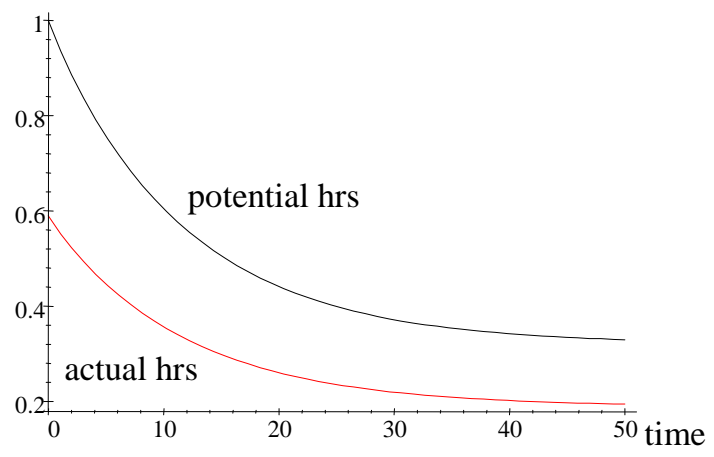

Figure 3.42 Potential and actual hours in the old sector

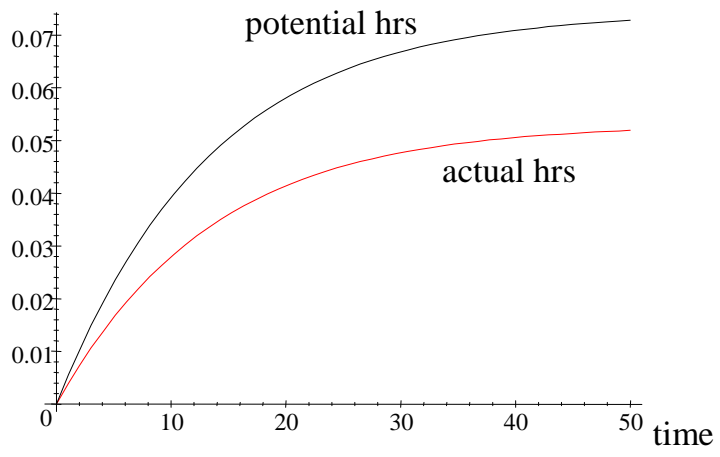

Figure 3.43 Potential and actual hours in the new sector

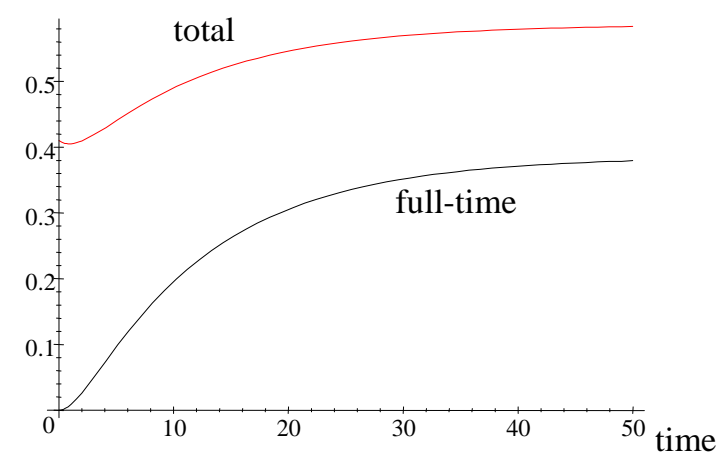

Figure 3.44 Total informal hours and hours of full-time informal workers

The set of parameters: $w_{o}=1, \tau_{o}=0.1, \tau_{n}=0.1, b_{o}=0.75, b_{u}=0.5, w_{i}=2.75, \boldsymbol{B}=\mathbf{0 . 5}, H=0.75, T=0.65, k=2.4$, $c=1, r=0.1, \lambda=\gamma=0.06, \alpha=0.3, \mu=1, \eta=0.1, q_{u}=0.63, \boldsymbol{q}_{o}>1$

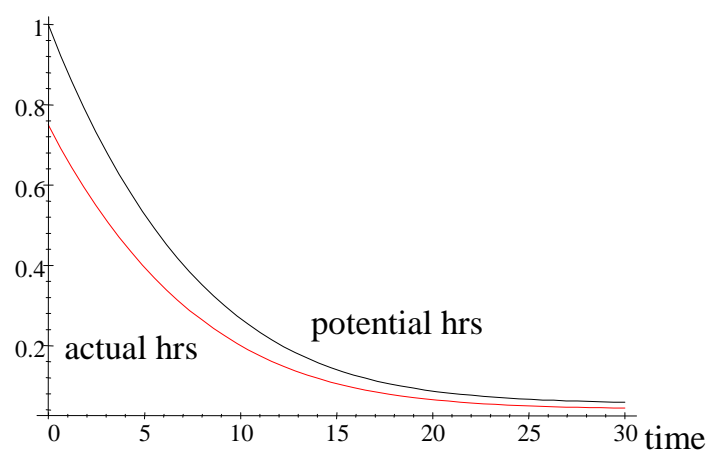

Figure 3.45 Potential and actual hours in the old sector

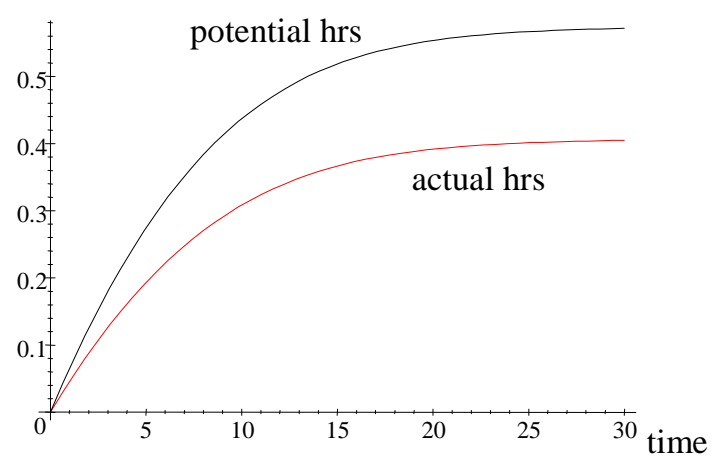

Figure 3.46 Potential and actual hours in the new sector 


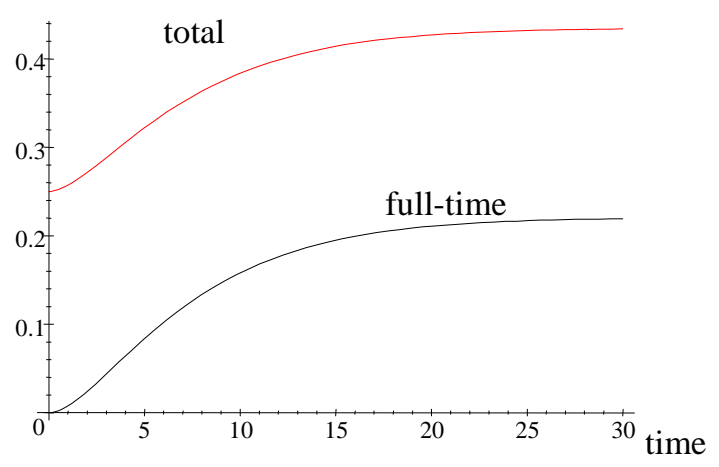

Figure 3.47 Total informal hours and hours of full-time informal workers

The set of parameters: $w_{o}=1, \tau_{o}=0.1, \tau_{n}=0.1, b_{o}=0.75, w_{i}=2.75, B=0.25, H=0.75, k=2.4, c=1, r=0.1$, $\lambda=\gamma=0.06, \alpha=0.3, \mu=1, \eta=0.1, q_{o}=0.76, \boldsymbol{q}_{u}=\mathbf{0 . 8 6}\left(\boldsymbol{T}=\mathbf{0 . 5}, b_{u}=0.5\right)$

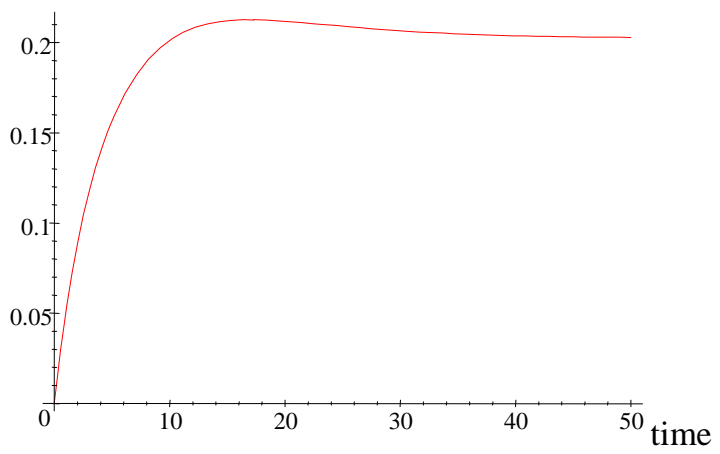

Figure 3.48 Unemployment rate

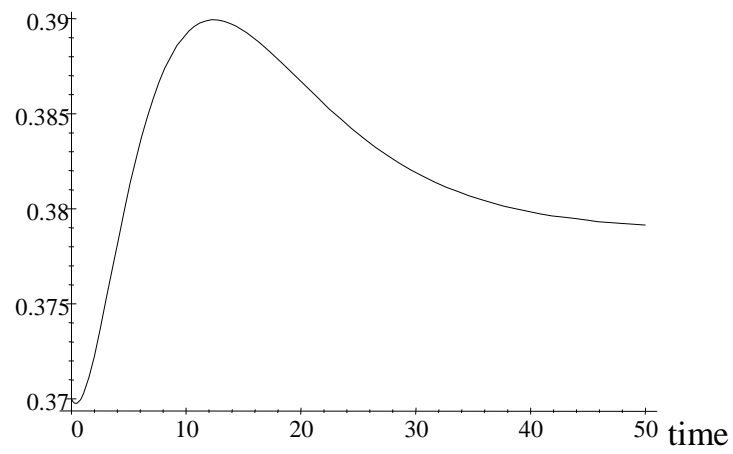

Figure 3.49 Total informal hours

The set of parameters: $w_{o}=1, \tau_{o}=0.1, \tau_{n}=0.1, b_{o}=0.75, w_{i}=2.75, B=0.25, H=0.75, k=2.4, c=1, r=0.1$, $\lambda=\gamma=0.06, \alpha=0.3, \mu=1, \eta=0.1, q_{o}=0.76, \boldsymbol{q}_{u}=\mathbf{0 . 8 6}\left(T=0.65, \boldsymbol{b}_{u}=\mathbf{0 . 7 5}\right)$

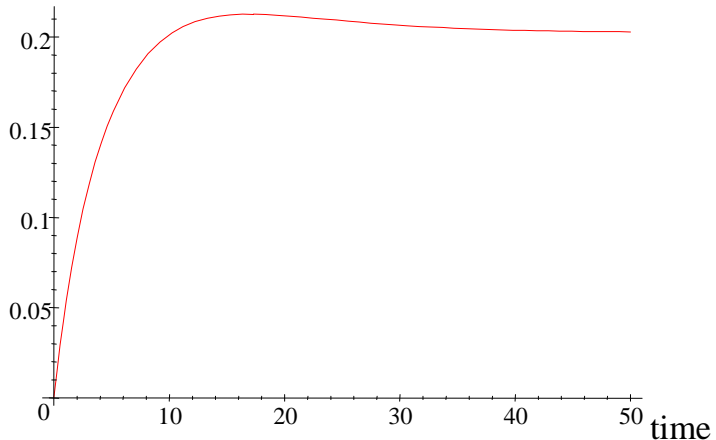

Figure 3.50 Unemployment rate

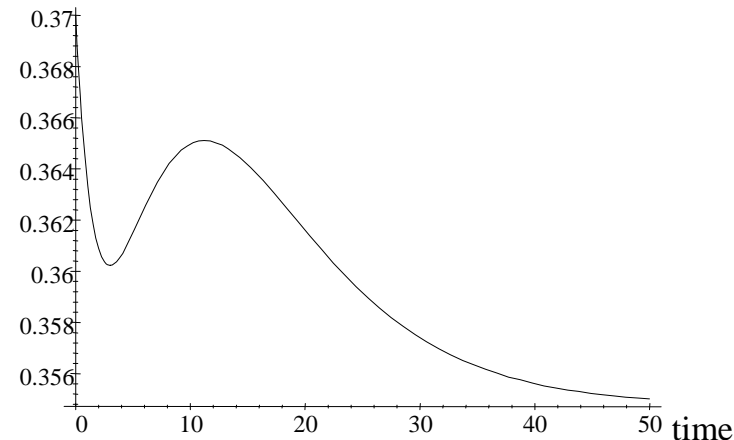

Figure 3.51 Total informal hours 
The benchmark set of parameters: $w_{o}=1, \tau_{o}=0.1, b_{o}=0.75, b_{u}=0.5, w_{i}=2.75, B=0.25, H=0.75, T=0.65$, $k=2.4, c=1, r=0.1, \lambda=\gamma=0.06, \alpha=0.3, \mu=1, \eta=0.1, q_{u}=0.63, q_{o}=0.76$

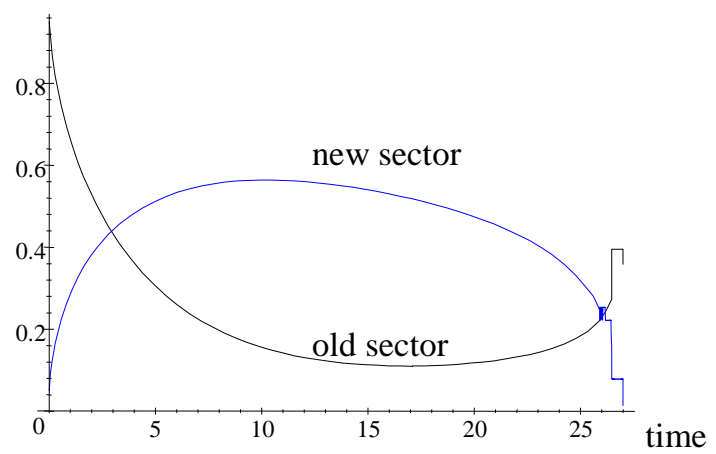

Figure 3.52 Old and new sector employment

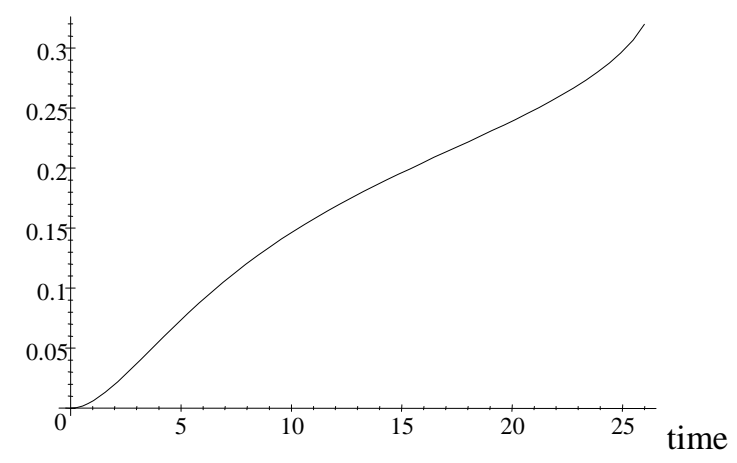

Figure 3.54 Informal sector employment (full-time)

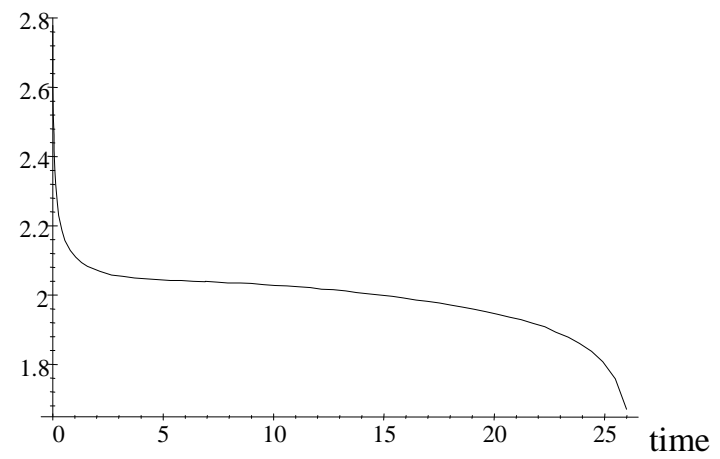

Figure 3.56 Wage in the new sector

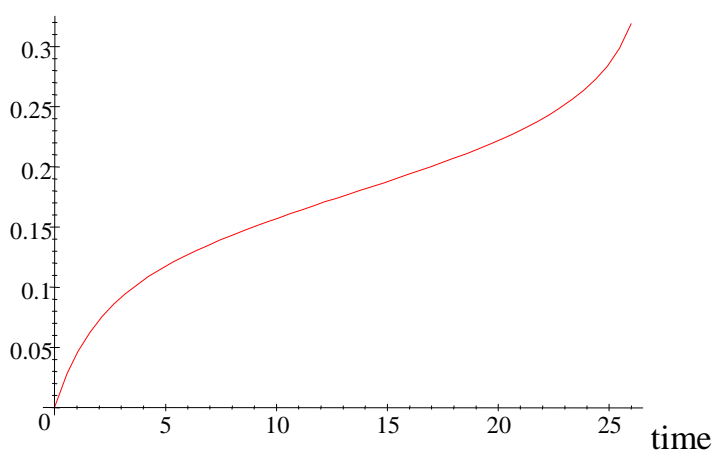

Figure 3.53 Unemployment rate

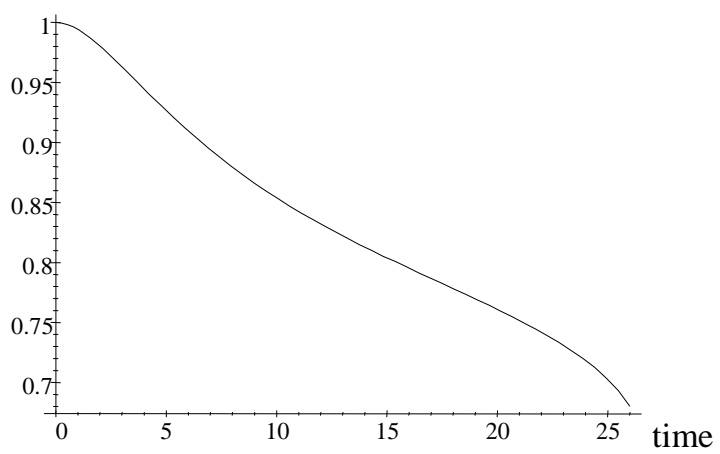

Figure 3.55 Participation rate

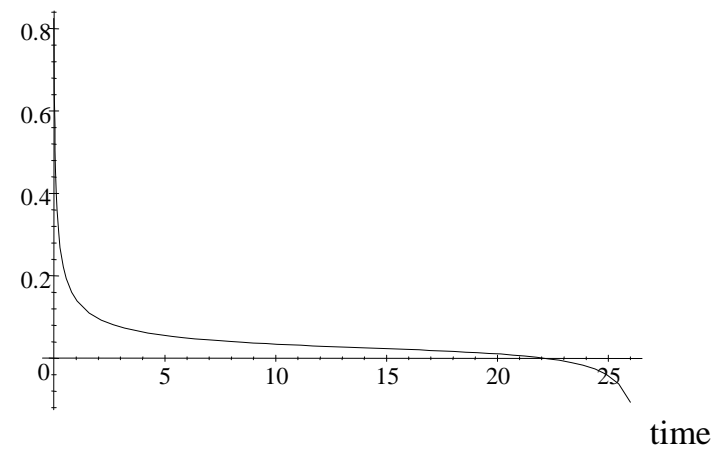

Figure 3.57 Job creation in the new sector

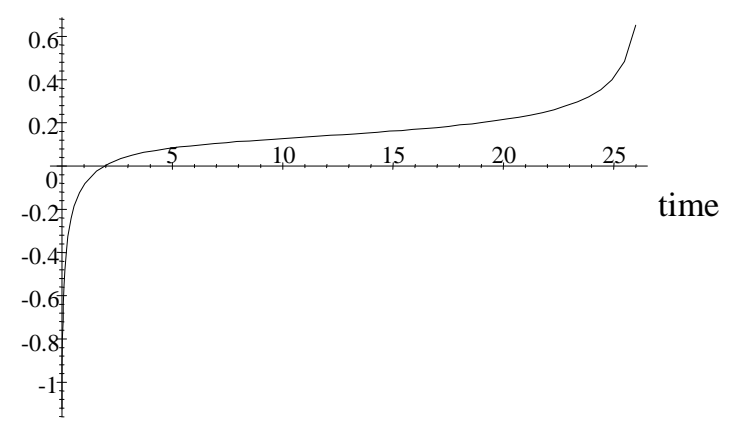

Figure 3.58 New sector tax rate 
The set of parameters: $w_{o}=1, \tau_{o}=0.1, b_{o}=0.75, b_{u}=0.5, w_{i}=2.75, B=0.25, H=0.75, T=0.65, k=2.4, c=1$, $r=0.1, \lambda=\gamma=0.06, \alpha=0.3, \mu=1, \eta=\mathbf{0 . 5}, q_{u}=0.63, q_{o}=0.76$

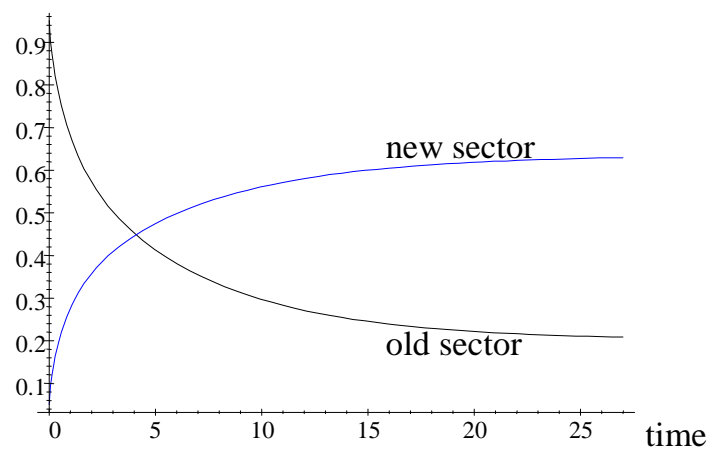

Figure 3.59 Old and new sector employment

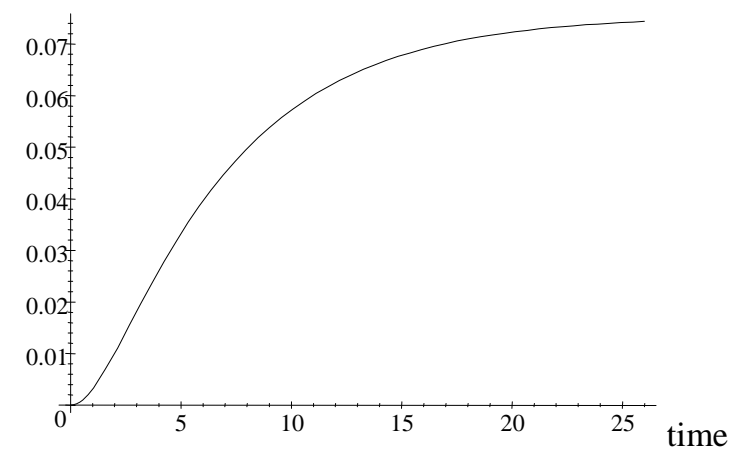

Figure 3.61 Informal sector employment (full-time)

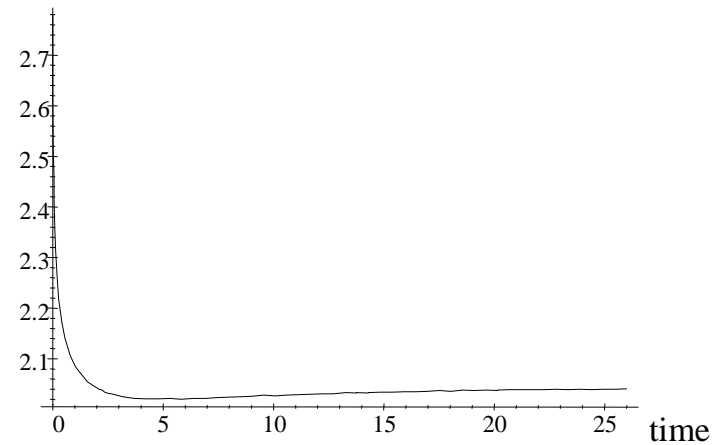

Figure 3.63 Wage in the new sector

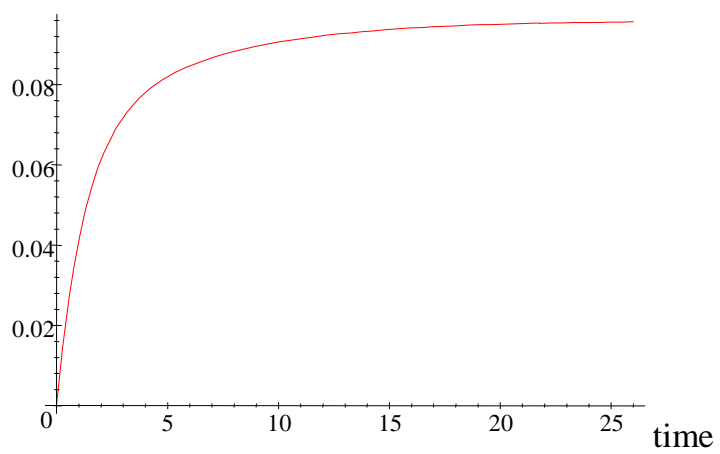

Figure 3.60 Unemployment rate

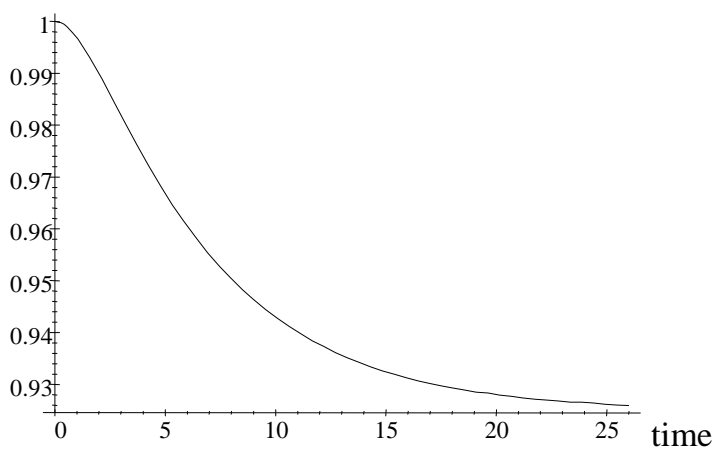

Figure 3.62 Participation rate

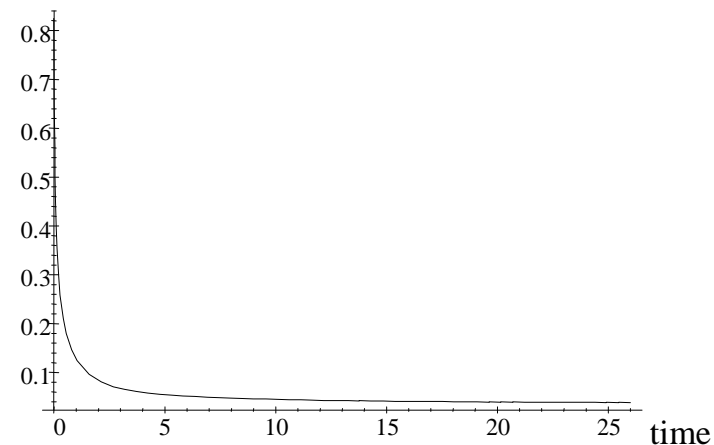

Figure 3.64 Job creation in the new sector

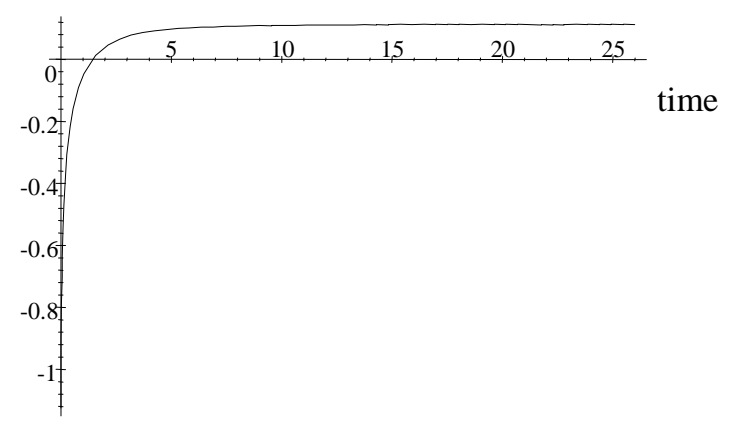

Figure 3.65 New sector tax rate 
The set of parameters: $w_{o}=1, \tau_{o}=0.1, b_{o}=0.75, b_{u}=0.5, w_{i}=2.75, B=0.25, H=0.75, T=0.65, k=2.4, c=1$, $r=0.1, \lambda=\gamma=0.06, \alpha=0.3, \mu=1, \boldsymbol{\eta}=\mathbf{0 . 9}, q_{u}=0.63, q_{o}=0.76$

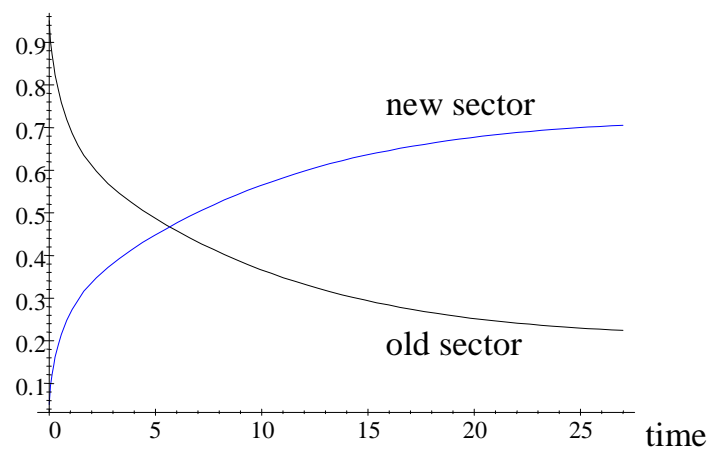

Figure 3.66 Old and new sector employment

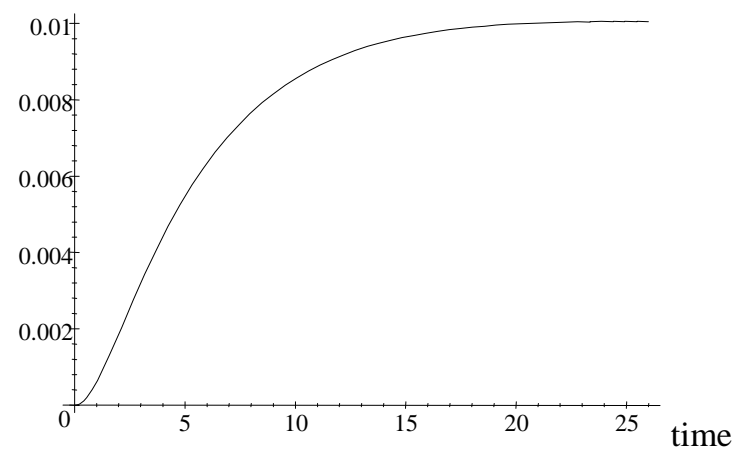

Figure 3.68 Informal sector employment (full-time)

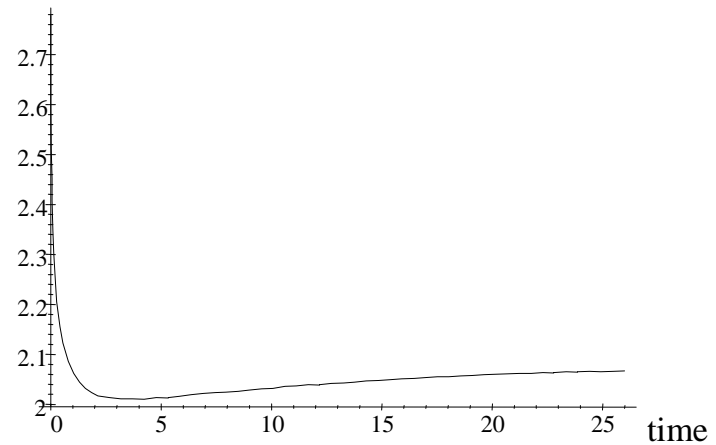

Figure 3.70 Wage in the new sector

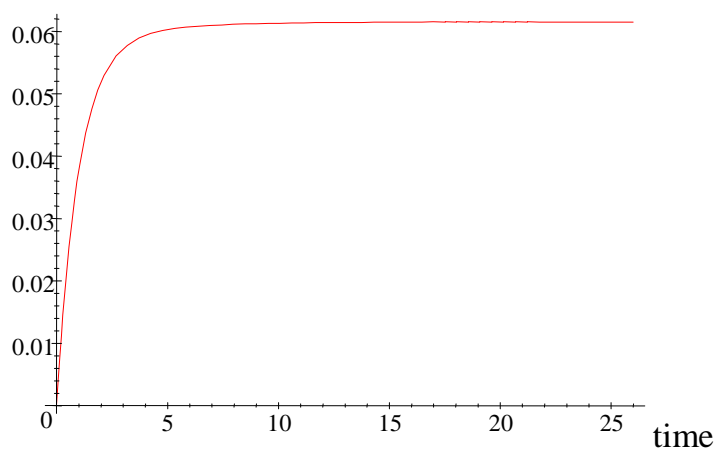

Figure 3.67 Unemployment rate

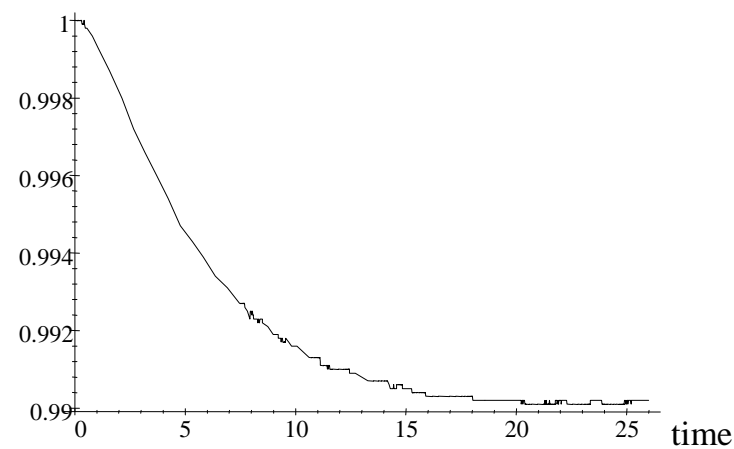

Figure 3.69 Participation rate

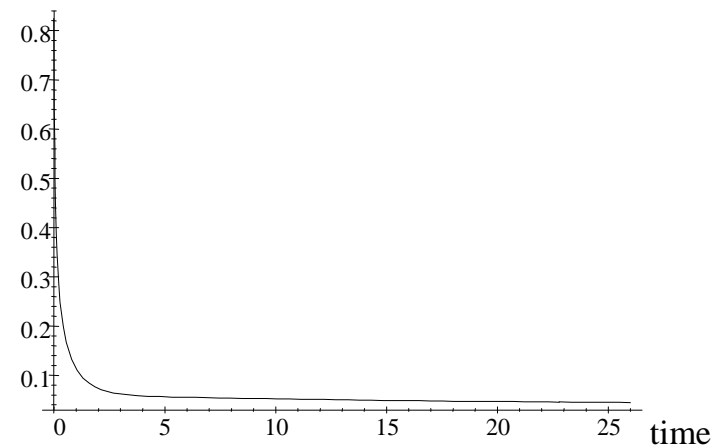

Figure 3.71 Job creation in the new sector

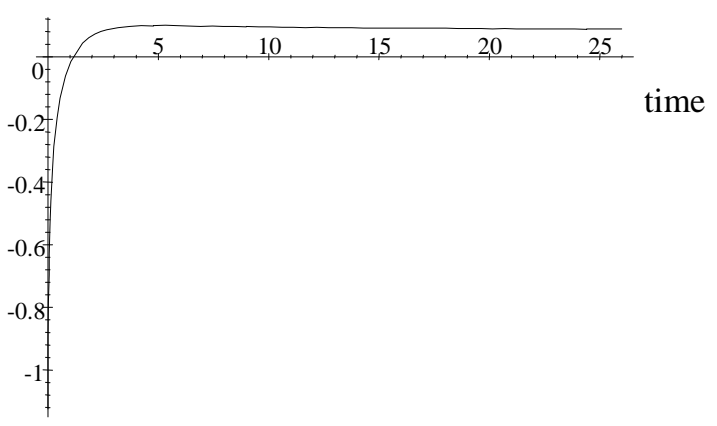

Figure 3.72 New sector tax rate 


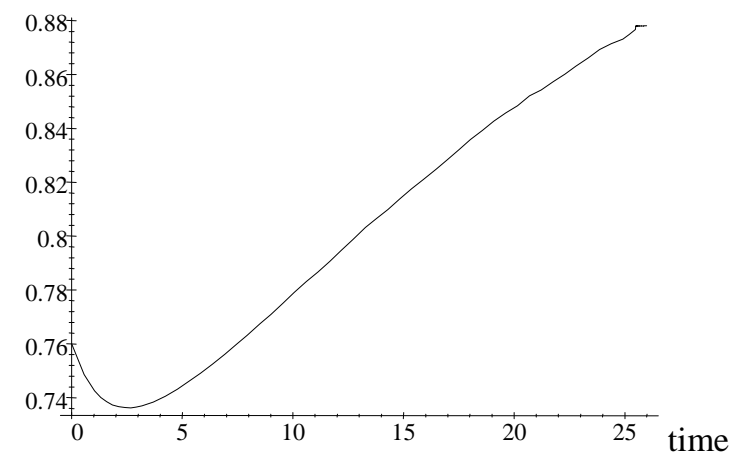

Figure 3.73 Evolution of output I

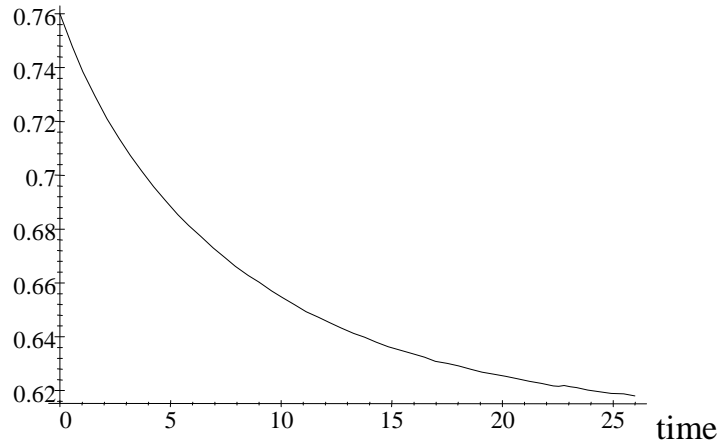

Figure 3.74 Evolution of output II

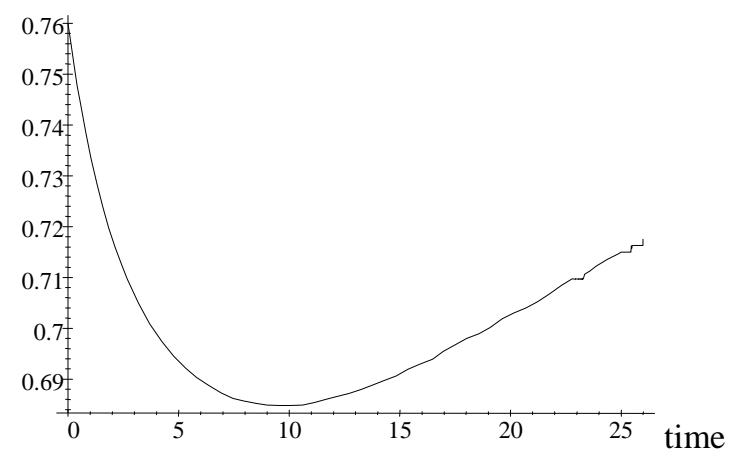

Figure 3.75 Evolution of output III 
Appendix 2 (Tables)

Table 1. The ratio of hidden economy to the official GDP in some CEE countries.

\begin{tabular}{|l|c|c|c|c|c|c|c|}
\hline Country & $\mathbf{1 9 8 9}$ & $\mathbf{1 9 9 0}$ & $\mathbf{1 9 9 1}$ & $\mathbf{1 9 9 2}$ & $\mathbf{1 9 9 3}$ & $\mathbf{1 9 9 4}$ & $\mathbf{1 9 9 5}$ \\
\hline Bulgaria & 23.3 & 28.9 & 33.7 & 34.1 & 34.0 & 35.9 & 34.0 \\
\hline Croatia & n.a. & n.a. & n.a. & 38.6 & 39.3 & 40.4 & 36.0 \\
\hline $\begin{array}{l}\text { Czech } \\
\text { Republic }\end{array}$ & 21.7 & 24.3 & 31.7 & 31.8 & 27.1 & 24.5 & 21.8 \\
\hline Hungary & 24.6 & 25.6 & 31.1 & 33.2 & 33.6 & 31.4 & 29.6 \\
\hline Poland & 22.9 & 31.6 & 32.5 & 31.7 & 31.1 & 27.9 & 23.9 \\
\hline Romania & 17.3 & 24.4 & 36.9 & 39.0 & 37.5 & 34.2 & 28.3 \\
\hline Russia & n.a. & n.a. & n.a. & $\mathbf{3 7 . 8}$ & $\mathbf{3 6 . 0}$ & $\mathbf{3 9 . 1}$ & $\mathbf{3 9 . 2}$ \\
\hline Slovakia & 21.7 & 24.3 & 32.0 & 32.0 & 34.1 & 32.0 & 28.4 \\
\hline Slovenia & 26.7 & 26.8 & 27.4 & 31.2 & 28.4 & 25.0 & 22.7 \\
\hline Ukraine & n.a. & n.a. & 28.1 & 37.4 & 47.0 & 54.6 & 52.8 \\
\hline
\end{tabular}

Source: Lackó (2000).

\section{Appendix 3 (Time Allocation Model)}

In this appendix we repeat the description of the time-allocation model from the text, derive the threshold levels for the individual's propensity to informal activity and find restricting conditions on parameters. We also make some comparison between the key threshold levels for the old, new sectors and unemployment.

\section{The Worker's Choice in the Old Sector}

The worker in the old sector maximises utility

$$
U^{q}=\ln \left(1+W_{o}\left(h_{o}\right)+B_{o}\left(h_{o}\right)\right)+q \ln \left(1+w_{i}\left(1-h_{o}\right)\right) \text {, }
$$

where $W_{o}\left(h_{o}\right)=\left\{\begin{array}{l}w_{o}, \text { if } h_{o} \geq H \\ 0, \text { if } h_{o}<H\end{array}, B_{o}\left(h_{o}\right)=\left\{\begin{array}{l}b_{o}, \text { if } B \leq h_{o} \leq 1 \\ 0, \text { if } 0 \leq h_{o}<B\end{array}\right.\right.$ and $B<H$.

There can be the three cases (see the main text):

1) Workers choose $h_{o}=0$, and enjoy utility $U_{1}=q \ln \left(1+w_{i}\right)$.

2) Workers choose $h_{o}=B$, the maximum utility is achieved at $U_{2}=\ln \left(1+b_{o}\right)+q \ln \left(1+w_{i}(1-B)\right)$.

3) Workers choose $h_{o}=H$, and obtain utility $U_{3}=\ln \left(1+w_{o}+b_{o}\right)+q \ln \left(1+w_{i}(1-H)\right)$.

All workers are different with respect to $q$. Let us derive the values of $q$ that determine the range of workers who will supply either $0, B$ or $H$ hours in the old sector.

Suppose, first, that $U_{1}<U_{2}$. Then $q \ln \left(1+w_{i}\right)<\ln \left(1+b_{o}\right)+q \ln \left(1+w_{i}(1-B)\right)$ or

$$
q<q_{1}=\frac{\ln \left(1+b_{o}\right)}{\ln \left(1+w_{i}\right)-\ln \left(1+w_{i}(1-B)\right)} .
$$

Suppose now that $U_{2}<U_{3}$. Then

$$
\begin{aligned}
& \ln \left(1+b_{o}\right)+q \ln \left(1+w_{i}(1-B)\right)<\ln \left(1+w_{o}+b_{o}\right)+q \ln \left(1+w_{i}(1-H)\right) \text { or } \\
& q<q_{2}=\frac{\ln \left(1+w_{o}+b_{o}\right)-\ln \left(1+b_{o}\right)}{\ln \left(1+w_{i}(1-B)\right)-\ln \left(1+w_{i}(1-H)\right)} .
\end{aligned}
$$

Finally, if $U_{1}<U_{3}$ then $q \ln \left(1+w_{i}\right)<\ln \left(1+w_{o}+b_{o}\right)+q \ln \left(1+w_{i}(1-H)\right)$ or

$$
q<q_{3}=\frac{\ln \left(1+w_{o}+b_{o}\right)}{\ln \left(1+w_{i}\right)-\ln \left(1+w_{i}(1-H)\right)} .
$$

Different values of parameters $\left(w_{o}, b_{o}, w_{i}, B, H\right)$ make $q_{1}, q_{2}$ and $q_{3}$ correspond to each other in different way, as noted in the main text. Thus, different solutions can be obtained for the same level of $q$, depending on a particular set of parameters. To see this, let us consider the following case. 
Assume that $w_{o}$ is fixed at $1-$ an innocuous normalisation. Let $b_{o}=0.5$. Later we will look as well at the effect of higher values of $b_{o}$. However, only further empirical research can clarify the actual value of $b_{o}$. Now, let us put $H=0.75 ; H$ is less than 1 by the normalisation of all working time and is definitely greater than 0.5 in reality (otherwise the old sector would have been a batch of idle dead enterprises). So we just take the average of these two values. We shall see that the most important thing for our analysis is the relative magnitude of $B$ and $H$ - so, ascribing a particular value to $H$ is somewhat innocuous. Finally, we put $w_{i}=2.75$. Kolev (1998) estimates the hourly wage differential between the informal and formal sector in Russia to be about 4.1 in 1995 for both men and women. Roshchin and Razumova (1999) find it to be 4.4 for any secondary job and 2.2 for not casual secondary jobs for both men and women in 1998. In the model we assume that the informal sector comprises not only informal entrepreneurship but also home production (e.g. growing its own crop). It is known (see, e.g. Gronau, 1977, 1980) that women (especially married) spend more time at home, and, apparently, they are main participants in home production. Roshchin and Razumova (1999) evaluate the informal-formal wage differential for any secondary job to be 2.75 for females. So, we take this number. ${ }^{54}$

Having ascribed the above values to the parameters of the model we plot $q_{1}, q_{2}$ and $q_{3}$ as functions of $B$. Fig.2.1 shows the results.

We can see that constraints $q_{1}, q_{2}$ and $q_{3}$ determine 6 possible regions on the left to vertical line $B=H$ (by definition $B<H$, so we consider only a left semiplane ${ }^{55}$ ).

In region $1 q<q_{1}, q<q_{2}$ and $q<q_{3}$, which implies $U_{1}<U_{2}<U_{3}$.

In region $2 q>q_{1}, q<q_{2}$ and $q<q_{3}$, which implies $U_{2}<U_{1}<U_{3}$.

In region $3 q>q_{1}, q<q_{2}$ and $q>q_{3}$, which implies $U_{2}<U_{3}<U_{1}$.

In region $4 q>q_{1}, q>q_{2}$ and $q>q_{3}$, which implies $U_{3}<U_{2}<U_{1}$.

In region $5 q<q_{1}, q>q_{2}$ and $q>q_{3}$, which implies $U_{3}<U_{1}<U_{2}$.

In region $6 q<q_{1}, q>q_{2}$ and $q<q_{3}$, which implies $U_{1}<U_{3}<U_{2}$.

So, workers whose $q$ 's fall into regions 1 and 2 will choose to supply to the old sector $h_{o}=H$ hours of labour; those whose $q$ 's are within regions 3 and 4 will not supply labour to the old sector at all and will prefer full time work in the informal economy; finally, those with $q$ 's such that conditions for regions 5 and 6 are met will supply $h_{o}=B$ hours of labour.

We are interested only in those values of $q$ that are in between 0 and $1 ; H$ must also be in between 0 and 1. These two constraints border the shadowed region (see Fig.2.1 to 2.6).

If the ratio $B / H$ is close enough to 1 (or $B$ is close enough to $H$ ), under the parameters' values we defined above, then all the workers will work in the old sector the minimum amount of time necessary to earn a positive wage: their $q$ 's will fall into regions 1 and 2 (Fig.2.1). The reasons for that are straightforward. The minimum informal income a worker gets while working in the old sector is $w_{i}(1-H)$. By deciding to work $B$ hours rather than $H$ the worker foregoes $w_{o}$ in the old sector and gains $w_{i}(H-B)$ in the informal sector. The closer is $B$ to $H$ the smaller is this additional premium in the shadow economy, $w_{i}(H-B)$, compared to the amount of money foregone, $w_{o}$.

If otherwise $B$ is rather far from $H$ and close to 0 then some workers will work for pay, and others will receive only benefits $b_{o}$. Nobody will prefer full-time work in the informal sector to moonlighting in the old sector (Fig.2.1).

If ceteris paribus the time constraint $H$ is even more slack then all the workers will spend as much time in the old sector as required to earn its wage together with fringe benefits (Fig.2.2). The reasons for such a choice are already familiar: the additional premium from work in the informal sector becomes not significant compared to the old sector wage.

If the monetary equivalent of fringe benefits is not that essential ( $b_{o}$ equals only $10 \%$ of the wage rate - Fig.2.3) then very low values of $B$ will give us the two categories of workers as for low

\footnotetext{
${ }^{54}$ In our model the official hourly wage in the old sector is $w_{o}$. However, the effective hourly rate for wage earners in the old sector is $\frac{w_{o}}{H}$. If $w_{i}=2.75$ then the wage differential between the effective rates is about 2.06. It still falls in the range of estimates reported by Roshchin and Razumova (1999) for women.

${ }^{55}$ Obviously, $q_{1}, q_{2}$ and $q_{3}$ are always positive in this semiplane.
} 
values of $B$ in Fig.2.1. For higher values of $B$, however, the workers will either work time $H$ (if their $q$ 's are in regions 1 and 2) or not work in the old sector at all (regions 3 and 4). Thus, they will not maintain access to fringe benefits if the latter are not significant and if minimum time constraints are quite tight. For some range of $B$ there will exist three ranges of $q$, i.e. there will be three categories of workers - those who work in the old sector for wages and benefits, those who work there for benefits only, and those who do not work there at all.

Again, by slackening more the time constraint $H$, the old sector attracts all possible categories of workers (with different $q$ 's) and they all work $H$ hours (Fig.2.4).

If the level of social (fringe) compensation $b_{o}$ is either comparable to the old sector wage (Fig.2.5) or even higher (Fig.2.6), the possible variants are as in Fig.2.1, since the restriction $q_{3}$ shifts up and is not binding.

The most likely situation that has been taking place in Russia may be that depicted in Fig.2.1, 2.5 or 2.6. That is, depending on the value of $B$ either all workers work for pay in the old sector, or there is a cohort who works for benefits only. In any case, there are no workers preferring full-time underground work. This situation as it can be seen from the figures is applicable to both medium and high levels of fringe benefits $b_{o}$. Otherwise, if benefits are low we end up in the situation shown in Fig.2.3. However, it has been argued in Section 1 that non-monetary benefits provided by Russian old sector firms have been quite large historically.

It can also be shown that for the reasonably large wage differential between the old and the informal sectors (when $w_{i} / w_{o}$ is up to 5.5) the case of Fig.2.1, 2.5 and 2.6 holds as well.

Then, $q_{2}<q_{3}<q_{1}$ holds if $B$ is small enough.

Now, $q_{1}>1$ iff $b_{o}>w_{i} \frac{B}{1+w_{i}(1-B)}$, which, apparently, holds for small $B$.

$q_{2}>1$ iff $b_{o}<\frac{w_{o}\left(1+w_{i}(1-H)\right)-w_{i}(H-B)}{w_{i}(H-B)}$. If $w_{o}=1$ as above the constraint becomes $b_{o}<\frac{\left(1+w_{i}(1-H)\right)}{w_{i}(H-B)}-1$, which never holds for high $H$ and small $B$.

Thus we have $0<q_{2}<1\left(q_{3}\right.$ is not essential here since in region 5 the solution to the utility maximisation problem is as in region 6) as a most likely variant. Then the labour supply of the individual in the old sector is

$$
h_{o}=\left\{\begin{array}{l}
B, \text { if } q_{2} \leq q \leq 1 \\
H, \text { if } 0 \leq q<q_{2}
\end{array}\right.
$$

and the indirect utility function is

$$
U_{o}^{q}=\left\{\begin{array}{l}
\ln \left(1+b_{o}\right)+q \ln \left(1+w_{i}(1-B)\right), \text { if } q_{2} \leq q \leq 1 \\
\ln \left(1+w_{o}+b_{o}\right)+q \ln \left(1+w_{i}(1-H)\right), \text { if } 0 \leq q<q_{2}
\end{array} .\right.
$$

\section{The Worker's Choice in the New Sector}

The worker in the new sector maximises utility

$$
U^{q}=\ln \left(1+w_{n} h_{n}\right)+q \ln \left(1+w_{i}\left(1-h_{n}\right)\right) \text {. }
$$

Assuming the interior solution, F.O.C. gives us $h_{n}=\frac{w_{n}\left(1+w_{i}\right)-q w_{i}}{w_{n} w_{i}(1+q)}$. For this solution we have $\frac{\partial h_{n}}{\partial w_{n}}=\frac{q}{w_{n}^{2}(1+q)}>0, \frac{\partial h_{n}}{\partial w_{i}}=-\frac{1}{(1+q) w_{i}^{2}}<0, \frac{\partial h_{n}}{\partial q}=-\frac{w_{n}\left(1+w_{i}\right)+w_{i}}{(1+q)^{2} w_{n} w_{i}}<0$, providing that $q$ is less than 1 and non-negative.

The expression for $h_{n}$ above is correct if $q$ falls into some range of values. By definition $h_{n}$ should be in between 0 and 1 . We have $h_{n}<0$ iff

$$
q>q_{1}=w_{n} \frac{\left(1+w_{i}\right)}{w_{i}},
$$




$$
\begin{aligned}
& \text { and } h_{n}>1 \text { iff } \\
& q<q_{2}=w_{n} \frac{1}{w_{i}\left(1+w_{n}\right)} .
\end{aligned}
$$

Holding other parameters fixed, $q_{1}$ and $q_{2}$ as functions of $w_{n}$ give us a ray and a curve, both starting at the origin. In Fig.2.7 and 2.8 we can see that for two different values of the informal wage, $w_{i}, q_{2}$ is always less than $q_{1}$. The ray and the curve have only one crosspoint at the origin and define three regions. The shadowed region shows the acceptable values of $q$.

Thus, the labour supply of the worker in the new sector is defined as

$$
h_{n}=\left\{\begin{array}{l}
0, \text { if } q_{1} \leq q(\text { corner solution }- \text { region } 3) \\
\left.\frac{w_{n}\left(1+w_{i}\right)-q w_{i}}{w_{n} w_{i}(1+q)}, \text { if } q_{2} \leq q<q_{1} \text { (interior solution - region } 2\right) . \\
1, \text { if } 0 \leq q<q_{2}(\text { corner solution - region } 1)
\end{array}\right.
$$

Fig.2.7 and 2.8 show that if the wage in the new sector accounts for at least about $50 \%$ of the informal sector wage then there will be only workers who work either full time in the new sector (workers with $q$ 's within region 1) or moonlight while working there (workers with $q$ 's within region 2). However, there will be no workers preferring full-time underground work to moonlighting or fulltime work in the new sector (workers with $q$ 's within region 3).

Evidence from Russia shows that the wage in the new sector is rather high (see, e.g., Fig.1.6) and amounts to about twice the old sector wage. Thus, one can argue that the most plausible situation in Russia is when workers end up only in regions 1 and 2.

Then $q_{1}>1$ since $w_{n}>\frac{w_{i}}{\left(1+w_{i}\right)\left(1-\tau_{n}\right)}$.

At the same time, $q_{2}<1$ since $w_{n}>-\frac{w_{i}}{\left(w_{i}-1\right)\left(1-\tau_{n}\right)}$ always holds provided $w_{i}>1$, i.e. the informal wage is greater than the wage rate in the old sector. The latter inequality is, obviously, valid as the evidence suggests.

Then $0<q_{2}<1$ and the labour supply in the new sector is

$$
h_{n}=\left\{\begin{array}{l}
\frac{w_{n}\left(1+w_{i}\right)-q w_{i}}{w_{n} w_{i}(1+q)}, \text { if } q_{2} \leq q \leq 1 \\
1, \text { if } 0 \leq q<q_{2}
\end{array}\right.
$$

The indirect utility function of the worker in the new sector is as follows:

$$
U_{n}^{q}=\left\{\begin{array}{l}
\ln \left(\frac{w_{n}\left(1+w_{i}\right)+w_{i}}{w_{i}(1+q)}\right)+q \ln q \frac{w_{n}\left(1+w_{i}\right)+w_{i}}{w_{n}(1+q)}, \text { if } q_{2} \leq q \leq 1 \\
\ln \left(1+w_{n}\right), \text { if } 0 \leq q<q_{2}
\end{array} .\right.
$$

\section{The Choice of Unemployed}

The unemployed worker maximises utility

$$
U^{q}=\ln \left(1+B_{u}\left(h_{u}\right)\right)+q \ln \left(1+w_{i}\left(1-h_{u}\right)\right) \text {, }
$$

where $B_{u}\left(h_{u}\right)=\left\{\begin{array}{l}b_{u}, \text { if } T \leq h_{u} \leq 1 \\ 0, \text { if } 0 \leq h_{u}<T\end{array}\right.$.

There can be the two following cases (see the main text):

1) Workers choose $h_{u}=0$ and enjoy utility $U_{1}=q \ln \left(1+w_{i}\right)$.

2) Workers choose $h_{u}=T$ and achieve utility level $U_{2}=\ln \left(1+b_{u}\right)+q \ln \left(1+w_{i}(1-T)\right)$.

Depending on the level of $q$ workers will prefer either $U_{1}$ or $U_{2}$. If $U_{1}<U_{2}$ then 


$$
q<\frac{\ln \left(1+b_{u}\right)}{\ln \left(1+w_{i}\right)-\ln \left(1+w_{i}(1-T)\right)} .
$$

We plot this constraint as a function of $T$ in Fig.2.9 and 2.10. The patched area borders the possible ranges of values for $q$ and $T$ (both must be in between 0 and 1). It is shown that the threshold value of $q$ divides the possibility set into two regions 1 and 2, where workers either search for an official job (and may hold a part-time informal business) or prefer not to search and work underground, respectively. It is easy to see that, other things being equal, lower unemployment benefits (Fig.2.10) lead to a higher probability that a worker will choose working underground all the available time. The larger part of the shaded possibility set is in region 2 .

In reality, we believe, the value of $T$ is close enough to 1 . Standing (1998) writes that Russia lacked a significant number of employment offices and the number of staff in them lagged below what was required at the beginning of transition and afterwards. He reports that registering as unemployed has often required travelling long distances at rising cost and inconvenience, standing in long queues for hours in adverse climatic conditions, etc. Thus, putting $T$ close to 1 is justifiable. But this, in turn, would mean that our modelled economy most likely ends up with the two categories of workers: those who work full-time underground ( $q$ 's within region 2, see Fig.2.9 and 2.10) when they are unemployed, and those who register at an employment office and spend time $T$, looking for a job or, e.g., being retrained ( $q$ 's within region 1). If $T$ were low enough then all workers would have preferred registering (region 1 ).

The constraint on $q$ must be lower than 1 to guarantee that for some $T$ the patched area is cut by both regions 1 and 2 . That is $\frac{\ln \left(1+b_{u}\right)}{\ln \left(1+w_{i}\right)-\ln \left(1+w_{i}(1-T)\right)}<1$. This holds whenever $b_{u}<w_{i} \frac{T}{1+w_{i}(1-T)}$. Unemployment benefits will satisfy the latter inequality for high enough values of $T$. Moreover, the evidence suggests that unemployment benefits have been extremely low in Russia (see, e.g. Coricelli, 1998; Standing, 1998).

The labour supply function of the unemployed worker is then

$$
h_{u}=\left\{\begin{array}{l}
0, \text { if } \frac{\ln \left(1+b_{u}\right)}{\ln \left(1+w_{i}\right)-\ln \left(1+w_{i}(1-T)\right)} \leq q \leq 1 \\
T, \text { if } 0 \leq q<\frac{\ln \left(1+b_{u}\right)}{\ln \left(1+w_{i}\right)-\ln \left(1+w_{i}(1-T)\right)}
\end{array},\right.
$$

and the indirect utility function is

$$
U_{u}^{q}=\left\{\begin{array}{l}
q \ln \left(1+w_{i}\right), \text { if } \frac{\ln \left(1+b_{u}\right)}{\ln \left(1+w_{i}\right)-\ln \left(1+w_{i}(1-T)\right)} \leq q \leq 1 \\
\ln \left(1+b_{u}\right)+q \ln \left(1+w_{i}(1-T)\right), \text { if } 0 \leq q<\frac{\ln \left(1+b_{u}\right)}{\ln \left(1+w_{i}\right)-\ln \left(1+w_{i}(1-T)\right)}
\end{array} .\right.
$$

\section{Comparing the Threshold Values and Utilities}

In the main text we denote

$$
\begin{aligned}
& q_{o}=\frac{\ln \left(1+b_{o}+w_{o}\right)-\ln \left(1+b_{o}\right)}{\ln \left(1+w_{i}(1-B)\right)-\ln \left(1+w_{i}(1-H)\right)}, \\
& q_{n}=w_{n} \frac{1}{w_{i}\left(1+w_{n}\right)}, \\
& q_{u}=\frac{\ln \left(1+b_{u}\right)}{\ln \left(1+w_{i}\right)-\ln \left(1+w_{i}(1-T)\right)} .
\end{aligned}
$$

If we plot $q_{o}, q_{n}$, and $q_{u}$ as functions of $w_{i}$ (for illustrative purposes), then it is easy to check that $q_{n}<q_{o}$ for a number of various combinations of $w_{o}, b_{o}, w_{i}, B, H, w_{n}, b_{u}$, and $T$. In particular, this holds whenever $B$ is not too close to zero, and $b_{o}$ does not exceed $w_{o}$ by too much. To put it 
another way, $q_{n}<q_{o}$ if $q_{o}$ is not too low, when many workers have a temptation to work in the old sector just a tiny amount of time indeed, and get enormous compensation in terms of benefits. The general situation is depicted in Fig.2.11. It implies that all new sector workers who work there fulltime would never choose working for benefits only, if they found themselves in the old sector. On the other hand, all the workers, who spend much of their time in the irregular sector and earn only benefits in the old sector, will moonlight once in the new sector.

Russian firms have been providers of a substantial range and amount of social benefits (Standing, 1998). However, the evidence by Commander et al. (1996b) suggests that spending on such benefits and services did not exceed the total wage bill of enterprises. Thus, the case of Fig.2.11 is perfectly acceptable.

Depending on the values of $T$ and $b_{u}, q_{u}$ can be either such that $q_{n}<q_{u}<q_{o}$ or $q_{u}<q_{n}<q_{o}$ or $q_{n}<q_{o}<q_{u}$ for all reasonable values of $w_{i}^{56}$ (Fig.2.12, 2.13 and 2.14, respectively). There can also be mixed cases when, e.g., $q_{u}<q_{n}<q_{o}$ holds for lower values of $w_{i}$, but $q_{n}<q_{u}<q_{o}$ holds for higher values of $w_{i}$, etc (Fig.2.15).

We have noted above that the evidence shows unemployment benefits to be very low in Russia while the time constraint $T$ is likely to be very tight. Clarke (1998) and Rutkowski (1999) report that the ratio of the average unemployment benefit to the average wage was $12 \%$ in 1993, 18\% in 1994 and $30 \%$ in 1998 in Russia. At the same time, state sector wages were much lower than private wages (Fig.1.6). If we put $b_{u}$ to be roughly $50 \%$ of the old sector wage then the most likely case is when $q_{n}<q_{u}<q_{o}$ (e.g., Fig.2.12) for the degrees of the informal-formal wage differential reported by Kolev (1998) and Roshchin and Razumova (1999). It implies that the workers who spend only time $B$ in the old sector will choose full-time informal work if they find themselves unemployed, while the workers who work full time in the new sector will never do that. The workers moonlighting in the new sector or working time $H$ in the old sector can either choose full-time informal work or not do that depending on a particular value of their $q$.

Having looked at the threshold values we can turn to the utilities.

In Fig.2.16 we plot the utility functions $U_{o}^{q}, U_{n}^{q}$ and $U_{u}^{q}$ as functions of $q$. To do that we set the following values of parameters: $w_{o}=1, b_{o}=0.75, w_{i}=2.75, B=0.25, H=0.75, w_{n}=2, b_{u}=$ 0.5 , and $T=0.65$. Some of these values have been explained in this appendix, others will be explained in Section 3: we use this set of parameters in benchmark case simulations of the dynamic model.

We can see that $U_{u}^{q}<U_{o}^{q}$ and $U_{u}^{q}<U_{n}^{q}$ for all values of $q$. It can be checked that these inequalities hold for all sensible combinations of parameters consistent with evidence from Russia. However, in general case they could well not be satisfied for all q.

In Fig.2.16 $U_{o}^{q}<U_{n}^{q}$ holds only for full-time workers in the old and new sectors as well as for a few employees with small values of $q$. For a greater number of people with higher values of $q$, $U_{o}^{q}>U_{n}^{q}$ holds. It implies that the majority of workers in the old sector will not voluntarily prefer working in the new sector if they were offered there a place. In general, other situations are possible as well.

\section{Appendix 4 (Dynamic Model of Transition)}

\section{Wage Determination and Employment Creation in the New Sector}

In the main text we derive expressions for wage and employment creation in the new sector (equations (12) and (13), Section 2):

$$
w_{n}=\frac{\alpha c k}{\alpha c\left(1+\tau_{n}\right)+N+U}+\frac{(N+U)\left(w_{o}+b_{o}+c(r+\gamma)\right)}{\alpha c\left(1+\tau_{n}\right)+N+U}
$$

and

\footnotetext{
${ }^{56}$ We consider $w_{i}$ only up to the value which is 6 times as high as the old sector wage.
} 


$$
J=\frac{\alpha(N+U)}{\alpha c\left(1+\tau_{n}\right)+N+U}\left(k-\left(w_{o}+b_{o}+c(r+\gamma)\right)\left(1+\tau_{n}\right)\right) .
$$

They are both functions of $N$ and $U$ such that

$$
\begin{aligned}
& \frac{\partial w_{n}}{\partial N}=\alpha c \frac{\left(w_{o}+b_{o}+c(r+\gamma)\right)\left(1+\tau_{n}\right)-k}{\left(\alpha c\left(1+\tau_{n}\right)+N+U\right)^{2}}<0, \\
& \frac{\partial w_{n}}{\partial U}=\alpha c \frac{\left(w_{o}+b_{o}+c(r+\gamma)\right)\left(1+\tau_{n}\right)-k}{\left(\alpha c\left(1+\tau_{n}\right)+N+U\right)^{2}}<0, \\
& \frac{\partial J}{\partial N}=-\alpha^{2}\left(\left(w_{o}+b_{o}+c(r+\gamma)\right)\left(1+\tau_{n}\right)-k\right) \frac{c\left(1+\tau_{n}\right)}{\left(\alpha c\left(1+\tau_{n}\right)+N+U\right)^{2}}>0, \\
& \frac{\partial J}{\partial U}=-\alpha^{2}\left(\left(w_{o}+b_{o}+c(r+\gamma)\right)\left(1+\tau_{n}\right)-k\right) \frac{c\left(1+\tau_{n}\right)}{\left(\alpha c\left(1+\tau_{n}\right)+N+U\right)^{2}}>0,
\end{aligned}
$$

if $k>\left(w_{o}+b_{o}+c(r+\gamma)\right)\left(1+\tau_{n}\right)$.

\section{Derivation of Functions $S(N, U)$ and $L(N, U)$} 3.2.1.2.1):

In the main text we derive general expressions for functions $S(N, U)$ and $L(N, U)$ (subsection

$$
S(N, U)=\int_{\frac{w_{n}(N, U)}{w_{i}\left(1+w_{n}(N, U)\right)}}^{1} \frac{w_{n}(N, U)\left(1+w_{i}\right)-q w_{i}}{w_{n}(N, U) w_{i}(1+q)} d q
$$

and

$$
\begin{array}{r}
L(N, U)=\int_{\frac{w_{n}(N, U)}{w_{i}\left(1+w_{n}(N, U)\right)}}^{1}\left(1-\frac{w_{n}(N, U)\left(1+w_{i}\right)-q w_{i}}{w_{n}(N, U) w_{i}(1+q)}\right) d q= \\
=1-\frac{w_{n}(N, U)}{w_{i}\left(1+w_{n}(N, U)\right)}-S(N, U) .
\end{array}
$$

Taking the integral on the right hand side of (1) we obtain:

$$
\begin{aligned}
S(N, U)= & \int_{\frac{w_{n}(N, U)}{w_{i}\left(1+w_{n}(N, U)\right)}}^{1} \frac{w_{n}(N, U)\left(1+w_{i}\right)-q w_{i}}{w_{n}(N, U) w_{i}(1+q)} d q= \\
& =-\frac{1}{w_{n}(N, U)}+\left(\frac{1+w_{i}}{w_{i}}+\frac{1}{w_{n}(N, U)}\right) \ln 2+ \\
& +\frac{1}{w_{i}\left(1+w_{n}(N, U)\right)}-\left(\frac{1+w_{i}}{w_{i}}+\frac{1}{w_{n}(N, U)}\right) \ln \left(\frac{w_{i}+\left(1+w_{i}\right) w_{n}(N, U)}{w_{i}\left(1+w_{n}(N, U)\right)}\right)
\end{aligned}
$$

and

where $w_{n}(N, U)$ is

$$
\begin{aligned}
L(N, U)=1- & \frac{w_{n}(N, U)}{w_{i}\left(1+w_{n}(N, U)\right)}+\frac{1}{w_{n}(N, U)}-\left(\frac{1+w_{i}}{w_{i}}+\frac{1}{w_{n}(N, U)}\right) \ln 2- \\
& -\frac{1}{w_{i}\left(1+w_{n}(N, U)\right)}+\left(\frac{1+w_{i}}{w_{i}}+\frac{1}{w_{n}(N, U)}\right) \ln \left(\frac{w_{i}+\left(1+w_{i}\right) w_{n}(N, U)}{w_{i}\left(1+w_{n}(N, U)\right)}\right),
\end{aligned}
$$

$$
w_{n}(N, U)=\frac{\alpha c k}{\alpha c\left(1+\tau_{n}\right)+N+U}+\frac{(N+U)\left(w_{o}+b_{o}+c(r+\gamma)\right)}{\alpha c\left(1+\tau_{n}\right)+N+U} .
$$




\section{References}

Aghion P., Blanchard O. (1994) On the Speed of Transition in Central Europe. NBER Macroeconomics Annual, 283-320.

Barsukova S. (2000) Shadow and Fictitious Labour Markets in Contemporary Russia. Pro et Contra, Vol.5(1). Publ. by Carnegie Moscow Centre (in Russian).

Becker G. (1965) A Theory of the Allocation of Time. Economic Journal, Vol.75(299), September, 493-517.

Benhabib J., Rogerson R., Wright R. (1991) Homework in Macroeconomics: Household Production and Aggregate Fluctuations. Journal of Political Economy, Vol.99(6), December, 11661187.

Blanchard O. (1997) The Economics of Post-Communist Transition. Clarendon Press. Oxford. 149p.

Blanchard O., Diamond P. (1992) The Flow Approach to Labor Markets. American Economic Review, Vol.82(2) Papers and Proceedings, May, 354-359.

Boeri T. (1999) Transition with Labour Supply. The William Davidson Institute, University of Michigan, Working Paper No.274, December.

Boeri T. (2000) Optimal Speed of Transition 10 Years After. CEPR Discussion Paper No.2384, London, February.

Boeri T., Bruno R. (1997) A Short Note on the Characteristics of Labour Turnover in Central and Eastern Europe. In: Labour Market Dynamics in the Russian Federation, OECD Proceedings, Centre for Co-operation with the Economies in Transition.

Boeri T., Burda M., Kollo J. (1998) Mediating the Transition: Labour Markets in Central and Eastern Europe. In: L. Ambrus-Lacatos, M.Schaffer, eds. Forum Report of the Economic Policy Initiative. No.4. CEPR, London.

Boeri T., Garibaldi P. (2001) Shadow Activity and Unemployment in a Depressed Labor Market. IGIER Working Paper No.77, June 13.

Brixiova Z. (1997) On the Speed of Transition in Central and Eastern Europe: Does On-theJob Search Matter? IMF Working Paper, WP/97/102, August.

Burda M. (1993) Labour Markets in Eastern Europe. Economic Policy, No.16, April, 101137.

Castanheira M., Roland G. (2000) The Optimal Speed of Transition: A General Equilibrium Analysis. International Economic Review, Vol.41(1), February, 219-239.

Chadha B., Coricelli F. (1994) 'Fiscal Constraints and the Speed of Transition'. CEPR Discussion Paper, No.993, London.

Clarke S. (1998) Introduction and Structural Adjustment without Mass Unemployment? Lessons from Russia. In: S. Clarke, eds. Structural Adjustment without Mass Unemployment? Lessons from Russia. Edward Elgar, Cheltenham, UK - Northampton, MA, USA. 355p.

Clarke S. (1999) The Formation of a Labour Market in Russia. Edward Elgar, Cheltenham, UK - Northampton, MA, USA. 315p.

Clarke S. (2000) Why Do Russian Households Make Employment Decisions? Paper for ESRC Central and Eastern Europe Seminar Series on Household Survival Strategies. February 26, 2000. University of Warwick.

Clarke S., Kabalina V., Kozina I., Donova I., Karelina M. (1998) The Restructuring of Employment and the Formation of a Labour Market in Russia. In: S. Clarke, eds. Structural Adjustment without Mass Unemployment? Lessons from Russia. Edward Elgar, Cheltenham, UK Northampton, MA, USA. 355p. 
Commander S., Tolstopiatenko A. (1996) Restructuring and Taxation in Transition Economies. The World Bank Policy Research Working Paper 1625, July.

Commander S., Tolstopiatenko A. (1997) A Model of the Informal Economy in Transition Economies. The William Davidson Institute, University of Michigan, Working Paper No.122, November.

Commander S., Yemtsov R. (1995) Russian Unemployment: Its Magnitude, Characteristics and Regional Dimensions. The World Bank Policy Research Working Paper 1426, February.

Commander S., Dhar S., Yemtsov R. (1996a) How Russian Firms Make Their Wage and Employment Decisions. In: S. Commander, Q. Fan and M.Schaffer, eds. Enterprise Restructuring and Economic Policy in Russia, Washington D.C.: The World Bank/EDI.

Commander S., Lee U., Tolstopiatenko A. (1996b) Social Benefits and the Russian Industrial Firm. In: S. Commander, Q. Fan and M.Schaffer, eds. Enterprise Restructuring and Economic Policy in Russia, Washington D.C.: The World Bank/EDI.

Coricelli F. (1998) Macroeconomic Policies and the Development of Markets in Transition Economies. CEU press, Budapest. 164p.

Eichenbaum M.S., Hansen L.P. (1990) Estimating Models with Intertemporal Substitution Using Aggregate Time Series Data. Journal of Business and Economic Statistics, 8, January, 53-69.

EBRD (1999) Transition Report.

Foley M. (1997a) Labor Market Dynamics in Russia. Economic Growth Center Discussion Paper No.780, Yale University, August.

Foley M. (1997b) Multiple Job Holding in Russia During Economic Transition. Economic Growth Center Discussion Paper No.781, Yale University, August.

Friedman E., Johnson S., Kaufmann D., Zoido-Lobaton P. (2000) Dodging the Grabbing Hand: the Determinants of Unofficial Activity in 69 Countries. Journal of Public Economics, Vol.76, 459-493.

Garibaldi P., Brixiova Z. (1998) Labor Market Institutions and Unemployment Dynamics in Transition Economies. IMF Staff Papers, Vol.45(2), June.

Gavin M. (1993) Unemployment, Labour Markets and Structural Change in Eastern Europe. Columbia University. Mimeo.

Gimpelson V., Lippoldt D. (1997) Labour Turnover in the Russian Economy. In: Labour Market Dynamics in the Russian Federation, OECD Proceedings, Centre for Co-operation with the Economies in Transition. Moscow.

Goskomstat (1999) Rossijskii statisticheskii ezhegodnik (Russian Statistical Yearbook).

Gronau R. (1977) Leisure, Home Production, and Work - the Theory of the Allocation of Time Revisited. Journal of Political Economy, Vol.85(6), December, 1099-1124.

Gronau R. (1980) Home Production - a Forgotten Industry. Review of Economics and Statistics, Vol.62(2), August, 408-415.

Guariglia A., Kim B.-Y. (1999) Unemployment Risk, Precautionary Savings, and Moonlighting in Russia. The William Davidson Institute, University of Michigan, Working Paper No.232, June.

Guriev S., Ickes B. (2000) Microeconomic Aspects of Economic Growth in Eastern Europe and the Former Soviet Union, 1950 - 2000. The William Davidson Institute, University of Michigan, Working Paper No.348, November.

Harris J., Todaro M. (1970) Migration, Unemployment and Development: A Two-Sector Analysis. American Economic Review, Vol.60, March, 126-142. 
IMF (2000) Russian Federation: Selected Issues. IMF Staff Country Report No.00/150, November.

Johnson S., Kaufmann D., Shleifer A. (1997) The Unofficial Economy in Transition. Brookings Papers on Economic Activity, 2, 159-239.

Jurajda S., Terrell K. (2000) Optimal Speed of Transition: Micro Evidence from the Czech Republic. The William Davidson Institute, University of Michigan, Working Paper No.355, December.

Kabalina V. Ryjikova Z. (1998) Statistika i praktika nepolnoi zanyatosti v Rossii (Statistics and Practice of Short-time Employment in Russia). Voprosy Statistiki, No.2, 31-40.

Kapeliushnikov R. (1997) Job Turnover in a Transitional Economy: The Behaviour and Expectations of Russian Industrial Enterprises. In: Labour Market Dynamics in the Russian Federation, OECD Proceedings, Centre for Co-operation with the Economies in Transition.

Kapelyushnikov R., Aukutsionek S. (1994) The Russian Labor Market in 1993. RFE/RL Research Report 3.

Kolev A. (1998) Labour Supply in the Informal Economy in Russia during Transition. Paper presented at the CEPR First Annual Transition Economics Summer Workshop. Prague. June-July.

Krishnan P. (1990) The Economics of Moonlighting: A Double Self-Selection Model. Review of Economics and Statistics, Vol.72(2), May, 361-367.

Lackó M. (2000) Hidden Economy - an Unknown Quantity? Comparative Analysis of Hidden Economies in Transition Countries, 1989-1995. Economics of Transition, Vol.8(1), 117-149.

Lacroix C., Fortin B. (1992) Utility-Based Estimation of Labour Supply Functions in the Regular and Irregular Sectors. Economic Journal, Vol.102(415), November, 1407-1422.

Layard R., Richter A. (1995) How Much Unemployment is Needed for Restructuring: the Russian Experience. Economics of Transition, Vol.3(1), 39-58.

Lehmann H., Wadsworth J. (1997) Labour Force Participation and the Household: Evidence from Five Russian Regions. In: Labour Market Dynamics in the Russian Federation, OECD Proceedings, Centre for Co-operation with the Economies in Transition.

Lemieux T., Fortin B., Frechette P. (1994) The Effects of Taxes on Labor Supply in the Underground Economy. American Economic Review, Vol.84(1), March, 231-254.

Linz S. (1995) Do Job Rights Govern Employment Patterns in Transition Economies? American Economic Review, Vol.85(2), May, 425-431.

Matveenko V., Vostroknoutova E., Bouev M. (1998) Transformational Decline and Preconditions of Growth in Russia. Economics Education and Research Consortium (EERC-Russia) Working Papers Series, No 98/03.

Pissarides C. (1990) Equilibrium Unemployment Theory. Basil Blackwell. Oxford. 173p.

Polterovich V.M. (1996) Transformatsionnyi spad v Rossii (Transformational Decline in Russia). Ekonomika i Matematicheskie Metody, Vol.32(1).

Popov V. (1999) Belka v kolese (A Squirrel in a Wheel). Expert, No.15, April.

Portes A., Sassen-Koob S. (1987) Making It Underground: Comparative Material on the Informal Sector in Western Economies. American Journal of Sociology, Vol.93(1), 30-61.

Richter A., Schaffer M. (1996) The Performance of De Novo Private Firms in Russian Manufacturing. In: S. Commander, Q. Fan and M.Schaffer, eds. Enterprise Restructuring and Economic Policy in Russia, Washington D.C.: The World Bank/EDI.

Rodrik D. (1995) The Dynamics of Political Support for Reforms in Economies in Transition. Journal of Japanese and International Economics, 9, 403-425. 
Roshchin S., Razumova T. (1999) Secondary Employment: Labour Supply Modelling. Final Report on Research Project. EERC-Russia. December.

Ruggerone L. (1996) Unemployment and Inflationary Finance: Dynamics at the Early Stages of Transition. Economic Journal, Vol.106, March, 483-494.

Russian Economic Trends (2001) No.1, January 16. RECEP, Moscow.

Rutkowski M. (1999) Russia's Social Protection Malaise: Key Reform Priorities as a Response to the Present Crisis. The World Bank Social Protection Discussion Paper No.9909, April.

Schaffer M. (1998) Do Firms in Transition Economies Have Soft-Budget Constraints? A Reconsideration of Concepts and Evidence. Journal of Comparative Economics, Vol.26(1), 80-103.

Schaffer M., Turley G. (2000) Effective versus Statutory Taxation: Measuring Effective Tax Administration in Transition Economies. The William Davidson Institute, University of Michigan, Working Paper No.347, November.

Shapiro C., Stiglitz J. (1984) Equilibrium Unemployment as a Worker Discipline Device. American Economic Review Vol.74, June, 433-444.

Shimer R. (1997) The Optimal Speed of Transition. Princeton University. Mimeo.

Shisko R., Rostker B. (1976) The Economics of Multiple Job Holding. American Economic Review, Vol.66(3), June, 298-308.

Standing G. (1998) Reviving Dead Souls: Russian Unemployment and Enterprise Restructuring. In: S. Clarke, eds. Structural Adjustment without Mass Unemployment? Lessons from Russia. Edward Elgar, Cheltenham, UK - Northampton, MA, USA. 355p.

Swafford M., eds. (1997) Sample of the Russian Federation Rounds V, VI, and VII of the Russian Longitudinal Monitoring Survey. Technical Report. March.

Treisman D. (1999) Russia's Tax Crisis: Explaining Falling Revenues in a Transitional Economy. Economics and Politics Vol.11(2), July, 145-169. Russia

VCIOM (1993-1999) the Monitoring of Public Opinion, various issues, Intercenter, Moscow,

Vostroknoutova E. (2000) Institutional Lock-In during Transition: an Evolutionary Approach. European University Institute June Paper, Florence, Italy. Mimeo. 


\section{DAVIDSON INSTITUTE WORKING PAPER SERIES - Most Recent Papers}

The entire Working Paper Series may be downloaded free of charge at: www.wdi.bus.umich.edu

CURRENT AS OF 11/29/01

\begin{tabular}{|c|c|c|}
\hline Publication & Authors & Date \\
\hline No. 408: Labor Supply, Informal Economy and Russian Transition & Maxim Bouev & May 2001 \\
\hline No. 407: Corporate Governance in China: Then and Now & Cindy Schipani and Liu Junhai & Nov. 2001 \\
\hline No. 406: Entrepreneurship and Post-Socialist Growth & $\begin{array}{l}\text { Daniel Berkowitz and David N. } \\
\text { DeJong }\end{array}$ & Oct. 2001 \\
\hline No. 405: Policy Reform and Growth in Post-Soviet Russia & $\begin{array}{l}\text { Daniel Berkowitz and David N. } \\
\text { DeJong }\end{array}$ & Oct. 2001 \\
\hline $\begin{array}{l}\text { No. 404: Social Policies and Structures: Institutional Frictions and Traps } \\
\text { in the Czech Republic after } 1989\end{array}$ & Jiří Večerník & Nov. 2001 \\
\hline $\begin{array}{l}\text { No. 403: Investment, Efficiency, and Credit Rationing: Evidence from } \\
\text { Hungarian Panel Data }\end{array}$ & Mathilde Maurel & Nov. 2001 \\
\hline $\begin{array}{l}\text { No. 402: Subduing High Inflation in Romania. How to Better Monetary } \\
\text { and Exchange Rate Mechanisms? }\end{array}$ & $\begin{array}{l}\text { Daniel Daianu and Radu } \\
\text { Vranceanu }\end{array}$ & Aug. 2001 \\
\hline $\begin{array}{l}\text { No. 401: The Gender Wage Gap in Bulgaria: A Semiparametric } \\
\text { Estimation of Discrimination }\end{array}$ & Dean Jolliffe & July 2001 \\
\hline $\begin{array}{l}\text { No. 400: Do External Auditors Perform a Corporate Governance Role in } \\
\text { Emerging Markets? Evidence from East Asia }\end{array}$ & Joseph P. H. Fan and T.J. Wong & Oct. 2001 \\
\hline $\begin{array}{l}\text { No. 399: Financial Conditions and Investment during the Transition: } \\
\text { Evidence from Czech Firms }\end{array}$ & Lubomír Lízal and Jan Svejnar & Oct. 2001 \\
\hline $\begin{array}{l}\text { No. 398: Accessible Pareto-Improvements: Using Market Information to } \\
\text { Reform Inefficiencies }\end{array}$ & Michael Mandler & May 2001 \\
\hline No. 397: The Making of an Integrated National Grain Market in China & ou & Oct. 2001 \\
\hline No. 396: Corruption and Resource Allocation: Evidence from China & Wei Li & June 2001 \\
\hline $\begin{array}{l}\text { No. 395: Government Shareholding and the Value of China's Modern } \\
\text { Firms }\end{array}$ & Lihui Tian & Apr. 2001 \\
\hline No. 394: Labor Hoarding in Russia: Where Does it Come from? & $\begin{array}{l}\text { Rouslan Koumakhov and Boris } \\
\text { Najman }\end{array}$ & June 2000 \\
\hline $\begin{array}{l}\text { No. 393: Ownership Structure, Corporate Governance, And Firm Value: } \\
\text { Evidence from the East Asian Financial Crisis }\end{array}$ & Michael Lemmon and Karl Lins & Apr. 2001 \\
\hline No. 392: Marshall and Labour Demand in Russia: Going Back to Basics & $\begin{array}{l}\text { Jozef Konings } \\
\text { Lehmann }\end{array}$ & Aug. 2001 \\
\hline No. 391: Economic Transition and Elections in Poland & $\begin{array}{l}\text { John E. Jackson, Jacek Klich, and } \\
\text { Krystyna Poznańska }\end{array}$ & June 2001 \\
\hline $\begin{array}{l}\text { No. 390: Effects of Bank Insolvency and Strategic Uncertain } \\
\text { Corporate Restructuring in Transition Economies }\end{array}$ & Christa Hainz & Aug. 2001 \\
\hline No. 389: Mark-Up Pricing In Bulgarian Manufacturing & $\begin{array}{l}\text { Rumen Dobrinsky, Boyko } \\
\text { Nikolov, and Nikolay Markov }\end{array}$ & June 2001 \\
\hline $\begin{array}{l}\text { No. 388: Globalization and Firms' Financing Choices: } \\
\text { Evidence from Emerging Economies }\end{array}$ & $\begin{array}{l}\text { Sergio Schmukler and Esteban } \\
\text { Vesperoni }\end{array}$ & May 2001 \\
\hline $\begin{array}{l}\text { No. 387: The Distributional Impacts of Indonesia's Financial Crisis on } \\
\text { Household Welfare: A "Rapid Response" Methodology }\end{array}$ & $\begin{array}{l}\text { Jed Friedman and James } \\
\text { Levinsohn }\end{array}$ & Sept. 2001 \\
\hline $\begin{array}{l}\text { No. 386a: Corporate Financial Policies and Performance Around } \\
\text { Currency Crises }\end{array}$ & $\begin{array}{l}\text { Arturo Bris, Yrjö Koskinen, and } \\
\text { Vicente Pons }\end{array}$ & Oct. 2001 \\
\hline No. 385: Ownership and Productive Efficiency: Evidence from Estonia & Derek C. Jones and Niels Mygind & Aug. 2001 \\
\hline $\begin{array}{l}\text { No. 384: Forthcoming in: Journal of Economic Perspectives, } \\
\text { "Institutional Determinants of Labor Reallocation in Transition" Vol. } \\
\text { 16, No. 2, Feb. } 2002 \text {. }\end{array}$ & Tito Boeri and Katherine Terrell & June 2001 \\
\hline $\begin{array}{l}\text { No. 383: Deindustrialisation and Structural Change During the Post- } \\
\text { Communist Transition }\end{array}$ & $\begin{array}{l}\text { Tomasz Mickiewicz and Anna } \\
\text { Zalewska }\end{array}$ & June 2001 \\
\hline No. 382: Markets and Growth & Štěpán Jurajda and Janet Mitchell & July 2001 \\
\hline
\end{tabular}

